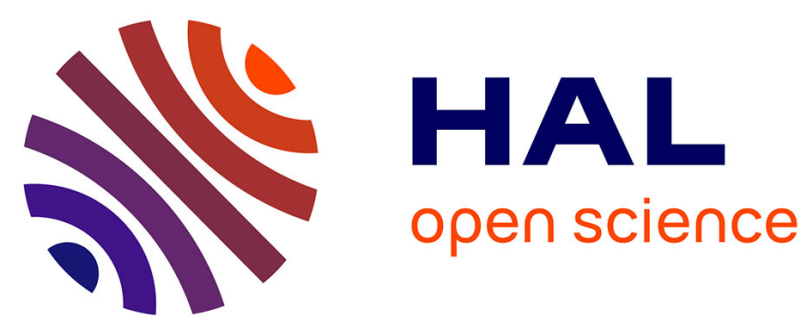

\title{
ESTIMATES OF THE AGGREGATE QUARTERLY CAPITAL STOCK FOR THE POST-WAR U.S. ECONOMY
}

\author{
Daniel Levy, Haiwei Chen
}

\section{- To cite this version:}

Daniel Levy, Haiwei Chen. ESTIMATES OF THE AGGREGATE QUARTERLY CAPITAL STOCK FOR THE POST-WAR U.S. ECONOMY. Review of Income and Wealth, 1994, 40 (3), pp.317-349. 10.1111/j.1475-4991.1994.tb00072.x . hal-02382769

\section{HAL Id: hal-02382769 \\ https://hal.science/hal-02382769}

Submitted on 27 Nov 2019

HAL is a multi-disciplinary open access archive for the deposit and dissemination of scientific research documents, whether they are published or not. The documents may come from teaching and research institutions in France or abroad, or from public or private research centers.
L'archive ouverte pluridisciplinaire HAL, est destinée au dépôt et à la diffusion de documents scientifiques de niveau recherche, publiés ou non, émanant des établissements d'enseignement et de recherche français ou étrangers, des laboratoires publics ou privés. 


\title{
Estimates of the Aggregate Quarterly Capital Stock for the Post-War U.S. Economy*
}

\author{
Daniel Levy \\ Department of Economics \\ Emory University \\ Atlanta, GA 30322 \\ and \\ Haiwei Chen \\ Department of Economics \\ Emory University \\ Atlanta, GA 30322
}

Last Revision: March 9, 1994

JEL Codes: E22, C82, E32

Key Words: Capital Stock, Consumer Durable Goods, Producer Durable Goods, Business Structures, Capital Depreciation and Discard, Capital Goods Prices, Frequency Domain, Cyclical Behavior, Linear Interpolation, Numerical Iteration

\begin{abstract}
We construct quarterly aggregate gross and net capital stock series for the post-war U.S. economy using annual capital stock, capital depreciation, and capital discard figures along with quarterly investment series. We construct nominal and real measures of all three categories in the aggregate capital stock: consumer durable goods, producer durable goods, and business structures. In constructing the nominal series we take into account the changes in capital goods' prices. The series are constructed using four different methods. Using time- and frequency domain techniques, we compare the constructed series and characterize their short-run, business cycle, and long-run cyclical properties. We find that the constructed series exhibit very different cyclical and shock persistence dynamics. Practical implications are discussed.
\end{abstract}

* Address all correspondence to: Daniel Levy, Department of Economics, Emory University, Atlanta, GA 30322-2240, USA. We are grateful to the anonymous referee for comments, suggestions, and especially the insight. We also thank John Musgrave of the BEA for patiently answering many of our questions and for providing us the annual capital stock discard and depreciation figures. Martin J. Bailey and John Musgrave have read earlier versions of this manuscript and provided many comments and suggestions. We also thank Shomu Banerjee, Bob Carpenter, Hashem Dezhbakhsh, Hal Fried, Eshi Motahar, and Shelton Schmidt for helpful discussions and Guofen Yi for programming assistance. The usual disclaimer applies. 


\section{INTRODUCTION}

Most economic time series are of accounting nature and are sampled in discrete time intervals. This distinguishes economic data from data generated by physical processes which often are recorded continuously. Some economic time series are sampled with relatively low frequency. For example, because of the nature of aggregate capital stock data and its collection method, it is only collected on annual basis. However, in the empirical macroeconomic literature that focuses on various aspects of input-output relationship, business cycles, growth accounting, etc., often there is a need for a high frequency data. For example, for estimating a short-run aggregate production function one would ideally use quarterly, rather than annual data, since with low frequency data it would be impossible to capture any short run phenomenon that occurs within a single period of sampling interval. Similarly, in analysing the dynamic relationship between aggregate factors of production and output, it is preferable to look at the data using quarterly observations because some dynamic phenomena that perhaps take place within the period of a year will not be captured if annual data is used. In addition, from econometric point of view, use of quarterly data instead of annual data quadruples the sample size which makes empirical statistical inference more reliable.

In this paper we construct quarterly aggregate gross and net capital stock series for the post war U.S. economy. The series are constructed for all three major categories of the capital stock: consumer durable goods (henceforth $C D G$ ), producers durable goods and equipment (henceforth $P D G$ ), and business structures (henceforth $B S$ ). ${ }^{1}$ The period covered is 1947:1-1991:4. All six quarterly series are constructed in real and nominal terms. Although, Gordon and Veitch (1986) have constructed quarterly capital stock estimates, the capital stock series reported in this paper are not identical to their series for several reasons. First, their series only go to 1983. Second, we are using recently revised annual capital stock series which significantly differ from older series they used. $^{2}$ Third, we adjust the gross capital stock estimates using the figures on the annual capital discards, which are quite significant, especially during the 70 s and 80 s. Fourth, we use four different techniques to construct the capital stock series. And fifth, our estimates of the nominal quarterly capital stock series are adjusted for quarterly changes in capital goods prices which during some years were very substantial. The constructed quarterly series are compared to each other as well as to the original annual series from which they were constructed by examining their statistical and cyclical properties using time and frequency domain techniques. Considerable attention is given to a comparative analysis of short run, business cycle, and long run behaviour of the constructed series using univariate spectral analysis. In addition, we compare long run shock persistence (i.e., unit root) properties of the constructed series using a frequency domain equivalent 
of the variance ratio test.

The paper is organized as follows. In the next section we discuss the methodology used in the paper. In section 3 we describe the data set used. In section 4 we describe and compare the constructed quarterly capital stock series using various time and frequency domain statistical measures. The paper ends with a brief summary and some concluding remarks.

\section{METHODOLOGY}

\section{Construction of Quarterly Net Capital Stock Series}

The quarterly net capital stock series reported here are constructed using four different techniques. The first method is a segmented linear interpolation of the corresponding annual series. ${ }^{3}$ Despite the fact that linear interpolation is a somewhat naive procedure, in case of capital stock series it is potentially useful, since time series of capital stock tend to be rather smooth and therefore the approximation error may not be significant in general. A linear interpolation method is implemented by generating quarterly data points along the segmented straight lines connecting two consecutive annual observations. More formally, linearly interpolated quarterly capital stock series are constructed by taking

$$
\begin{aligned}
& K_{i: j}=K_{i-1}+k \quad i=1948,49, \ldots, 91 ; \\
& j=1,2,3, \text { and } 4,
\end{aligned}
$$

with

$$
k_{j}=\frac{K_{i}-K_{i-1}}{4}
$$

where $i$ denotes the year and $j$ denotes the quarter, $K_{i}$. is the quarterly net capital stock for year:quarter $i: j$ and $K_{i}$ is the end of year $i$ capital stock.

Substituting (2) into (1) and rearranging yields an alternative representation of the linear interpolation formula:

$$
\begin{aligned}
& K_{i: j}=\left(1-\frac{j}{4}\right) K_{i-1}+\frac{j}{4} K_{i}^{1}, \quad i=1948,49, \ldots, 91 \text {; } \\
& j=1,2,3 \text {, and } 4 \text {, }
\end{aligned}
$$

which represents the quarterly capital stock series as a linear combination of the annual values by defining the capital stock of year:quarter $i: j$ as a weighted average of the last year's and this year's annual capital stock series, where the weights within the year are changing with quarters. By construction, the above formula implies that the fourth quarter capital stock exactly equals the end 
of the year value. That is, $K_{i: j}=K_{i}$ for $j=4$.

The second technique uses the annual capital stock data and exploits the capital accumulation relationship between capital stock and the corresponding investment series to estimate quarterly depreciation rates which vary over time. These depreciation rates are then used in construction of quarterly capital stock series. ${ }^{4}$ Thus, denoting investment of year:quarter $i: j$ by $I_{i:}$, and the quarterly depreciation rate of year $i$ by $\delta_{i}$, which by assumption remains unchanged within the period of a year, for net capital stock series we have

$$
\begin{aligned}
& K_{i: 1}=\left(1-\delta_{j}\right) K_{i-1}+I_{i: 1} \\
& K_{i: 2}=\left(1-\delta_{j}\right) K_{i: 1}+I_{i: 2} \\
& K_{i: 3}=\left(1-\delta_{j}\right) K_{i: 2}+I_{i: 3} \\
& K_{i: 4}=\left(1-\delta_{j}\right) K_{i: 3}+I_{i: 4}
\end{aligned}
$$

which after recursive substitution of (4), (5), and (6) into (7), and using the fact that $K_{\dot{i} .4}=K_{i}$, yields

$$
K_{i}=\left(1-\delta_{i}\right)^{4} K_{i-1}+\left(1-\delta_{i}\right)^{3} I_{i: 1}+\left(1-\delta_{i}\right)^{2} I_{i: 2}+\left(1-\delta_{i}\right) I_{i: 3}+I_{i: 4}{ }^{1}
$$

where $i=1948,49, \ldots, 91$. Equation (8) express the quarterly depreciation rate, $\delta_{i}$, as a nonlinear function of the last year's and this year's annual capital stock and this year's quarterly investment. The system of equations given in (8) are solved for $\delta_{i}$ using Newton's iteration formula. For most years the convergence was achieved within 3-4 iterations, although for some years we needed as many as 6 iterations. Once the $\delta_{i}$ 's are determined, equations (4)-(6) are used recursively to estimate the quarterly capital stock.

The third method estimates the quarterly depreciation by linearly interpolating the annual depreciation figures. Thus,

$$
\begin{aligned}
& \Delta_{i: j}=\Delta_{i-1}+\theta \quad i=1948,49, \ldots, 91 \\
& j=1,2,3, \text { and } 4
\end{aligned}
$$

with

$$
\theta=\frac{\Delta_{i}-\Delta_{i-1}}{4}
$$

where $\Delta_{i:}$ is the quarterly depreciation of the capital stock for year:quarter $i: j$ and $\Delta_{i}$ is the depreciation during year $i$. Next, these estimates are used along with the annual net capital stock 
and the quarterly investment series to construct the quarterly net capital stock series:

$$
\begin{aligned}
& K_{i . j}=K_{i: j 1}-\Delta_{i . j}+I_{i:} i=1948,49, \ldots, 91 ; \\
& j=1,2,3, \text { and } 4,
\end{aligned}
$$

which after substitution of (9) can be rewritten as

$$
K_{i: j}=K_{i: j 1}-\left[\left(1-\frac{j}{4}\right) \Delta_{i-1}+\frac{j}{4} \Delta_{i}\right]+I_{i: j}
$$

where $K_{i: j 1}=K_{i-1}$ for $j=1$. Note that the comment made above on the usefulness of the linear interpolation applies here as well since the actual annual depreciation series turned out to be relatively smooth.

The fourth method estimates the quarterly depreciation figures by assuming that the annual depreciation is spread equally across the four quarters of the year. This leads to the following estimate of the quarterly net capital stock series:

$$
\begin{aligned}
K_{\dot{i} . j}=K_{i: j 1}-\frac{\Delta_{i}}{4}+I_{i:} & i=1948,49, \ldots, 91 \\
& j=1,2,3, \text { and } 4
\end{aligned}
$$

where $K_{i: j 1}=K_{i-1}$ for $j=1$.

It should be mentioned that by construction, with the exception of method three, the fourth quarter capital stock estimates will equal the corresponding annual values regardless of the method used. To see why method three gives a different estimate of the fourth quarter capital stock, let us compare the fourth quarter estimate from that method to the fourth quarter estimate of say, method four. Starting with method four, quarterly evaluation of (12) yields

$$
\begin{gathered}
K_{i: 1}=K_{i-1}+I_{i: 1}-\frac{\Delta_{i}}{4} \\
K_{i: 2}=K_{i: 1}+I_{i: 2}-\frac{\Delta_{i}}{4} \\
K_{i: 3}=K_{i: 2}+I_{i: 3}-\frac{\Delta_{i}}{4} \\
K_{i: 4}=K_{i: 3}+I_{i: 4}-\frac{\Delta_{i}}{4}
\end{gathered}
$$

where we used the fact that $K_{i: j 1}=K_{i-1}$ for $j=1$. A recursive substitution of (13), (14), and (15) into (16) yields 


$$
K_{i: 4}=K_{i-1}+I_{i: 1}+I_{i: 2}+I_{i: 3}+I_{i: 4}-4 \frac{\Delta_{i}}{4}
$$

which implies that according to method four,

$$
K_{i: 4}=K_{i-1}+I_{i}-\Delta_{i}
$$

That is, the end of the year (end of the fourth quarter) net capital stock equals last year's net capital stock plus this year's investment minus this year's depreciation.

To derive a similar expression for method three, start with (11) to get the quarterly capital stock estimates,

$$
\begin{aligned}
& K_{i: 1}=K_{i-1}+I_{i: 1}-\left[\left(1-\frac{1}{4}\right) \Delta_{i-1}+\frac{1}{4} \Delta_{i}\right] \\
& K_{i: 2}=K_{i: 1}+I_{i: 2}-\left[\left(1-\frac{2}{4}\right) \Delta_{i-1}+\frac{2}{4} \Delta_{i}\right] \\
& K_{i: 3}=K_{i: 2}+I_{i: 3}-\left[\left(1-\frac{3}{4}\right) \Delta_{i-1}+\frac{3}{4} \Delta_{i}\right] \\
& K_{i: 4}=K_{i: 3}+I_{i: 4}-\left[\left(1-\frac{4}{4}\right) \Delta_{i-1}+\frac{4}{4} \Delta_{i}\right]
\end{aligned}
$$

which after recursive substitution of (18), (19), and (20) into (21) yields

$$
K_{i: 4}=K_{i-1}+I_{i}-\left(\frac{3}{2} \Delta_{i-1}+\frac{5}{2} \Delta_{i}\right)
$$

Comparing (22) to (17), it is clear that the two methods will yield different estimates for the fourth

quarter unless $\Delta_{i}=\frac{3}{2} \Delta_{i-1}+\frac{5}{2} \Delta_{i}$. However, for the latter to hold, $\Delta_{i}$ must equal $-\Delta_{i-1}$, which usually will not be true. An intuitive explanation of this finding is that for estimating quarterly depreciation figures, method four uses only this year's depreciation while method three uses this year's as well as last year's depreciation figures.

\section{Construction of Quarterly Gross Capital Stock Series}

To construct gross capital stock series, we use two methods. The first method uses a linear interpolation given by (1)-(3). The second technique uses the annual figures on capital discards, $D_{i}$, to construct the quarterly series:

$$
\begin{array}{rl}
K_{i . j}=K_{i: j 1}+I_{i: j}-\frac{D_{i}}{4} & i=1948,49, \ldots, 91 \\
j & j=1,2,3, \text { and } 4
\end{array}
$$


where $K_{i: j 1}=K_{i-1}$ for $j=1$. Here also the fourth quarter capital stock estimates will equal the corresponding annual values regardless of the method used.

The methods described above are used for the construction of real as well as nominal capital stock series. All the estimates of the nominal quarterly capital stock series reported here are adjusted for quarterly variations in the prices of the capital goods which have been quite significant during some years. The various construction methods used here implicitly impose a constant rate of change in the price of capital goods. Therefore, we multiply the nominal quarterly capital stock

series by the factor $\left(\frac{K P I_{t}^{T}}{K P I_{t}^{C}}\right)^{1}$, where the numerator is the quarterly implicit price deflator of the capital good (i.e., the true capital price index taken from the CITIBASE and further described below), while the denominator is the quarterly implicit price deflator we have constructed from the annual implicit price deflator, computed using the series from Musgrave (1992), under the assumption that its quarterly rate of change is fixed within the year.

Although not reported, we have also constructed the quarterly capital stock series using perpetual inventory technique. However, the results were very unsatisfactory since (depending on the starting point) the time series of the capital stock estimated using this technique tend to increase at a very unreasonable fast rate.

\section{THE DATA}

The data series used in this work consists of annual nominal and real capital stock series of consumer durable goods, producer durable goods, and nonresidential business structures along with their price deflators. In addition, we use the annual depreciation, annual discard, and the quarterly investment series of these three categories. The source of the annual capital stock series is Musgrave (1992). The source of investment and their price deflator series is Citicorp (1993). The annual depreciation and discard figures are from the Bureau of Economic Analysis (BEA). All real figures in this paper are in 1987 dollars. All the capital stock data are for the end of the period. The particular series we used are listed below. For each series we provide exact name/location used in the original source.
a) Annual gross stock of CDG: Musgrave (1992), Tables 17 and 19 (Total)
b) Annual net stock of CDG: Musgrave (1992), Tables 17 and 19 (Total)
c) Annual gross stock of PDG \& BS: Musgrave (1992), Tables 5 and 7 (Equipment, Structures)
d) Annual net stock of PDG \& BS: Musgrave (1992), Tables 6 and 8 (Equipment, Structures)
e) Quarterly investment in CDG: CITICORP (1993), Series GCD, GCDQ, and GDCD
f) Quarterly investment in PDG: CITICORP (1993), Series GIPD, GIPDQ, and GDIPD
g) Quarterly investment in BS: CITICORP (1993), Series GIS, GISQ, and GDIS
h) Annual depreciation of CDG, PDG, and BS: BEA (1992) 
i) Annual discard of CDG, PDG, and BS: BEA (1992)

\section{ESTIMATION RESULTS}

In order to save space, we only report the figures of the constructed real net capital stock series. A complete set of tables containing the estimated quarterly nominal and real series of gross and net capital stock of all three categories are available from the authors upon request. Time varying annual depreciation rates estimated by solving the system of equations given in (8) are reported and analysed by Levy (1994).

\section{Visual Comparison of the Constructed Series}

In order to compare the capital stock series constructed using the four different methods described in section 2, Table 1 (as an example) presents the estimated quarterly real net capital stock series of consumer durable goods constructed using the four methods.

\section{Place $\underline{\text { Table } 1}$ here}

As expected, the end of fourth-quarter values of the capital stock series are identical for the methods of segmented linear interpolation, numerical iteration, and equal quarterly depreciation. The end of fourth-quarter values for the series generated using the method of interpolated depreciation are different as predicted by equation (22).

\section{Place $\underline{\text { Table } 2}$ here}

In Tables 2 we present the estimated quarterly real net capital stock series of producer durable goods. Similarly, in Table 3 we present the estimated quarterly real net capital stock series of nonresidential business structures.

\section{Place Table 3 here}

The correlation coefficient between the constructed quarterly capital stock series is relatively high (between 0.95-0.99). Therefore, in order to highlight the differences between the four methods, on Figure 1 we plot the four estimated series of real, net capital stock of consumer durable goods measured in first differences for the period 1989:1-1991:4. A visual comparison of the series reveals that segmented linear interpolation of the annual capital stock series (method one) yields the least volatile quarterly series, while segmented linear interpolation of the annual depreciation series (method three) yields the most volatile quarterly series. In terms of relative volatility, the other two series fall between these two extremes. ${ }^{5}$ 
Place Figure 1 here

In order to say more about time series properties of the quarterly capital stock series constructed by various methods, we consider three statistical measures. One is autocorrelation function, $\rho_{k}$, which is the correlation coefficient of the current value of the series with the series lagged $k$ periods. In this paper we consider $k=1,2, \ldots, 24$. The second measure is spectral density function. The third measure is a frequency domain version of the variance ratio test often used to analyse shock persistence properties of economic time series. Unlike the autocorrelation function which is estimated in time domain, spectral density function is defined in frequency domain. Spectral analysis of the estimated capital stock series can be useful since spectral density can provide us information on cyclical properties of time series. Below we briefly explain the concept of spectral density. For a more detailed discussion of frequency domain methods see Koopmans (1974).

\section{Variance Decomposition in Frequency Domain}

Spectral analysis is based on the idea that a stationary series can be decomposed into a sum of sine and cosine waves of different frequencies and amplitudes. Just as musical tones are constructed by a superimposition of pure harmonics, or light of various colors is composed of a mix of monochromatic components, in frequency domain analysis we assume that an observed stochastic process is actually made up of many (possibly infinite) cyclical components of various wavelength and amplitude. We are interested in determining how much of the total variance ("power") of the series is determined by each cyclical (or frequency) component.

Consider a covariance stationary real valued univariate time series, $y(t),-\infty<t<\infty$. Its autocovariance function is given by

$$
\gamma(\tau)=\lim _{T \rightarrow \infty} \frac{1}{2 T} \int_{-T}^{T} y(t+\tau) y(t) d t
$$

which exists and is finite for every $\tau$ by assumption. By changing variables it is easy to show that $\gamma(\tau)=\gamma(-\tau)$, which makes past observations useful in describing the present or the future.

The spectrum of the series $y(t)$ is defined as the Fourier transform of its autocovariance function, and is given by polar representation

$$
f_{y}(\omega)=\frac{1}{2 \pi} \int_{-\infty}^{\infty} \gamma(\tau) e^{-i \pi \omega} d \tau \quad-\pi \leq \omega \leq \pi
$$

where $\omega$ is the frequency and is measured in cycles per period. ${ }^{6}$ Since $f_{y}(\omega)$ is symmetric about 
$\omega=0$, it is customary to limit the analysis to the frequency interval $0 \leq \omega \leq \pi$. Note that the area under the spectrum exactly equals the unconditional variance of $y(t)$. That is, $\int_{-\pi}^{\pi} f_{y}(\omega) d \omega=\gamma(0)$, which is the variance of the series as (24) indicates. Therefore, the area under the spectral density between any two frequencies measures the portion of the variation in the series that is due to cyclical components between those two frequencies. This implies that the spectrum of a time series tells us how much each frequency component contributes to the total variance of the series. In other words, the spectrum of a series decomposes the total variation in the time series by the cycle length of various periodic components. Additional feature practitioners often emphasize in spectral analysis is the presence of peaks in the spectrum which indicates an existence of statistically important periodicities in the time series.

By definition, frequency is reciprocal of the periodicity. The latter measures the number of time units required for completion of a cycle. Each frequency corresponds to a particular periodicity (or a cycle length) according to the mapping, $p=2 \pi / \omega$, where $p$ which denotes "period," measures the length of a cycle. For example, with quarterly data, the frequency $\omega=0.52$ corresponds to a 3-year (12-quarter) cycle while the frequency $\omega=0.20$ corresponds to a 8 -year (32-quarter) cycle. Below, on the figures displaying estimated spectral densities, in addition to the standard frequency scale we also present the corresponding time scale indicating periodicity in quarters. (On Figure 11, the periodicities are measured in years since there we use annual data.)

Following a common practice in macroeconomic applications of spectral analysis, we divide the frequency interval $0 \leq \omega \leq \pi$ into three segments: long-run frequency band, business cycle frequency band, and short-run frequency band. The cut-off points of these frequency bands we use are identical to those used in modern business cycle literature. For example, Prescott (1986) defines business cycles as 12-32 quarter cycles. Therefore, when we use quarterly data, we identify the frequency interval $0.20 \leq \omega \leq 0.52$ as business cycle frequency band. The frequencies below the business cycle frequency band $(\omega \leq 0.20)$ correspond to the long-run, while the frequencies above the business cycle frequency band $(\omega \geq 0.52)$ correspond to the short-run. ${ }^{7}$ In order to make the plottings of the spectral estimates easier to interpret, on each figure we also display vertical guidelines which identify these cut-off points.

The spectral estimates reported here are obtained by first estimating periodograms of the series. However these periodograms are inconsistent estimates of spectrum since they tend to be very erratic in the neighborhood of the frequencies considered in estimation. Therefore, the estimated periodograms are smoothed in order to get consistent estimates of the spectra. Smoothing is usually done by taking weighted integral of the periodogram ordinates considered. Several 
weight structures, also called lag windows, have been proposed in this literature. The main difference between the various lag windows is in the way they generate the weights. For example, the Daniell window, which is a truncated rectangular window, implicitly assigns equal weights to the autocovariances in the neighborhood of the frequencies considered and zero weight thereafter.

In this paper the smoothing is done using three different lag windows: Bartlett's, Tukey's, and Parzen's. ${ }^{8}$ However, since all three windows yield almost identical results, we only report the spectral estimates derived using Bartlett's lag window which assigns linearly decreasing weights to the autocovariances in the neighborhood of the frequencies considered and zero weight thereafter. ${ }^{9}$ The number of ordinates, $m$, which is the number of frequency points for which the spectrum is estimated, is set using the rule $m=2 \sqrt{n}$, where $n$ is the number of observations. Thus, we

estimate $f(\omega)$, where $\omega_{j}=\frac{j}{m}$, and $j=0,1,2, \ldots, m$. In addition to point estimates, we have also computed the confidence interval using asymptotic standard errors for each spectral estimates reported in this paper. The confidence intervals are plotted on each figure along with the estimated spectral density functions.

\section{Comparison of the Constructed Series Using Autocorrelation and Spectral Density Functions}

Figure 2 displays the estimated autocorrelation function of the quarterly consumer durable goods (measured in first differences) constructed by segmented linear interpolation of the annual capital stock series (method 1). Figure 3 displays the estimated spectral densities of the same series. Similarly, Figures 4-9 display the estimated autocorrelation and spectral density functions of the quarterly consumer durable goods series constructed by other three methods. The dotted lines on these figures indicate $95 \%$ confidence interval ( \pm 2 S.E.).

\section{Place Figure 2 here}

According to Figure 2, the quarterly consumer durable goods series constructed by segmented linear interpolation of the annual capital stock series (method 1) is characterized by a weak seasonal pattern as indicated by the value of autocorrelations at lags 4,12 , and 16 . Other than these seasonals, the autocorrelations are not different from zero, which is an indicator of a white noise process.

\section{Place Figure 3 here}

This interpretation is not very consistent with the estimated spectrum shown on Figure 3. The spectrum should contain a peak at frequency $\omega=1.57$, which would correspond to a 4-quarter cycle. The estimated spectrum, however, attains a local minimum at that frequency, suggesting a low power concentration at that frequency. The reason for this failure of the spectrum to identify 
the periodic structure of the linearly interpolated series might be the finding reported recently by Dezhbakhsh and Levy (1994) that segmented linear interpolation may introduce a nonstationarity of periodic nature in the generated series. With the exception of this particular frequency, the flatness of the spectrum indicates that each specific frequency in the business cycle and short run frequency band contributes equally to the variation in the constructed capital stock. ${ }^{10}$ From comparing the areas under the spectrum at each of the three specified frequency bands on Figure 3 it is clear that most of the variation in the constructed CDG series is caused by short-run fluctuations and relatively very little variation is caused by long-run or business-cycle fluctuations.

Place Figure 4 here

Figures 4 and 5 display the estimated autocorrelation and spectral density functions of the quarterly consumer durable goods series constructed by numerical iteration of capital accumulation equation (method 2). Here the autocorrelation function displays no clear pattern. In fact, for most lags it is not different from zero.

\section{Place Figure 5 here}

However, the spectral density contains significant peaks at frequencies $\omega=1.05, \omega=2.10$, and $\omega=3.14$. These frequencies correspond to 6,3 , and 2 quarter cycles. Since the original capital stock data used here is annual, the reason for these periodicities might be the quarterly investment series we used with this method.

\section{Place Figure 5a here}

To examine this possibility, we estimate the spectral density function of the quarterly CDG investment series for the 1948:1-1991:4 period. As the spectral density plot displayed in Figure 5a indicates, it indeed contains peaks in the neighborhoods of those frequencies. Overall, the spectrum in Figure 5 indicates that most of the variation in the constructed CDG series is due to short-run fluctuations.

\section{Place Figure 6 here}

Figures 6 and 7 display the estimated autocorrelation and spectral density functions of the quarterly consumer durable goods series constructed by segmented linear interpolation of the annual depreciation series (method 3). Here the autocorrelation displays a strong seasonal pattern as indicated by high and statistically significant values of estimated autocorrelations at the seasonal lags $4,8,12$, etc. The autocorrelations are also significant at lags $2,6,10,14$, and 18 , though 
they are much smaller than the seasonals.

\section{Place Figure 7 here}

This pattern is consistent with the estimated spectrum on Figure 7 which contains a peak at frequency $\omega=1.57$, which corresponds to a 4-quarter cycle. The concentration of a relatively large spectral mass around the 4-quarter cycle emphasizes the importance of this cycle in the total

variation of the series. ${ }^{11}$ Although the spectrum appears to have peaks also at $\omega=1.05, \omega=2.10$, and $\omega=2.50$ (which correspond to 6,3 , and $2 \frac{1}{2}$-quarter cycles), these peaks are relatively minor. Similar to the previous spectral densities, Figure 7 also indicates that most of the variation in the constructed CDG series can be attributed to short-run fluctuations.

\section{Place Figure 8 here}

Figures 8 and 9 display the estimated autocorrelation and spectral density functions of the quarterly consumer durable goods series constructed by assuming equal quarterly depreciation (method 4). Here the autocorrelation function displays a complex pattern. It is statistically significant at lags $2,4,6,10,14$, and 16 .

\section{Place Figure 9 here}

The spectral density function shown on Figure 9 contains significant peaks at frequencies $\omega=1.05, \omega=1.57, \omega=2.10$, and $\omega=2.88$, which correspond to $6,4,3$, and $2 \frac{1}{5}$-quarter cycles. As with method 2, the reason for these periodicities might be periodic behavior of the quarterly CDG investment series we used. As with previous spectral densities, here also we find that most of the variation in the constructed quarterly CDG series is explained by short-run fluctuations.

\section{Place Figure 10 here}

For comparison, we also estimate the autocorrelation and spectral density functions of the differenced original annual consumer durable goods series which we use with all four methods. These functions are displayed on Figures 10 and 11. According to Figure 10, the estimated autocorrelation is not statistically significant at any of the 24 lags considered. In terms of the properties of the autocorrelation function, the quarterly series constructed using numerical iteration of the capital evolution equation (method 2) exhibits a behaviour most similar to the behavior of the annual series in comparison to the series constructed using the other three methods.

\section{Place Figure 11 here}

Because the annual data has a lower frequency than the constructed quarterly data, the 
comparison of the spectral density functions should be done carefully. This is because now cyclical periodicities are measured in years instead of quarters. In addition, the shortest cycle that can be identified with spectral analysis is two-time-units long, i.e., for the highest frequency $\omega=\pi$, we have $2 \pi / \omega=2 \pi / \pi=2$. Therefore, with annual data the highest observable frequency corresponds to a 2-year cycle while with quarterly data it corresponds to a 2-quarter cycle. ${ }^{12}$ Consequently, the spectrum displayed in Figure 11 contains no information on the cyclical dynamics of the capital stock series for periodicities less than 8 quarters ( $=2$ years). This means that the information contained in the entire frequency band $0 \leq \omega \leq \pi$ on Figure 11, corresponds to the information contained in the frequency band $0 \leq \omega \leq 0.78$ on Figures $2,4,6$, and $8 .{ }^{13}$

Thus, comparing the values as well as the shapes of all four quarterly spectral density functions in the frequency band $0 \leq \omega \leq 0.78$ with the annual spectrum in the frequency band $0 \leq \omega \leq \pi$, it seems that the spectrum displayed on Figure 3 is the closer to the annual spectrum in comparison to the other three. With the exception of the zero-frequency band, the quarterly spectrum in the frequency range $0 \leq \omega \leq 0.78$ on Figure 3 fluctuates around 1.05. According to Figure 11, the spectrum estimated using annual data also fluctuates around that value with the exception of the $\omega=0$ and $\omega=\pi$ frequency bands. In contrast to this pattern, the spectral density functions displayed on Figures 5, 7, and 9 remain below 1.05 in the frequency band $0 \leq \omega \leq 0.78$.

On the other hand, if the constructed quarterly capital stock series is to be used in studying some short-run phenomenon, and if we believe that the true quarterly series (which we do not have) is a smooth series like its annual counterpart, then we would expect the constructed series to exhibit low variation in the high, or short-run, frequencies. This suggests that we can rank the constructed quarterly capital stock series by measuring the areas underneath the estimated spectral density functions at the short-run frequency band, $\omega \geq 0.52$, by using a numerical integration technique. Following this line of thought, we computed the areas underneath the estimated spectral density functions in the shortrun frequency bands on figures $3,5,7$, and 9 , and found that they equal 21.92, 24.56, 26.78, and 25.32 , respectively. Thus, we see that the quarterly series constructed using method 1 (segmented linear interpolation) and method 2 (numerical iteration of capital evolution equation) have a lower short-run variation in comparison to methods 3 and 4 . Therefore, for short-run analysis we would choose quarterly capital stock series generated by either method 1 or method 2 .

\section{Comparison of the Constructed Series Using Variance Ratio Test}

It would be interesting to compare long run shock persistence characteristics of the constructed quarterly time series with the persistence displayed by the annual series. For this we use a frequency domain equivalent of a measure of persistence suggested by Cochrane (1988) as a 
substitute to more standard unit root tests. The measure is based on the variance ratio statistic, $V$ :

$$
V=\frac{\frac{1}{k} \operatorname{var}[y(t)-y(t-k)]}{\operatorname{var}[y(t)-y(t-1)\rceil}
$$

where the numerator measures the variance of cumulative growth over a horizon of many years while the expression in denominator is the variance of 1-year growth. Cochrane (1988) proves that the numerator of variance ratio statistic is asymptotically equivalent to the Bartlett's estimate of spectral density at frequency zero. That is,

$$
\not(\omega)=\lim _{k \rightarrow \infty}\left\{\frac{1}{k} \operatorname{var}[y(t)-y(t-k)]\right\}
$$

where $\beta(\omega)$ denotes the Bartlett's estimate of spectral density.

The denominator in (26) can be estimated by computing unconditional variance of differenced $y_{i}$. Therefore, computing the Bartlett's estimate of spectral density at the zero-frequency and standardizing it by the unconditional variance of the differenced series will yield consistent estimate of Cochrane's variance ratio statistic. Bartlett's estimate of standardized spectral density of the constructed quarterly CDG series is shown on figures 3, 5, 7, 9, and 11 by the solid line and their zero frequency value for methods $1,2,3$, and 4 equals $0.64,0.30,0.17$, and 0.32 , respectively. In contrast to this, the corresponding value for the annual series equals $0.38 .^{14}$ This means that in terms of long run shock persistence properties the constructed quarterly capital stock series differ substantially from each other as well as from the original annual series. The series constructed using method 1 exhibits more shock persistence than the original series, while the series constructed by other three methods exhibit less shock persistence than the original series.

In a recent study, Granger (1991) shows that shock persistence properties of time series are preserved under temporal aggregation. That is, if a series is generated over one time interval (say, a month) but is recorded over a longer interval (such as a quarter), the shock persistence properties should remain unaltered. If this is true for stock series also, then it seems that the quarterly capital stock series constructed by method 2 (numerical iteration of capital evolution equation) and method 4 (equal annual depreciation) yield series with long-run shock persistence properties that are very similar to the shock persistence properties of the original annual data. Overall, it is clear that the four methods used here produce series with very different long run shock persistence properties.

\section{SUMMARY AND CONCLUSIONS}

In this paper we construct quarterly nominal and real, gross as well as net capital stock series 
for the post-war U.S. economy. The series constructed include all three categories of the aggregate capital stock: consumer durable goods, producer durable goods and equipment, and nonresidential business structures.

The quarterly capital stock series are constructed using four different procedures. The first is a segmented linear year-to-year interpolation technique. The second technique exploits the dynamic relationship between the capital stock and the corresponding capital investment series and uses annual beginning-of-the-year and end-of-the-year capital stock data to estimate the implied quarterly depreciation rates for all three categories of the aggregate capital stock by numerical iteration over the depreciation rates until a convergence is achieved. ${ }^{15}$ These depreciation rates are then used along with the quarterly investment and the annual capital stock series to construct quarterly capital stock series. The third method estimates the quarterly depreciation by linearly interpolating the annual depreciation figures which are then used along with the annual capital stock and the quarterly investment series to construct the quarterly capital stock series. The fourth method estimates the quarterly depreciation figures by assuming that the annual depreciation is spread equally across the four quarters of the year.

In order to compare and contrast the constructed quarterly capital stock series to each other and to the original annual series from which they are constructed, we compare the time series properties of these series. For this we use one time domain measure, namely the autocorrelation function, and two frequency domain measures. The latter are, (1) the spectral density function, which allows us to decompose the total variation in the series by frequency (short-run, business cycle, and long-run), and (2) frequency domain equivalent of the variance ratio statistic often used to measure a long-run shock persistence (i.e., unit root) properties of the time series.

The constructed series share one cyclical characteristic: most of the variation in the constructed series is caused by short-run fluctuations and relatively very little variation is caused by long-run or business-cycle fluctuations. Other than this, the constructed capital stock series exhibit markedly different statistical behavior. In particular, using various time and frequency domain measures we demonstrate that the generated series exhibit very different cyclical dynamics. For example, we show that the generated series are characterized by different short run and business cycle periodic patterns. Interestingly, we find that out of the four methods examined, the simplest method, namely segmented linear interpolation of the annual capital stock series, yields quarterly series with business cycle properties that are very similar to the properties we find in the original annual data.

Using frequency domain equivalent of Cochrane's (1988) variance ratio test, we show that the constructed series are characterized by different long run shock persistence properties. This is somewhat surprising because one would expect that an increase in the data frequency from annual to quarterly would alter short run and perhaps business cycle dynamics of the original series, but 
not necessarily long run behavior. This is especially true because by construction, the end-of-the-

fourth-quarter capital stock values coincide with the corresponding end-of-the-year annual values. ${ }^{16}$

Although it is fair to conclude that the findings reported in this paper are mixed, the usefulness of the quarterly capital stock series constructed here may still be ranked based on the results of the statistical comparison discussed in section IV. If the goal is to study some kind of long-run phenomenon, then our preferred method is the method of numerical iteration (method 2). This is because method 2 uses a well established capital accumulation relationship and does not involve any statistical approximation of the type used with other methods. In addition, since recent studies (e.g., Granger, 1991) have shown that temporal aggregation of time series should not alter the shock persistence properties of the series, the estimated value of the frequency domain version of the variance ratio statistic can be used to rank the constructed series. According to our findings, the quarterly capital stock series constructed by method 2 exhibits long-run shock persistence properties that is very close to the shock persistence properties of the original annual data.

If, on the other hand, the goal of using quarterly capital stock series is to examine some short-run phenomenon, then none of the four methods used here seem to be clearly superior to the rest. However, if we believe that the true quarterly capital stock series (i.e, the stock of capital actually in place in each quarter) contains no jumps and is rather smooth, then its spectral density function will show a low power concentration underneath the spectrum at short-run frequencies. This will indicate that most of the variation in the existing stock of capital is due to long-run and business cycle frequencies, and very little variation is due to short-run frequencies.

Following this line of thought, we compared the constructed quarterly capital stock series by comparing the areas underneath the estimated spectral density functions at the short-run frequency bands on figures $3,5,7$, and 9 . Numerically integrating the areas underneath the spectral density functions, we find that the quarterly series constructed using method 1 (segmented linear interpolation) and method 2 (numerical iteration of capital evolution equation) have a lower short-run variation in comparison to methods 3 and 4 . Thus, in choosing a method for constructing a quarterly capital stock series, the frequency domain differences found between the methods used here should be taken into account, especially if the constructed series are used in empirical statistical analysis. ${ }^{17}$

In our view, the quarterly capital stock series constructed here are good estimates of the true capital stock data because of the relative smoothness of the capital stock series and also because, by construction, the end-of-the-fourth-quarter capital stock values coincide with the corresponding end-of-the-year annual values. In the future, it may be worthwhile to use similar techniques to construct capital stock series at more disaggregated level. 


\section{Footnotes}

1. Consumer durable goods are not usually counted as part of capital stock. In fact, as the referee noted, U.S. is the only country to include consumer durable goods in capital stock.

2. The revision of the annual capital stock series followed the recent comprehensive revision of the National Income and Product Accounts (NIPA). In addition to the inclusion of these NIPA revisions, the revised capital stock data as well as the revised NIPA estimates of consumption of fixed capital, reflect a revision in the service lives of several types of assets. As Musgrave (1992) suggests, the resulting changes in the annual capital stock series are quite significant, especially after 1970. See Musgrave (1992) for details.

3. According to Boyer and Merzbach (1991), linear interpolation was apparently used as early as 2000 B.C. in ancient Babylonian Mesopotamia to construct exponential tables.

4. The annual depreciation estimates published by the Bureau of Economic Analysis are based on a straight-line formula, which assumes equal dollar depreciation over the life of the asset.

5. The plot generated by segmented linear interpolation of the annual capital stock series has flat portions since the interpolation is essentially done by adding to each quarterly value $1 / 4$ of the linear distance between the annual observations. Therefore, when we compute first difference of the interpolated quarterly series, within the interpolation period (a year) it should remain unchanged.

6. Thus, the autocovariance function is the inverse Fourier transform of the spectrum. That is, $\gamma(\tau)=\int_{-\infty}^{\infty} f_{y}(\omega) e^{i \tau \omega} d \omega$. Therefore, autocovariance function and spectrum are equivalent and if either is known, the other can be determined exactly. However, as Koopmans (1974) argues and as we demonstrate below, these functions display different aspects of the covariation information about the time series, and some dynamic and cyclical features of the data are easier to identify and interpret in the frequency domain.

7. When we use annual data, these cutoff points are $\omega \leq 0.78$ and $\omega \geq 2.10$, respectively.

8. See Koopmans (1974) for technical details.

9. The estimated spectral densities derived using Tukey's and Parzen's windows are available upon request. 
10. A pure white noise process has a completely flat spectrum which means that all frequency components contribute equally to the variation of the process.

11. As noted above, linearly interpolated capital stock series (method 1) also exhibit a 4-quarter cycle. This finding is not a coincidence. In a study by Dezhbakhsh and Levy (1994) it is shown that the moments of linearly interpolated series will exhibit a significant periodic (in this case seasonal) variation.

12. This is known as Nyquist frequency.

13. This is why the location of the vertical lines on Figure 11 differs from the other figures.

14. Some of the differences between quarterly and annual spectral density functions may be due to the difference in the number of observations used in estimating them: 44 annual vs 176 quarterly. For example, Choi (1992) finds that using the data generated by aggregating subinterval data reduces the power of augmented Dickey-Fuller tests.

15. For the 1948-91 period, the estimated average depreciation rates of consumer durable goods, producer durable goods, and nonresidential business structures are $0.24,0.12$, and 0.05 , respectively. Gordon and Veitch's (1986) estimated average depreciation rates of consumer durable goods, producer durable goods, and nonresidential business structures are 0.20 , 0.14 , and 0.06 , respectively.

16. Method 3 is obviously an exception as was shown in section 2 of the paper. It should be noted that since we use the annual capital stock series constructed by the BEA as a benchmark for constructing quarterly series, our capital stock and depreciation series are conditional on the BEA's estimates.

17. An extension of this study (Levy and Chen, 1994) compares the constructed capital stock series by estimating time varying value added aggregate production functions for the post-war U.S. economy using the constructed capital stock series along with the aggregate labor input series. 


\section{References}

Boyer, C.B. and U.C. Merzbach, A History of Mathematics, Wiley, New York, 1991.

Choi, In, "Effects of Data Aggregation on the Power of Tests for a Unit Root," Economics Letters, 40, 397-401, 1992.

Citicorp Database Services, CITIBASE: Macroeconomic Database, 1993.

Cochrane, John H., "How Big is the Random Walk in GNP?" Journal of Political Economy, 96 (5), 893-920, 1988.

Dezhbakhsh, Hashem and Daniel Levy, "Periodic Properties of Interpolated Time Series," Economics Letters, April 1994.

Gordon, Robert J. and John M. Veitch, "Fixed Investment in the American Business Cycle: 1919-83," in Robert J. Gordon (ed.), The American Business Cycle: Continuity and Change, 267-335, The University of Chicago Press, Chicago, 1986.

Granger, Clive W.J., "Some Recent Generalizations of Cointegration and the Analysis of LongRun Relationships," in Robert F. Engle and Clive W.J. Granger (ed.), Long-Run Economic Relationships: Readings in Cointegration, 277-287, Oxford University Press, New York, 1991.

Koopmans, Lambert H., The Spectral Analysis of Time Series, Academic Press, New York, 1974.

Levy, Daniel, "Estimates of Time Varying Aggregate Capital Stock Depreciation Rates for the Post-War U.S. Economy,” Working Paper, 1994. and Haiwei Chen, "Comparison of Four Different Aggregate Quarterly Capital Stock Series Based on Production Function Estimates," Mimeo, 1994.

Musgrave, John C., "Fixed Reproducible Tangible Wealth in the United States: Revised Estimates," Survey of Current Business, 106-35, January, 1992.

Prescott, Edward, "Theory Ahead of Business Cycle Measurement," Carnegie-Rochester Conference Series on Public Policy, Vol. 25, Autumn, 11-44, 1986. 
Table 1. Estimated Quarterly Net Capital Stock: Consumer Durable Goods (billions of 1987 dollars)

\begin{tabular}{|c|c|c|c|c|}
\hline Time & $\begin{array}{l}\text { Linear } \\
\text { Interpolation }\end{array}$ & $\begin{array}{l}\text { Numerical } \\
\text { Iteration }\end{array}$ & $\begin{array}{l}\text { Interpolated } \\
\text { Depreciation }\end{array}$ & $\begin{array}{l}\text { Equal Quarterly } \\
\text { Depreciation }\end{array}$ \\
\hline 1948.1 & 195.62 & 195.84 & 196.24 & 195.30 \\
\hline 1948.2 & 201.35 & 201.30 & 202.17 & 200.60 \\
\hline 1948.3 & 207.08 & 207.08 & 208.43 & 206.55 \\
\hline 1948.4 & 212.80 & 212.80 & 214.68 & 212.80 \\
\hline 1949.1 & 219.10 & 217.93 & 218.43 & 217.38 \\
\hline 1949.2 & 225.40 & 224.73 & 225.68 & 223.94 \\
\hline 1949.3 & 231.70 & 231.50 & 232.99 & 230.89 \\
\hline 1949.4 & 238.00 & 238.00 & 240.09 & 238.00 \\
\hline 1950.1 & 246.48 & 244.80 & 245.27 & 244.10 \\
\hline 1950.2 & 254.95 & 251.45 & 252.42 & 250.48 \\
\hline 1950.3 & 263.43 & 263.28 & 264.76 & 262.43 \\
\hline 1950.4 & 271.90 & 271.90 & 274.24 & 271.90 \\
\hline 1951.1 & 278.02 & 281.30 & 281.16 & 280.67 \\
\hline 1951.2 & 284.15 & 287.04 & 287.13 & 286.31 \\
\hline 1951.3 & 290.27 & 291.88 & 292.37 & 291.38 \\
\hline 1951.4 & 296.40 & 296.40 & 297.38 & 296.40 \\
\hline 1952.1 & 300.73 & 300.92 & 301.55 & 300.54 \\
\hline 1952.2 & 305.05 & 305.78 & 306.98 & 305.29 \\
\hline 1952.3 & 309.38 & 308.89 & 310.58 & 308.56 \\
\hline 1952.4 & 313.70 & 313.70 & 315.73 & 313.70 \\
\hline 1953.1 & 319.10 & 319.55 & 319.88 & 319.09 \\
\hline 1953.2 & 324.50 & 324.67 & 325.40 & 324.08 \\
\hline 1953.3 & 329.90 & 329.55 & 330.70 & 329.11 \\
\hline 1953.4 & 335.30 & 335.30 & 336.89 & 335.30 \\
\hline 1954.1 & 339.32 & 339.00 & 340.05 & 338.67 \\
\hline 1954.2 & 343.35 & 342.42 & 344.29 & 342.00 \\
\hline 1954.3 & 347.37 & 346.22 & 348.65 & 345.90 \\
\hline 1954.4 & 351.40 & 351.40 & 354.15 & 351.40 \\
\hline 1955.1 & 358.08 & 357.01 & 357.81 & 356.42 \\
\hline 1955.2 & 364.75 & 364.02 & 365.51 & 363.20 \\
\hline
\end{tabular}


Table 1. Continued.

\begin{tabular}{lllll}
\hline Time & $\begin{array}{l}\text { Linear } \\
\text { Interpolation }\end{array}$ & $\begin{array}{l}\text { Numerical } \\
\text { Iteration }\end{array}$ & $\begin{array}{c}\text { Interpolated } \\
\text { Depreciation }\end{array}$ & $\begin{array}{l}\text { Equal Quarterly } \\
\text { Depreciation }\end{array}$ \\
\hline 1955.3 & 371.42 & 371.20 & 373.35 & 370.57 \\
1955.4 & 378.10 & 378.10 & 380.88 & 378.10 \\
1956.1 & 382.45 & 383.37 & 383.64 & 382.94 \\
1956.2 & 386.80 & 387.82 & 388.45 & 387.27 \\
1956.3 & 391.15 & 391.83 & 392.85 & 391.44 \\
1956.4 & 395.50 & 395.50 & 396.91 & 395.50 \\
1957.1 & 398.85 & 399.89 & 400.21 & 399.55 \\
1957.2 & 402.20 & 403.45 & 404.13 & 403.02 \\
1957.3 & 405.55 & 406.17 & 407.21 & 405.88 \\
1957.4 & 408.90 & 408.90 & 410.23 & 408.90 \\
1958.1 & 409.98 & 409.93 & 410.38 & 409.85 \\
1958.2 & 411.05 & 410.70 & 411.48 & 410.60 \\
1958.3 & 412.13 & 411.55 & 412.52 & 411.48 \\
1958.4 & 413.20 & 413.20 & 414.25 & 413.20 \\
1959.1 & 416.00 & 415.64 & 416.31 & 415.37 \\
1959.2 & 418.80 & 419.00 & 420.18 & 418.61 \\
1959.3 & 421.60 & 422.51 & 424.09 & 422.20 \\
1959.4 & 424.40 & 424.40 & 426.28 & 424.40 \\
1960.1 & 427.12 & 427.18 & 427.14 & 426.90 \\
1960.2 & 429.85 & 430.56 & 430.58 & 430.18 \\
1960.3 & 432.58 & 433.39 & 433.59 & 433.11 \\
1960.4 & 435.30 & 435.30 & 435.77 & 435.29 \\
1961.1 & 436.60 & 436.00 & 435.87 & 435.92 \\
1961.2 & 437.90 & 436.78 & 436.59 & 436.67 \\
1961.3 & 439.20 & 438.04 & 437.85 & 437.95 \\
1961.4 & 440.50 & 440.50 & 440.39 & 440.50 \\
1962.1 & 443.83 & 443.21 & 443.45 & 442.94 \\
1962.2 & 447.15 & 446.35 & 446.84 & 445.99 \\
1962.3 & 450.48 & 449.56 & 450.30 & 449.28 \\
1962.4 & 453.80 & 453.80 & 454.82 & 453.80 \\
\hline & & & &
\end{tabular}


Table 1. Continued.

\begin{tabular}{|c|c|c|c|c|}
\hline Time & $\begin{array}{l}\text { Linear } \\
\text { Interpolation }\end{array}$ & $\begin{array}{l}\text { Numerical } \\
\text { Iteration }\end{array}$ & $\begin{array}{l}\text { Interpolated } \\
\text { Depreciation }\end{array}$ & $\begin{array}{l}\text { Equal Quarterly } \\
\text { Depreciation }\end{array}$ \\
\hline 1963.1 & 458.72 & 458.40 & 458.66 & 457.97 \\
\hline 1963.2 & 463.65 & 463.32 & 463.89 & 462.74 \\
\hline 1963.3 & 468.57 & 468.35 & 469.29 & 467.91 \\
\hline 1963.4 & 473.50 & 473.50 & 474.89 & 473.51 \\
\hline 1964.1 & 479.92 & 479.80 & 480.02 & 479.21 \\
\hline 1964.2 & 486.35 & 486.42 & 486.98 & 485.62 \\
\hline 1964.3 & 492.77 & 493.70 & 494.71 & 493.09 \\
\hline 1964.4 & 499.20 & 499.20 & 500.82 & 499.20 \\
\hline 1965.1 & 508.38 & 508.15 & 508.23 & 507.38 \\
\hline 1965.2 & 517.55 & 516.64 & 517.03 & 515.61 \\
\hline 1965.3 & 526.72 & 525.85 & 526.77 & 525.07 \\
\hline 1965.4 & 535.90 & 535.90 & 537.60 & 535.91 \\
\hline 1966.1 & 546.30 & 548.20 & 548.20 & 547.26 \\
\hline 1966.2 & 556.70 & 557.82 & 558.21 & 556.65 \\
\hline 1966.3 & 567.10 & 567.99 & 568.98 & 567.11 \\
\hline 1966.4 & 577.50 & 577.50 & 579.37 & 577.50 \\
\hline 1967.1 & 586.67 & 586.35 & 586.71 & 585.58 \\
\hline 1967.2 & 595.85 & 596.52 & 597.35 & 595.47 \\
\hline 1967.3 & 605.02 & 605.65 & 607.13 & 604.87 \\
\hline 1967.4 & 614.20 & 614.20 & 616.46 & 614.21 \\
\hline 1968.1 & 625.83 & 625.17 & 625.66 & 624.24 \\
\hline 1968.2 & 637.45 & 636.50 & 637.60 & 635.24 \\
\hline 1968.3 & 649.08 & 649.06 & 650.91 & 648.08 \\
\hline 1968.4 & 660.70 & 660.70 & 663.53 & 660.70 \\
\hline 1969.1 & 671.47 & 672.71 & 673.59 & 671.78 \\
\hline 1969.2 & 682.25 & 683.79 & 685.60 & 682.58 \\
\hline 1969.3 & 693.03 & 694.19 & 696.93 & 693.30 \\
\hline 1969.4 & 703.80 & 703.80 & 707.43 & 703.80 \\
\hline 1970.1 & 711.05 & 712.09 & 712.73 & 711.42 \\
\hline 1970.2 & 718.30 & 720.46 & 721.76 & 719.56 \\
\hline
\end{tabular}


Table 1. Continued.

\begin{tabular}{|c|c|c|c|c|}
\hline Time & $\begin{array}{l}\text { Linear } \\
\text { Interpolation }\end{array}$ & $\begin{array}{l}\text { Numerical } \\
\text { Iteration }\end{array}$ & $\begin{array}{l}\text { Interpolated } \\
\text { Depreciation }\end{array}$ & $\begin{array}{l}\text { Equal Quarterly } \\
\text { Depreciation }\end{array}$ \\
\hline 1970.3 & 725.55 & 728.60 & 730.57 & 727.93 \\
\hline 1970.4 & 732.80 & 732.80 & 735.43 & 732.79 \\
\hline 1971.1 & 742.38 & 740.99 & 741.84 & 740.27 \\
\hline 1971.2 & 751.95 & 749.93 & 751.57 & 748.95 \\
\hline 1971.3 & 761.53 & 759.76 & 762.14 & 759.00 \\
\hline 1971.4 & 771.10 & 771.10 & 774.24 & 771.10 \\
\hline 1972.1 & 783.72 & 782.37 & 783.57 & 781.40 \\
\hline 1972.2 & 796.35 & 794.27 & 796.57 & 792.95 \\
\hline 1972.3 & 808.97 & 806.70 & 810.05 & 805.70 \\
\hline 1972.4 & 821.60 & 821.60 & 825.95 & 821.60 \\
\hline 1973.1 & 837.17 & 840.28 & 840.67 & 838.87 \\
\hline 1973.2 & 852.75 & 856.64 & 857.84 & 854.84 \\
\hline 1973.3 & 868.33 & 871.54 & 873.84 & 870.23 \\
\hline 1973.4 & 883.90 & 883.90 & 887.51 & 883.90 \\
\hline 1974.1 & 893.08 & 894.87 & 895.16 & 894.00 \\
\hline 1974.2 & 902.25 & 905.91 & 906.68 & 904.75 \\
\hline 1974.3 & 911.42 & 916.82 & 918.27 & 915.95 \\
\hline 1974.4 & 920.60 & 920.60 & 922.92 & 920.60 \\
\hline 1975.1 & 928.27 & 925.71 & 926.28 & 925.23 \\
\hline 1975.2 & 935.95 & 931.52 & 932.58 & 930.84 \\
\hline 1975.3 & 943.62 & 940.73 & 942.23 & 940.15 \\
\hline 1975.4 & 951.30 & 951.30 & 953.39 & 951.30 \\
\hline 1976.1 & 963.47 & 963.86 & 965.05 & 962.88 \\
\hline 1976.2 & 975.65 & 975.84 & 978.18 & 974.55 \\
\hline 1976.3 & 987.82 & 987.64 & 991.03 & 986.67 \\
\hline 1976.4 & 1000.00 & 1000.00 & 1004.36 & 1000.00 \\
\hline 1977.1 & 1015.25 & 1014.53 & 1015.45 & 1013.34 \\
\hline 1977.2 & 1030.50 & 1029.74 & 1031.64 & 1028.12 \\
\hline 1977.3 & 1045.75 & 1045.13 & 1048.13 & 1043.91 \\
\hline 1977.4 & 1061.00 & 1061.00 & 1065.22 & 1061.00 \\
\hline
\end{tabular}


Table 1. Continued.

\begin{tabular}{|c|c|c|c|c|}
\hline Time & $\begin{array}{l}\text { Linear } \\
\text { Interpolation }\end{array}$ & $\begin{array}{l}\text { Numerical } \\
\text { Iteration }\end{array}$ & $\begin{array}{l}\text { Interpolated } \\
\text { Depreciation }\end{array}$ & $\begin{array}{l}\text { Equal Quarterly } \\
\text { Depreciation }\end{array}$ \\
\hline 1978.1 & 1077.60 & 1075.40 & 1075.54 & 1074.12 \\
\hline 1978.2 & 1094.20 & 1094.40 & 1094.96 & 1092.60 \\
\hline 1978.3 & 1110.80 & 1111.11 & 1112.61 & 1109.78 \\
\hline 1978.4 & 1127.40 & 1127.40 & 1130.23 & 1127.40 \\
\hline 1979.1 & 1141.03 & 1143.36 & 1143.73 & 1142.23 \\
\hline 1979.2 & 1154.65 & 1156.53 & 1157.58 & 1155.08 \\
\hline 1979.3 & 1168.28 & 1170.65 & 1172.56 & 1169.56 \\
\hline 1979.4 & 1181.90 & 1181.90 & 1184.89 & 1181.89 \\
\hline 1980.1 & 1187.18 & 1191.87 & 1192.76 & 1191.41 \\
\hline 1980.2 & 1192.45 & 1192.99 & 1194.82 & 1192.57 \\
\hline 1980.3 & 1197.73 & 1197.07 & 1199.45 & 1196.76 \\
\hline 1980.4 & 1203.00 & 1203.00 & 1205.69 & 1203.00 \\
\hline 1981.1 & 1207.93 & 1210.88 & 1210.98 & 1210.38 \\
\hline 1981.2 & 1212.85 & 1215.40 & 1215.82 & 1214.81 \\
\hline 1981.3 & 1217.78 & 1221.88 & 1222.63 & 1221.42 \\
\hline 1981.4 & 1222.70 & 1222.70 & 1223.91 & 1222.70 \\
\hline 1982.1 & 1226.07 & 1225.46 & 1226.04 & 1225.26 \\
\hline 1982.2 & 1229.45 & 1227.91 & 1228.95 & 1227.65 \\
\hline 1982.3 & 1232.82 & 1230.59 & 1231.95 & 1230.39 \\
\hline 1982.4 & 1236.20 & 1236.20 & 1237.77 & 1236.20 \\
\hline 1983.1 & 1246.62 & 1241.38 & 1242.08 & 1240.78 \\
\hline 1983.2 & 1257.05 & 1251.22 & 1252.45 & 1250.29 \\
\hline 1983.3 & 1267.48 & 1262.89 & 1264.72 & 1262.12 \\
\hline 1983.4 & 1277.90 & 1277.90 & 1280.50 & 1277.90 \\
\hline 1984.1 & 1296.40 & 1295.56 & 1295.78 & 1294.18 \\
\hline 1984.2 & 1314.90 & 1314.68 & 1315.47 & 1312.81 \\
\hline 1984.3 & 1333.40 & 1332.48 & 1334.28 & 1331.09 \\
\hline 1984.4 & 1351.90 & 1351.90 & 1355.09 & 1351.90 \\
\hline 1985.1 & 1374.50 & 1373.70 & 1374.85 & 1371.99 \\
\hline 1985.2 & 1397.10 & 1395.47 & 1397.93 & 1393.17 \\
\hline
\end{tabular}


Table 1. Continued.

\begin{tabular}{|c|c|c|c|c|}
\hline Time & $\begin{array}{l}\text { Linear } \\
\text { Interpolation }\end{array}$ & $\begin{array}{l}\text { Numerical } \\
\text { Iteration }\end{array}$ & $\begin{array}{l}\text { Interpolated } \\
\text { Depreciation }\end{array}$ & $\begin{array}{l}\text { Equal Quarterly } \\
\text { Depreciation }\end{array}$ \\
\hline 1985.3 & 1419.70 & 1421.65 & 1425.55 & 1419.84 \\
\hline 1985.4 & 1442.30 & 1442.30 & 1448.02 & 1442.31 \\
\hline 1986.1 & 1468.58 & 1464.64 & 1466.02 & 1462.81 \\
\hline 1986.2 & 1494.85 & 1488.68 & 1491.50 & 1486.14 \\
\hline 1986.3 & 1521.13 & 1519.75 & 1524.12 & 1517.69 \\
\hline 1986.4 & 1547.40 & 1547.40 & 1553.83 & 1547.40 \\
\hline 1987.1 & 1570.30 & 1568.39 & 1569.58 & 1566.72 \\
\hline 1987.2 & 1593.20 & 1591.77 & 1594.23 & 1589.46 \\
\hline 1987.3 & 1616.10 & 1617.65 & 1621.58 & 1615.85 \\
\hline 1987.4 & 1639.00 & 1639.00 & 1644.72 & 1638.99 \\
\hline 1988.1 & 1663.85 & 1664.78 & 1666.17 & 1662.94 \\
\hline 1988.2 & 1688.70 & 1689.75 & 1692.71 & 1687.32 \\
\hline 1988.3 & 1713.55 & 1712.71 & 1717.40 & 1710.94 \\
\hline 1988.4 & 1738.40 & 1738.40 & 1744.86 & 1738.40 \\
\hline 1989.1 & 1761.50 & 1761.87 & 1763.68 & 1760.12 \\
\hline 1989.2 & 1784.60 & 1785.45 & 1789.02 & 1783.10 \\
\hline 1989.3 & 1807.70 & 1810.46 & 1815.78 & 1808.67 \\
\hline 1989.4 & 1830.80 & 1830.80 & 1837.91 & 1830.80 \\
\hline 1990.1 & 1848.88 & 1853.32 & 1856.02 & 1851.81 \\
\hline 1990.2 & 1866.95 & 1871.47 & 1876.59 & 1869.57 \\
\hline 1990.3 & 1885.02 & 1888.87 & 1895.91 & 1887.49 \\
\hline 1990.4 & 1903.10 & 1903.10 & 1911.52 & 1903.10 \\
\hline 1991.1 & 1912.32 & 1911.41 & 1914.30 & 1910.75 \\
\hline 1991.2 & 1921.55 & 1919.73 & 1924.74 & 1918.82 \\
\hline 1991.3 & 1930.77 & 1930.27 & 1936.66 & 1929.55 \\
\hline 1991.4 & 1940.00 & 1940.00 & 1947.10 & 1940.00 \\
\hline
\end{tabular}

Source: Authors' calculations. 
Table 2. Estimated Quarterly Net Capital Stock: Producer Durable Goods (billions of 1987 dollars)

\begin{tabular}{|c|c|c|c|c|}
\hline Time & $\begin{array}{l}\text { Linear } \\
\text { Interpolation }\end{array}$ & $\begin{array}{l}\text { Numerical } \\
\text { Iteration }\end{array}$ & $\begin{array}{l}\text { Interpolated } \\
\text { Depreciation }\end{array}$ & $\begin{array}{l}\text { Equal Quarterly } \\
\text { Depreciation }\end{array}$ \\
\hline 1948.1 & 357.53 & 358.98 & 359.16 & 358.51 \\
\hline 1948.2 & 368.35 & 369.67 & 370.15 & 369.06 \\
\hline 1948.3 & 379.18 & 379.61 & 380.47 & 379.17 \\
\hline 1948.4 & 390.00 & 390.00 & 391.30 & 390.00 \\
\hline 1949.1 & 396.73 & 398.79 & 399.15 & 398.48 \\
\hline 1949.2 & 403.45 & 405.82 & 406.56 & 405.43 \\
\hline 1949.3 & 410.18 & 411.58 & 412.66 & 411.30 \\
\hline 1949.4 & 416.90 & 416.90 & 418.26 & 416.90 \\
\hline 1950.1 & 424.52 & 422.22 & 422.58 & 421.94 \\
\hline 1950.2 & 432.15 & 429.54 & 430.21 & 429.14 \\
\hline 1950.3 & 439.77 & 438.66 & 439.61 & 438.33 \\
\hline 1950.4 & 447.40 & 447.40 & 448.68 & 447.40 \\
\hline 1951.1 & 455.12 & 454.74 & 455.11 & 454.42 \\
\hline 1951.2 & 462.85 & 462.32 & 463.04 & 461.89 \\
\hline 1951.3 & 470.58 & 470.46 & 471.52 & 470.13 \\
\hline 1951.4 & 478.30 & 478.30 & 479.68 & 478.30 \\
\hline 1952.1 & 484.72 & 486.04 & 486.34 & 485.74 \\
\hline 1952.2 & 491.15 & 493.71 & 494.33 & 493.32 \\
\hline 1952.3 & 497.57 & 498.01 & 498.97 & 497.76 \\
\hline 1952.4 & 504.00 & 504.00 & 505.21 & 504.00 \\
\hline 1953.1 & 510.65 & 510.91 & 511.44 & 510.62 \\
\hline 1953.2 & 517.30 & 517.40 & 518.38 & 517.01 \\
\hline 1953.3 & 523.95 & 524.32 & 525.67 & 524.03 \\
\hline 1953.4 & 530.60 & 530.60 & 532.24 & 530.60 \\
\hline 1954.1 & 535.05 & 535.31 & 535.85 & 535.11 \\
\hline 1954.2 & 539.50 & 539.50 & 540.47 & 539.24 \\
\hline 1954.3 & 543.95 & 544.19 & 545.47 & 543.99 \\
\hline 1954.4 & 548.40 & 548.40 & 549.88 & 548.40 \\
\hline 1955.1 & 554.45 & 552.26 & 552.69 & 552.04 \\
\hline 1955.2 & 560.50 & 557.93 & 558.69 & 557.60 \\
\hline
\end{tabular}


Table 2. Continued.

\begin{tabular}{lllll}
\hline Time & $\begin{array}{l}\text { Linear } \\
\text { Interpolation }\end{array}$ & $\begin{array}{l}\text { Numerical } \\
\text { Iteration }\end{array}$ & $\begin{array}{l}\text { Interpolated } \\
\text { Depreciation }\end{array}$ & $\begin{array}{l}\text { Equal Quarterly } \\
\text { Depreciation }\end{array}$ \\
\hline 1955.3 & 566.55 & 564.81 & 565.84 & 564.54 \\
1955.4 & 572.60 & 572.60 & 573.91 & 572.60 \\
1956.1 & 578.95 & 579.23 & 579.37 & 578.94 \\
1956.2 & 585.30 & 585.48 & 585.82 & 585.10 \\
1956.3 & 591.65 & 592.05 & 592.62 & 591.76 \\
1956.4 & 598.00 & 598.00 & 598.86 & 598.00 \\
1957.1 & 603.70 & 603.95 & 604.33 & 603.69 \\
1957.2 & 609.40 & 609.48 & 610.19 & 609.14 \\
1957.3 & 615.10 & 615.67 & 616.67 & 615.41 \\
1957.4 & 620.80 & 620.80 & 622.07 & 620.80 \\
1958.1 & 622.33 & 623.10 & 623.66 & 623.02 \\
1958.2 & 623.85 & 624.36 & 625.33 & 624.27 \\
1958.3 & 625.38 & 625.18 & 626.39 & 625.12 \\
1958.4 & 626.90 & 626.90 & 628.16 & 626.90 \\
1959.1 & 630.43 & 629.66 & 629.71 & 629.52 \\
1959.2 & 633.95 & 633.02 & 633.13 & 632.81 \\
1959.3 & 637.48 & 637.02 & 637.24 & 636.86 \\
1959.4 & 641.00 & 641.00 & 641.38 & 641.00 \\
1960.1 & 644.62 & 645.37 & 645.43 & 645.17 \\
1960.2 & 648.25 & 649.95 & 650.13 & 649.70 \\
1960.3 & 651.88 & 653.23 & 653.57 & 653.05 \\
1960.4 & 655.50 & 655.50 & 656.02 & 655.50 \\
1961.1 & 658.15 & 657.16 & 657.30 & 657.06 \\
1961.2 & 660.80 & 659.61 & 659.86 & 659.47 \\
1961.3 & 663.45 & 662.22 & 662.58 & 662.11 \\
1961.4 & 666.10 & 666.10 & 666.57 & 666.10 \\
1962.1 & 670.67 & 670.42 & 670.45 & 670.21 \\
1962.2 & 675.25 & 675.33 & 675.45 & 675.05 \\
1962.3 & 679.83 & 680.02 & 680.30 & 679.81 \\
1962.4 & 684.40 & 684.40 & 684.89 & 684.40 \\
\hline & & & & \\
\hline & & & & \\
\hline
\end{tabular}


Table 2. Continued.

\begin{tabular}{lcccc}
\hline Time & $\begin{array}{l}\text { Linear } \\
\text { Interpolation }\end{array}$ & $\begin{array}{l}\text { Numerical } \\
\text { Iteration }\end{array}$ & $\begin{array}{l}\text { Interpolated } \\
\text { Depreciation }\end{array}$ & $\begin{array}{l}\text { Equal Quarterly } \\
\text { Depreciation }\end{array}$ \\
\hline 1963.1 & 690.08 & 689.06 & 689.23 & 688.83 \\
1963.2 & 695.75 & 694.10 & 694.45 & 693.79 \\
1963.3 & 701.42 & 700.19 & 700.74 & 699.94 \\
1963.4 & 707.10 & 707.10 & 707.90 & 707.10 \\
1964.1 & 715.35 & 714.52 & 714.63 & 714.18 \\
1964.2 & 723.60 & 722.25 & 722.54 & 721.79 \\
1964.3 & 731.85 & 730.78 & 731.32 & 730.42 \\
1964.4 & 740.10 & 740.10 & 741.00 & 740.10 \\
1965.1 & 752.57 & 751.39 & 751.65 & 750.88 \\
1965.2 & 765.05 & 762.90 & 763.49 & 762.20 \\
1965.3 & 777.52 & 776.04 & 777.04 & 775.50 \\
1965.4 & 790.00 & 790.00 & 791.54 & 790.00 \\
1966.1 & 805.30 & 805.18 & 805.85 & 804.50 \\
1966.2 & 820.60 & 820.97 & 822.30 & 820.05 \\
1966.3 & 835.90 & 836.24 & 838.25 & 835.55 \\
1966.4 & 851.20 & 851.20 & 853.90 & 851.20 \\
1967.1 & 864.42 & 864.58 & 865.03 & 864.00 \\
1967.2 & 877.65 & 878.13 & 879.07 & 877.35 \\
1967.3 & 890.87 & 890.75 & 892.23 & 890.17 \\
1967.4 & 904.10 & 904.10 & 906.16 & 904.10 \\
1968.1 & 918.07 & 918.72 & 919.04 & 918.12 \\
1968.2 & 932.05 & 931.77 & 932.53 & 930.99 \\
1968.3 & 946.02 & 945.29 & 946.55 & 944.71 \\
1968.4 & 960.00 & 960.00 & 961.85 & 960.00 \\
1969.1 & 975.25 & 975.94 & 976.23 & 975.28 \\
1969.2 & 990.50 & 991.36 & 992.06 & 990.48 \\
1969.3 & 1005.75 & 1006.66 & 1007.91 & 1006.00 \\
1969.4 & 1021.00 & 1021.00 & 1022.91 & 1021.00 \\
1970.1 & 1033.38 & 1034.31 & 1035.12 & 1033.75 \\
1970.2 & 1045.75 & 1047.04 & 1048.58 & 1046.30 \\
\hline & & & &
\end{tabular}


Table 2. Continued.

\begin{tabular}{lllll}
\hline Time & $\begin{array}{l}\text { Linear } \\
\text { Interpolation }\end{array}$ & $\begin{array}{l}\text { Numerical } \\
\text { Iteration }\end{array}$ & $\begin{array}{l}\text { Interpolated } \\
\text { Depreciation }\end{array}$ & $\begin{array}{l}\text { Equal Quarterly } \\
\text { Depreciation }\end{array}$ \\
\hline 1970.3 & 1058.12 & 1060.11 & 1062.29 & 1059.55 \\
1970.4 & 1070.50 & 1070.50 & 1073.24 & 1070.50 \\
1971.1 & 1080.88 & 1080.73 & 1081.22 & 1080.29 \\
1971.2 & 1091.25 & 1091.10 & 1092.05 & 1090.51 \\
1971.3 & 1101.62 & 1101.09 & 1102.51 & 1100.65 \\
1971.4 & 1112.00 & 1112.00 & 1113.85 & 1111.99 \\
1972.1 & 1125.32 & 1123.16 & 1124.39 & 1122.64 \\
1972.2 & 1138.65 & 1135.40 & 1137.59 & 1134.67 \\
1972.3 & 1151.97 & 1148.57 & 1151.51 & 1148.01 \\
1972.4 & 1165.30 & 1165.30 & 1168.80 & 1165.30 \\
1973.1 & 1185.93 & 1184.60 & 1184.93 & 1183.71 \\
1973.2 & 1206.55 & 1205.68 & 1206.51 & 1204.47 \\
1973.3 & 1227.18 & 1226.75 & 1228.28 & 1225.84 \\
1973.4 & 1247.80 & 1247.80 & 1250.24 & 1247.80 \\
1974.1 & 1267.18 & 1269.01 & 1269.39 & 1268.12 \\
1974.2 & 1286.55 & 1289.57 & 1290.51 & 1288.40 \\
1974.3 & 1305.93 & 1308.91 & 1310.58 & 1308.05 \\
1974.4 & 1325.30 & 1325.30 & 1327.83 & 1325.30 \\
1975.1 & 1335.62 & 1336.26 & 1337.83 & 1335.80 \\
1975.2 & 1345.95 & 1345.99 & 1348.78 & 1345.40 \\
1975.3 & 1356.27 & 1356.07 & 1359.68 & 1355.62 \\
1975.4 & 1366.60 & 1366.60 & 1370.65 & 1366.60 \\
1976.1 & 1377.03 & 1376.20 & 1377.44 & 1375.75 \\
1976.2 & 1387.45 & 1386.00 & 1388.21 & 1385.40 \\
1976.3 & 1397.88 & 1396.74 & 1399.65 & 1396.28 \\
1976.4 & 1408.30 & 1408.30 & 1411.68 & 1408.30 \\
1977.1 & 1424.45 & 1422.95 & 1423.60 & 1422.26 \\
1977.2 & 1440.60 & 1438.44 & 1439.73 & 1437.50 \\
1977.3 & 1456.75 & 1454.55 & 1456.52 & 1453.84 \\
1977.4 & 1472.90 & 1472.90 & 1475.58 & 1472.90 \\
\hline & & & &
\end{tabular}


Table 2. Continued.

\begin{tabular}{|c|c|c|c|c|}
\hline Time & $\begin{array}{l}\text { Linear } \\
\text { Interpolation }\end{array}$ & $\begin{array}{l}\text { Numerical } \\
\text { Iteration }\end{array}$ & $\begin{array}{l}\text { Interpolated } \\
\text { Depreciation }\end{array}$ & $\begin{array}{l}\text { Equal Quarterly } \\
\text { Depreciation }\end{array}$ \\
\hline 1978.1 & 1493.85 & 1490.69 & 1491.90 & 1489.78 \\
\hline 1978.2 & 1514.80 & 1512.27 & 1514.54 & 1511.00 \\
\hline 1978.3 & 1535.75 & 1534.10 & 1537.38 & 1533.12 \\
\hline 1978.4 & 1556.70 & 1556.70 & 1560.95 & 1556.70 \\
\hline 1979.1 & 1579.07 & 1580.88 & 1581.86 & 1579.80 \\
\hline 1979.2 & 1601.45 & 1603.04 & 1605.07 & 1601.63 \\
\hline 1979.3 & 1623.82 & 1625.82 & 1628.89 & 1624.76 \\
\hline 1979.4 & 1646.20 & 1646.20 & 1650.32 & 1646.19 \\
\hline 1980.1 & 1661.95 & 1666.91 & 1667.74 & 1666.11 \\
\hline 1980.2 & 1677.70 & 1681.27 & 1683.01 & 1680.30 \\
\hline 1980.3 & 1693.45 & 1695.03 & 1697.59 & 1694.34 \\
\hline 1980.4 & 1709.20 & 1709.20 & 1712.45 & 1709.20 \\
\hline 1981.1 & 1722.65 & 1722.84 & 1724.74 & 1722.19 \\
\hline 1981.2 & 1736.10 & 1736.28 & 1739.66 & 1735.41 \\
\hline 1981.3 & 1749.55 & 1750.64 & 1755.07 & 1749.98 \\
\hline 1981.4 & 1763.00 & 1763.00 & 1768.09 & 1763.00 \\
\hline 1982.1 & 1767.78 & 1770.72 & 1773.29 & 1770.41 \\
\hline 1982.2 & 1772.55 & 1776.01 & 1780.44 & 1775.65 \\
\hline 1982.3 & 1777.33 & 1779.73 & 1785.23 & 1779.49 \\
\hline 1982.4 & 1782.10 & 1782.10 & 1787.85 & 1782.10 \\
\hline 1983.1 & 1787.68 & 1782.69 & 1783.44 & 1782.57 \\
\hline 1983.2 & 1793.25 & 1786.12 & 1787.35 & 1785.89 \\
\hline 1983.3 & 1798.82 & 1792.43 & 1793.96 & 1792.21 \\
\hline 1983.4 & 1804.40 & 1804.40 & 1806.15 & 1804.40 \\
\hline 1984.1 & 1818.85 & 1815.56 & 1817.03 & 1814.89 \\
\hline 1984.2 & 1833.30 & 1829.73 & 1832.35 & 1828.79 \\
\hline 1984.3 & 1847.75 & 1845.32 & 1848.85 & 1844.58 \\
\hline 1984.4 & 1862.20 & 1862.20 & 1866.47 & 1862.20 \\
\hline 1985.1 & 1878.90 & 1878.82 & 1879.47 & 1877.96 \\
\hline 1985.2 & 1895.60 & 1896.36 & 1897.71 & 1895.20 \\
\hline
\end{tabular}


Table 2. Continued.

\begin{tabular}{|c|c|c|c|c|}
\hline Time & $\begin{array}{l}\text { Linear } \\
\text { Interpolation }\end{array}$ & $\begin{array}{l}\text { Numerical } \\
\text { Iteration }\end{array}$ & $\begin{array}{l}\text { Interpolated } \\
\text { Depreciation }\end{array}$ & $\begin{array}{l}\text { Equal Quarterly } \\
\text { Depreciation }\end{array}$ \\
\hline 1985.3 & 1912.30 & 1912.47 & 1914.62 & 1911.61 \\
\hline 1985.4 & 1929.00 & 1929.00 & 1932.01 & 1929.00 \\
\hline 1986.1 & 1943.32 & 1943.49 & 1944.39 & 1942.75 \\
\hline 1986.2 & 1957.65 & 1958.39 & 1960.14 & 1957.40 \\
\hline 1986.3 & 1971.97 & 1972.39 & 1974.93 & 1971.65 \\
\hline 1986.4 & 1986.30 & 1986.30 & 1989.58 & 1986.30 \\
\hline 1987.1 & 1998.25 & 1996.14 & 1997.86 & 1995.57 \\
\hline 1987.2 & 2010.20 & 2007.57 & 2010.58 & 2006.76 \\
\hline 1987.3 & 2022.15 & 2021.22 & 2025.17 & 2020.58 \\
\hline 1987.4 & 2034.10 & 2034.10 & 2038.68 & 2034.09 \\
\hline 1988.1 & 2048.57 & 2046.66 & 2049.70 & 2045.91 \\
\hline 1988.2 & 2063.05 & 2061.46 & 2066.74 & 2060.42 \\
\hline 1988.3 & 2077.53 & 2076.74 & 2083.54 & 2075.95 \\
\hline 1988.4 & 2092.00 & 2092.00 & 2099.60 & 2092.01 \\
\hline 1989.1 & 2107.73 & 2108.60 & 2107.84 & 2107.71 \\
\hline 1989.2 & 2123.45 & 2125.88 & 2124.91 & 2124.70 \\
\hline 1989.3 & 2139.18 & 2141.43 & 2140.82 & 2140.56 \\
\hline 1989.4 & 2154.90 & 2154.90 & 2155.16 & 2154.90 \\
\hline 1990.1 & 2167.25 & 2168.01 & 2170.71 & 2167.32 \\
\hline 1990.2 & 2179.60 & 2179.57 & 2184.32 & 2178.68 \\
\hline 1990.3 & 2191.95 & 2192.54 & 2198.62 & 2191.85 \\
\hline 1990.4 & 2204.30 & 2204.30 & 2211.07 & 2204.30 \\
\hline 1991.1 & 2210.73 & 2210.61 & 2212.33 & 2210.26 \\
\hline 1991.2 & 2217.15 & 2216.71 & 2219.70 & 2216.24 \\
\hline 1991.3 & 2223.58 & 2223.74 & 2227.52 & 2223.37 \\
\hline 1991.4 & 2230.00 & 2230.00 & 2234.15 & 2230.00 \\
\hline
\end{tabular}

Source: Authors' calculations. 
Table 3. Estimated Quarterly Net Capital Stock: Business Structures (billions of 1987 dollars)

\begin{tabular}{|c|c|c|c|c|}
\hline Time & $\begin{array}{l}\text { Linear } \\
\text { Interpolation }\end{array}$ & $\begin{array}{l}\text { Numerical } \\
\text { Iteration }\end{array}$ & $\begin{array}{l}\text { Interpolated } \\
\text { Depreciation }\end{array}$ & $\begin{array}{l}\text { Equal Quarterly } \\
\text { Depreciation }\end{array}$ \\
\hline 1948.1 & 669.90 & 669.43 & 668.88 & 669.36 \\
\hline 1948.2 & 673.20 & 672.57 & 671.68 & 672.47 \\
\hline 1948.3 & 676.50 & 676.08 & 675.06 & 676.01 \\
\hline 1948.4 & 679.80 & 679.80 & 678.84 & 679.80 \\
\hline 1949.1 & 682.88 & 683.52 & 683.40 & 683.44 \\
\hline 1949.2 & 685.95 & 686.91 & 686.74 & 686.81 \\
\hline 1949.3 & 689.03 & 689.70 & 689.55 & 689.63 \\
\hline 1949.4 & 692.10 & 692.10 & 692.02 & 692.10 \\
\hline 1950.1 & 696.12 & 695.28 & 695.12 & 695.21 \\
\hline 1950.2 & 700.15 & 699.04 & 698.80 & 698.94 \\
\hline 1950.3 & 704.18 & 703.48 & 703.22 & 703.39 \\
\hline 1950.4 & 708.20 & 708.20 & 708.03 & 708.20 \\
\hline 1951.1 & 712.25 & 712.16 & 712.81 & 712.07 \\
\hline 1951.2 & 716.30 & 716.54 & 717.65 & 716.41 \\
\hline 1951.3 & 720.35 & 720.77 & 722.16 & 720.68 \\
\hline 1951.4 & 724.40 & 724.40 & 725.88 & 724.40 \\
\hline 1952.1 & 729.83 & 729.63 & 728.49 & 729.53 \\
\hline 1952.2 & 735.25 & 734.92 & 733.05 & 734.79 \\
\hline 1952.3 & 740.67 & 740.27 & 738.09 & 740.17 \\
\hline 1952.4 & 746.10 & 746.10 & 744.02 & 746.10 \\
\hline 1953.1 & 751.90 & 751.70 & 752.24 & 751.59 \\
\hline 1953.2 & 757.70 & 757.50 & 758.44 & 757.35 \\
\hline 1953.3 & 763.50 & 763.30 & 764.49 & 763.19 \\
\hline 1953.4 & 769.30 & 769.30 & 770.60 & 769.30 \\
\hline 1954.1 & 775.47 & 775.57 & 775.57 & 775.44 \\
\hline 1954.2 & 781.65 & 781.85 & 781.90 & 781.69 \\
\hline 1954.3 & 787.82 & 788.00 & 788.13 & 787.88 \\
\hline 1954.4 & 794.00 & 794.00 & 794.25 & 794.00 \\
\hline 1955.1 & 800.90 & 800.36 & 800.52 & 800.23 \\
\hline 1955.2 & 807.80 & 807.04 & 807.35 & 806.86 \\
\hline
\end{tabular}


Table 3. Continued.

\begin{tabular}{|c|c|c|c|c|}
\hline Time & $\begin{array}{l}\text { Linear } \\
\text { Interpolation }\end{array}$ & $\begin{array}{l}\text { Numerical } \\
\text { Iteration }\end{array}$ & $\begin{array}{l}\text { Interpolated } \\
\text { Depreciation }\end{array}$ & $\begin{array}{l}\text { Equal Quarterly } \\
\text { Depreciation }\end{array}$ \\
\hline 1955.3 & 814.70 & 814.15 & 814.60 & 814.02 \\
\hline 1955.4 & 821.60 & 821.60 & 822.18 & 821.60 \\
\hline 1956.1 & 830.42 & 830.03 & 829.76 & 829.86 \\
\hline 1956.2 & 839.25 & 839.02 & 838.64 & 838.80 \\
\hline 1956.3 & 848.08 & 848.03 & 847.67 & 847.86 \\
\hline 1956.4 & 856.90 & 856.90 & 856.70 & 856.90 \\
\hline 1957.1 & 865.30 & 865.49 & 865.67 & 865.33 \\
\hline 1957.2 & 873.70 & 873.97 & 874.33 & 873.76 \\
\hline 1957.3 & 882.10 & 882.35 & 882.88 & 882.19 \\
\hline 1957.4 & 890.50 & 890.50 & 891.18 & 890.50 \\
\hline 1958.1 & 897.33 & 898.04 & 898.26 & 897.91 \\
\hline 1958.2 & 904.15 & 904.89 & 905.30 & 904.71 \\
\hline 1958.3 & 910.98 & 911.25 & 911.83 & 911.12 \\
\hline 1958.4 & 917.80 & 917.80 & 918.51 & 917.80 \\
\hline 1959.1 & 925.15 & 924.60 & 924.40 & 924.47 \\
\hline 1959.2 & 932.50 & 931.86 & 931.58 & 931.69 \\
\hline 1959.3 & 939.85 & 939.64 & 939.37 & 939.51 \\
\hline 1959.4 & 947.20 & 947.20 & 947.07 & 947.20 \\
\hline 1960.1 & 955.80 & 955.54 & 955.64 & 955.39 \\
\hline 1960.2 & 964.40 & 964.00 & 964.21 & 963.80 \\
\hline 1960.3 & 973.00 & 972.44 & 972.78 & 972.29 \\
\hline 1960.4 & 981.60 & 981.60 & 982.10 & 981.60 \\
\hline 1961.1 & 990.30 & 990.76 & 990.82 & 990.60 \\
\hline 1961.2 & 999.00 & 999.46 & 999.61 & 999.25 \\
\hline 1961.3 & 1007.70 & 1008.03 & 1008.31 & 1007.88 \\
\hline 1961.4 & 1016.40 & 1016.40 & 1016.83 & 1016.40 \\
\hline 1962.1 & 1025.72 & 1025.13 & 1025.22 & 1024.97 \\
\hline 1962.2 & 1035.05 & 1034.56 & 1034.75 & 1034.34 \\
\hline 1962.3 & 1044.37 & 1044.48 & 1044.81 & 1044.31 \\
\hline 1962.4 & 1053.70 & 1053.70 & 1054.20 & 1053.70 \\
\hline
\end{tabular}


Table 3. Continued.

\begin{tabular}{lllll}
\hline Time & $\begin{array}{l}\text { Linear } \\
\text { Interpolation }\end{array}$ & $\begin{array}{l}\text { Numerical } \\
\text { Iteration }\end{array}$ & $\begin{array}{l}\text { Interpolated } \\
\text { Depreciation }\end{array}$ & $\begin{array}{l}\text { Equal Quarterly } \\
\text { Depreciation }\end{array}$ \\
\hline 1963.1 & 1062.80 & 1062.06 & 1062.21 & 1061.90 \\
1963.2 & 1071.90 & 1071.26 & 1071.57 & 1071.05 \\
1963.3 & 1081.00 & 1080.54 & 1081.01 & 1080.37 \\
1963.4 & 1090.10 & 1090.10 & 1090.73 & 1090.10 \\
1964.1 & 1101.18 & 1100.32 & 1100.35 & 1100.14 \\
1964.2 & 1112.25 & 1111.20 & 1111.31 & 1110.95 \\
1964.3 & 1123.32 & 1122.78 & 1123.02 & 1122.59 \\
1964.4 & 1134.40 & 1134.40 & 1134.83 & 1134.40 \\
1965.1 & 1148.65 & 1147.04 & 1147.34 & 1146.80 \\
1965.2 & 1162.90 & 1161.35 & 1161.92 & 1161.03 \\
1965.3 & 1177.15 & 1175.80 & 1176.62 & 1175.55 \\
1965.4 & 1191.40 & 1191.40 & 1192.47 & 1191.40 \\
1966.1 & 1206.40 & 1207.08 & 1207.66 & 1206.80 \\
1966.2 & 1221.40 & 1221.94 & 1223.01 & 1221.58 \\
1966.3 & 1236.40 & 1237.28 & 1238.72 & 1237.00 \\
1966.4 & 1251.40 & 1251.40 & 1253.12 & 1251.40 \\
1967.1 & 1265.03 & 1265.76 & 1265.95 & 1265.51 \\
1967.2 & 1278.65 & 1279.08 & 1279.48 & 1278.75 \\
1967.3 & 1292.28 & 1292.56 & 1293.19 & 1292.31 \\
1967.4 & 1305.90 & 1305.90 & 1306.78 & 1305.90 \\
1968.1 & 1319.50 & 1319.90 & 1319.94 & 1319.66 \\
1968.2 & 1333.10 & 1333.51 & 1333.67 & 1333.19 \\
1968.3 & 1346.70 & 1346.68 & 1347.02 & 1346.44 \\
1968.4 & 1360.30 & 1360.30 & 1360.88 & 1360.30 \\
1969.1 & 1374.80 & 1374.21 & 1374.43 & 1373.96 \\
1969.2 & 1389.30 & 1388.21 & 1388.65 & 1387.88 \\
1969.3 & 1403.80 & 1403.47 & 1404.14 & 1403.21 \\
1969.4 & 1418.30 & 1418.30 & 1419.23 & 1418.30 \\
1970.1 & 1432.00 & 1432.63 & 1432.95 & 1432.38 \\
1970.2 & 1445.70 & 1446.35 & 1446.98 & 1446.03 \\
\hline & & & &
\end{tabular}


Table 3. Continued.

\begin{tabular}{|c|c|c|c|c|}
\hline Time & $\begin{array}{l}\text { Linear } \\
\text { Interpolation }\end{array}$ & $\begin{array}{l}\text { Numerical } \\
\text { Iteration }\end{array}$ & $\begin{array}{l}\text { Interpolated } \\
\text { Depreciation }\end{array}$ & $\begin{array}{l}\text { Equal Quarterly } \\
\text { Depreciation }\end{array}$ \\
\hline 1970.3 & 1459.40 & 1460.00 & 1460.89 & 1459.75 \\
\hline 1970.4 & 1473.10 & 1473.10 & 1474.24 & 1473.10 \\
\hline 1971.1 & 1485.70 & 1486.03 & 1486.23 & 1485.81 \\
\hline 1971.2 & 1498.30 & 1498.71 & 1499.12 & 1498.41 \\
\hline 1971.3 & 1510.90 & 1511.22 & 1511.84 & 1510.99 \\
\hline 1971.4 & 1523.50 & 1523.50 & 1524.35 & 1523.50 \\
\hline 1972.1 & 1535.22 & 1535.17 & 1536.29 & 1534.94 \\
\hline 1972.2 & 1546.95 & 1546.88 & 1548.82 & 1546.59 \\
\hline 1972.3 & 1558.67 & 1558.48 & 1560.94 & 1558.26 \\
\hline 1972.4 & 1570.40 & 1570.40 & 1573.08 & 1570.40 \\
\hline 1973.1 & 1584.32 & 1583.52 & 1583.51 & 1583.27 \\
\hline 1973.2 & 1598.25 & 1597.48 & 1597.54 & 1597.14 \\
\hline 1973.3 & 1612.18 & 1612.02 & 1612.24 & 1611.76 \\
\hline 1973.4 & 1626.10 & 1626.10 & 1626.59 & 1626.10 \\
\hline 1974.1 & 1638.43 & 1639.58 & 1640.03 & 1639.33 \\
\hline 1974.2 & 1650.75 & 1652.79 & 1653.63 & 1652.46 \\
\hline 1974.3 & 1663.07 & 1664.35 & 1665.52 & 1664.12 \\
\hline 1974.4 & 1675.40 & 1675.40 & 1676.81 & 1675.40 \\
\hline 1975.1 & 1684.35 & 1685.32 & 1685.01 & 1685.15 \\
\hline 1975.2 & 1693.30 & 1693.94 & 1693.48 & 1693.72 \\
\hline 1975.3 & 1702.25 & 1702.64 & 1702.19 & 1702.47 \\
\hline 1975.4 & 1711.20 & 1711.20 & 1710.91 & 1711.20 \\
\hline 1976.1 & 1719.35 & 1719.50 & 1720.42 & 1719.34 \\
\hline 1976.2 & 1727.50 & 1727.52 & 1729.10 & 1727.31 \\
\hline 1976.3 & 1735.65 & 1735.69 & 1737.68 & 1735.53 \\
\hline 1976.4 & 1743.80 & 1743.80 & 1745.95 & 1743.80 \\
\hline 1977.1 & 1752.60 & 1751.77 & 1752.16 & 1751.61 \\
\hline 1977.2 & 1761.40 & 1760.59 & 1761.29 & 1760.36 \\
\hline 1977.3 & 1770.20 & 1769.74 & 1770.68 & 1769.57 \\
\hline 1977.4 & 1779.00 & 1779.00 & 1780.11 & 1779.00 \\
\hline
\end{tabular}


Table 3. Continued.

\begin{tabular}{|c|c|c|c|c|}
\hline Time & $\begin{array}{l}\text { Linear } \\
\text { Interpolation }\end{array}$ & $\begin{array}{l}\text { Numerical } \\
\text { Iteration }\end{array}$ & $\begin{array}{l}\text { Interpolated } \\
\text { Depreciation }\end{array}$ & $\begin{array}{l}\text { Equal Quarterly } \\
\text { Depreciation }\end{array}$ \\
\hline 1978.1 & 1791.95 & 1788.80 & 1788.84 & 1788.58 \\
\hline 1978.2 & 1804.90 & 1801.13 & 1801.25 & 1800.81 \\
\hline 1978.3 & 1817.85 & 1815.37 & 1815.65 & 1815.12 \\
\hline 1978.4 & 1830.80 & 1830.80 & 1831.33 & 1830.80 \\
\hline 1979.1 & 1847.33 & 1845.72 & 1846.35 & 1845.42 \\
\hline 1979.2 & 1863.85 & 1861.43 & 1862.56 & 1861.01 \\
\hline 1979.3 & 1880.38 & 1878.60 & 1880.14 & 1878.28 \\
\hline 1979.4 & 1896.90 & 1896.90 & 1898.76 & 1896.90 \\
\hline 1980.1 & 1914.75 & 1915.92 & 1915.87 & 1915.57 \\
\hline 1980.2 & 1932.60 & 1933.65 & 1933.69 & 1933.19 \\
\hline 1980.3 & 1950.45 & 1950.67 & 1950.93 & 1950.33 \\
\hline 1980.4 & 1968.30 & 1968.30 & 1968.90 & 1968.30 \\
\hline 1981.1 & 1988.12 & 1986.46 & 1986.99 & 1986.09 \\
\hline 1981.2 & 2007.95 & 2005.64 & 2006.64 & 2005.14 \\
\hline 1981.3 & 2027.77 & 2025.86 & 2027.28 & 2025.48 \\
\hline 1981.4 & 2047.60 & 2047.60 & 2049.40 & 2047.60 \\
\hline 1982.1 & 2065.32 & 2067.99 & 2068.87 & 2067.61 \\
\hline 1982.2 & 2083.05 & 2086.91 & 2088.52 & 2086.42 \\
\hline 1982.3 & 2100.78 & 2103.15 & 2105.32 & 2102.80 \\
\hline 1982.4 & 2118.50 & 2118.50 & 2121.03 & 2118.51 \\
\hline 1983.1 & 2130.32 & 2131.24 & 2131.49 & 2131.00 \\
\hline 1983.2 & 2142.15 & 2142.08 & 2142.59 & 2141.77 \\
\hline 1983.3 & 2153.97 & 2153.63 & 2154.39 & 2153.40 \\
\hline 1983.4 & 2165.80 & 2165.80 & 2166.78 & 2165.80 \\
\hline 1984.1 & 2183.02 & 2180.67 & 2180.52 & 2180.35 \\
\hline 1984.2 & 2200.25 & 2197.81 & 2197.66 & 2197.38 \\
\hline 1984.3 & 2217.48 & 2216.14 & 2216.14 & 2215.80 \\
\hline 1984.4 & 2234.70 & 2234.70 & 2235.04 & 2234.70 \\
\hline 1985.1 & 2255.75 & 2256.34 & 2255.80 & 2255.94 \\
\hline 1985.2 & 2276.80 & 2277.95 & 2277.19 & 2277.43 \\
\hline
\end{tabular}


Table 3. Continued.

\begin{tabular}{|c|c|c|c|c|}
\hline Time & $\begin{array}{l}\text { Linear } \\
\text { Interpolation }\end{array}$ & $\begin{array}{l}\text { Numerical } \\
\text { Iteration }\end{array}$ & $\begin{array}{l}\text { Interpolated } \\
\text { Depreciation }\end{array}$ & $\begin{array}{l}\text { Equal Quarterly } \\
\text { Depreciation }\end{array}$ \\
\hline 1985.3 & 2297.85 & 2298.00 & 2297.33 & 2297.61 \\
\hline 1985.4 & 2318.90 & 2318.90 & 2318.62 & 2318.90 \\
\hline 1986.1 & 2332.97 & 2337.10 & 2338.14 & 2336.80 \\
\hline 1986.2 & 2347.05 & 2350.87 & 2352.73 & 2350.50 \\
\hline 1986.3 & 2361.12 & 2362.94 & 2365.35 & 2362.67 \\
\hline 1986.4 & 2375.20 & 2375.20 & 2377.88 & 2375.20 \\
\hline 1987.1 & 2387.15 & 2385.88 & 2386.27 & 2385.67 \\
\hline 1987.2 & 2399.10 & 2396.91 & 2397.62 & 2396.61 \\
\hline 1987.3 & 2411.05 & 2409.64 & 2410.61 & 2409.41 \\
\hline 1987.4 & 2423.00 & 2423.00 & 2424.21 & 2423.00 \\
\hline 1988.1 & 2434.70 & 2434.34 & 2434.79 & 2434.11 \\
\hline 1988.2 & 2446.40 & 2446.23 & 2447.06 & 2445.93 \\
\hline 1988.3 & 2458.10 & 2457.89 & 2459.02 & 2457.66 \\
\hline 1988.4 & 2469.80 & 2469.80 & 2471.16 & 2469.80 \\
\hline 1989.1 & 2481.85 & 2481.94 & 2482.12 & 2481.71 \\
\hline 1989.2 & 2493.90 & 2493.34 & 2493.73 & 2493.04 \\
\hline 1989.3 & 2505.95 & 2505.63 & 2506.23 & 2505.39 \\
\hline 1989.4 & 2518.00 & 2518.00 & 2518.83 & 2518.00 \\
\hline 1990.1 & 2530.57 & 2531.67 & 2531.39 & 2531.41 \\
\hline 1990.2 & 2543.15 & 2544.84 & 2544.46 & 2544.50 \\
\hline 1990.3 & 2555.72 & 2557.66 & 2557.37 & 2557.41 \\
\hline 1990.4 & 2568.30 & 2568.30 & 2568.25 & 2568.30 \\
\hline 1991.1 & 2574.98 & 2577.33 & 2577.97 & 2577.18 \\
\hline 1991.2 & 2581.65 & 2585.30 & 2586.43 & 2585.10 \\
\hline 1991.3 & 2588.33 & 2590.76 & 2592.22 & 2590.62 \\
\hline 1991.4 & 2595.00 & 2595.00 & 2596.59 & 2595.00 \\
\hline
\end{tabular}

Source: Authors' calculations. 


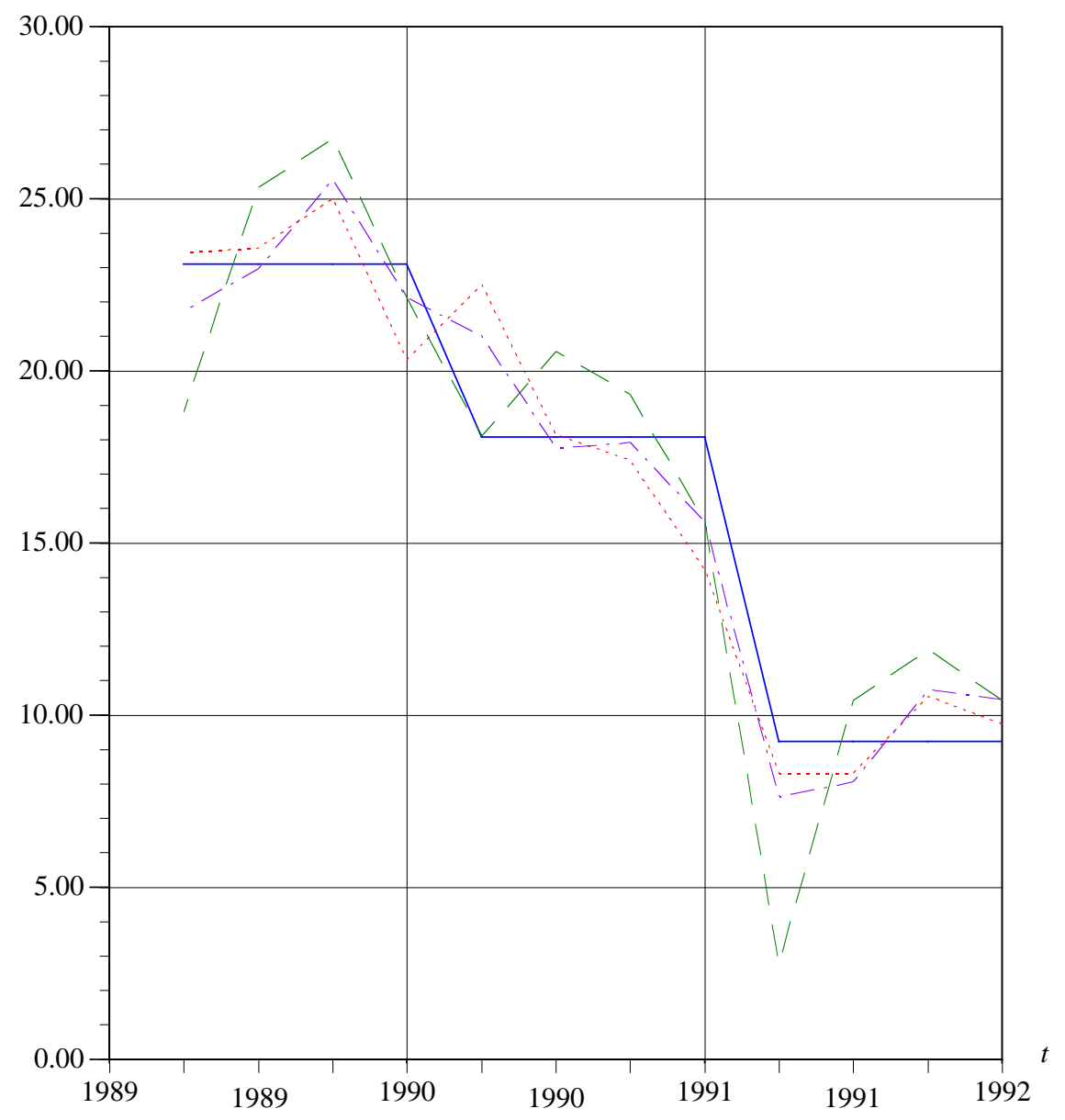

\begin{tabular}{|ll|}
\hline & Method 1: Segmented Linear Interpolation \\
$\ldots \ldots \ldots \ldots \ldots \ldots$ & Method 2: Numerical Iteration \\
$--\ldots-$ & Method 3: Linearly Interpolated Depreciation \\
$-\cdot-\cdot--$ & Method 4: Equal Quarterly Depreciation \\
\hline
\end{tabular}

Figure 1. Four Different Estimates of Consumer Durable Good Series (in First Differences), U.S., 1989:1-1991:4. 


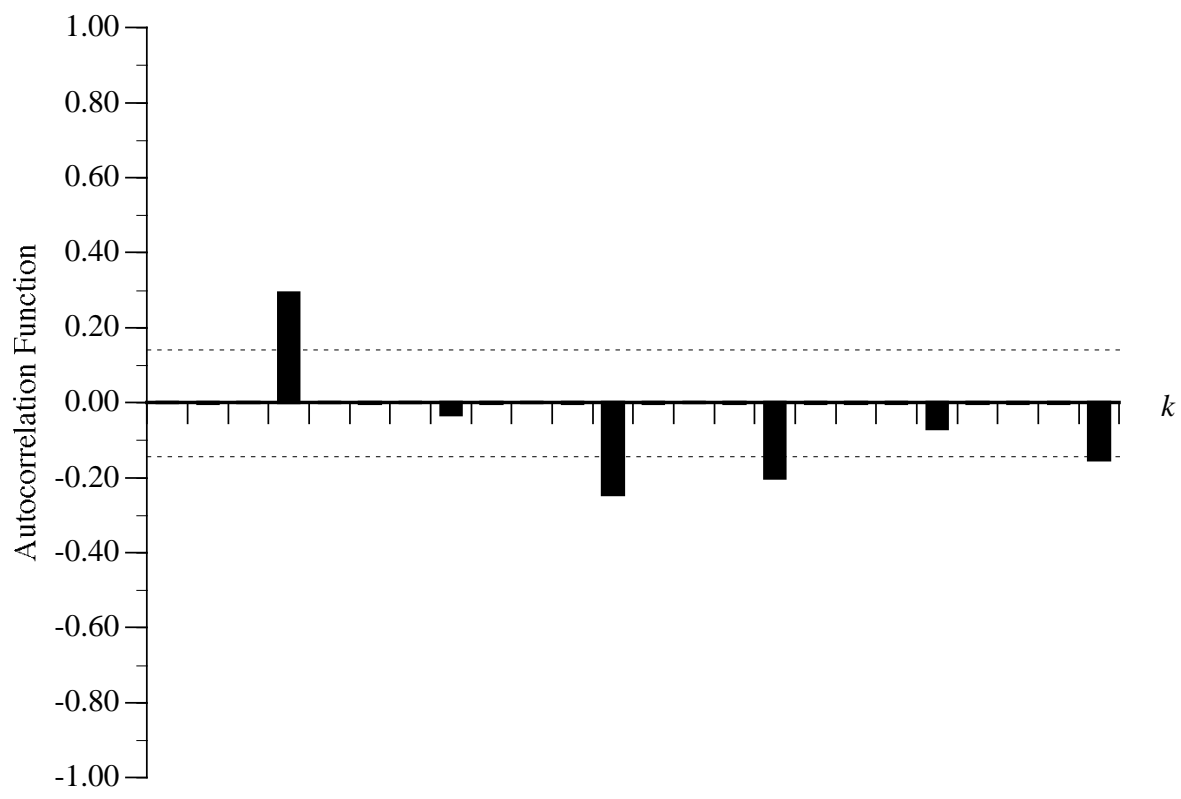

Figure 2. Autocorrelation Function ( \pm 2 S.E.) of Quarterly Consumer Durable Good (CDG) Series Constructed by Linear Interpolation of the Annual Data (Method 1), U.S., 1948:1-1991:4. $k=$ number of lags. 


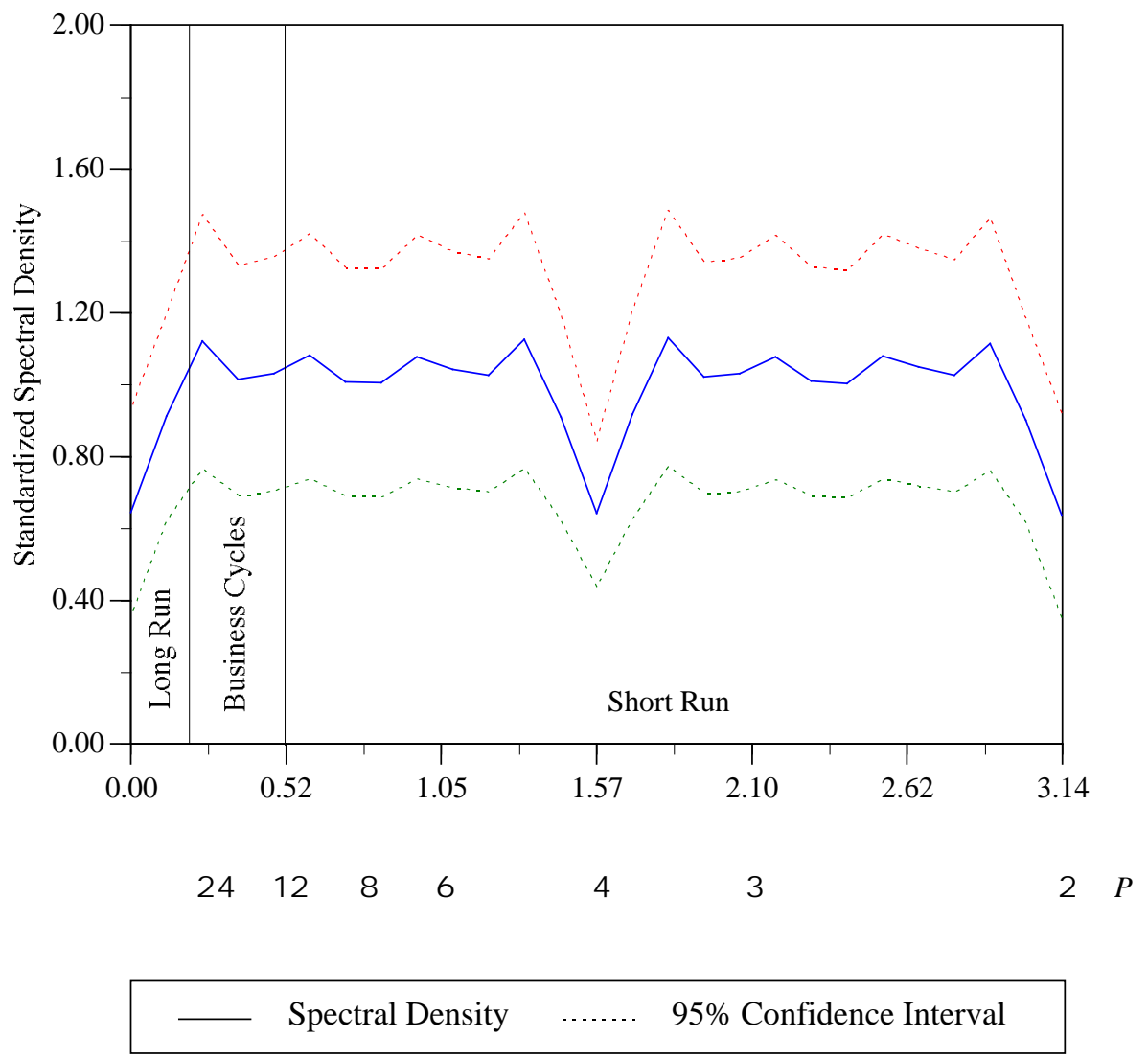

Figure 3. Estimate of Spectral Density Function ( \pm 2 S.E.) of Consumer Durable Good (CDG) Series Constructed by Linear Interpolation of the Annual Data (Method 1), U.S., 1948:1-1991:4. 


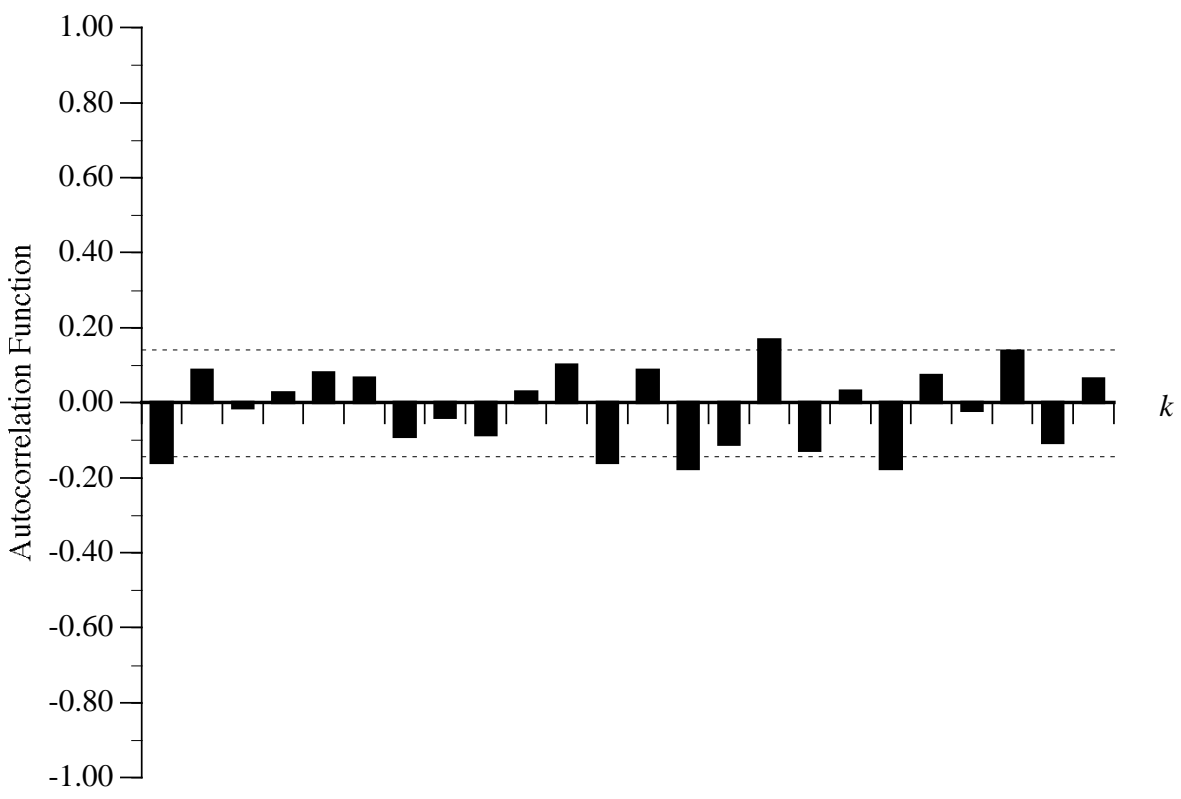

Figure 4. Autocorrelation Function ( \pm 2 S.E.) of Quarterly

Consumer Durable Good (CDG) Series

Constructed by Numerical Iteration of Capital

Accumulation Equation (Method 2), U.S.,

1948:1-1991:4. $k=$ number of lags. 


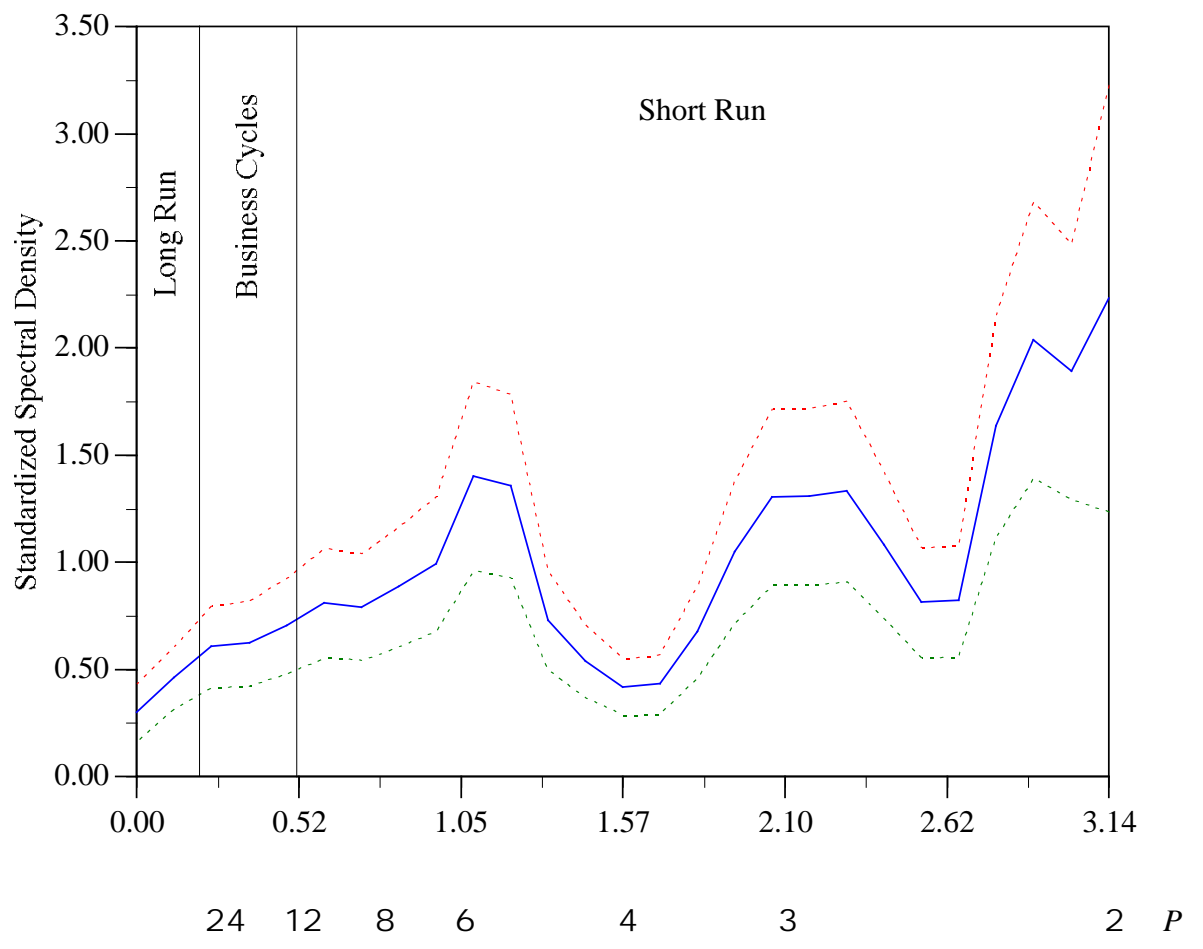

Spectral Density 95\% Confidence Interval

Figure 5. Estimate of Spectral Density Function ( \pm 2 S.E.) of Consumer Durable Good (CDG) Series Constructed by Numerical Iteration of Capital Accumulation Equation (Method 2), U.S., 1948:1-1991:4. 


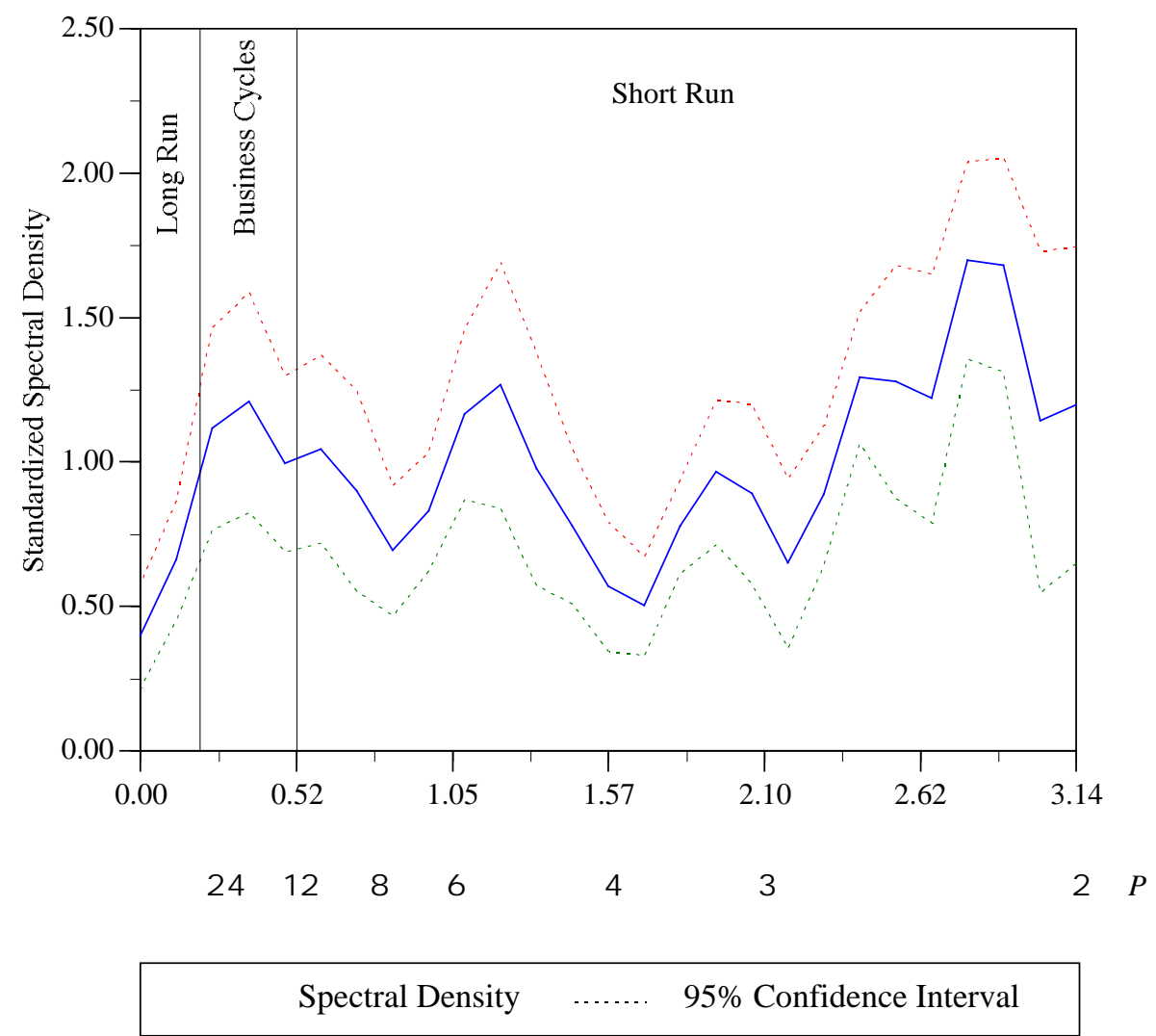

Figure 5a. Estimate of Spectral Density Function ( \pm 2 S.E.) of the Consumer Durable Goods Investment, U.S., 1948:1-1991:4. 


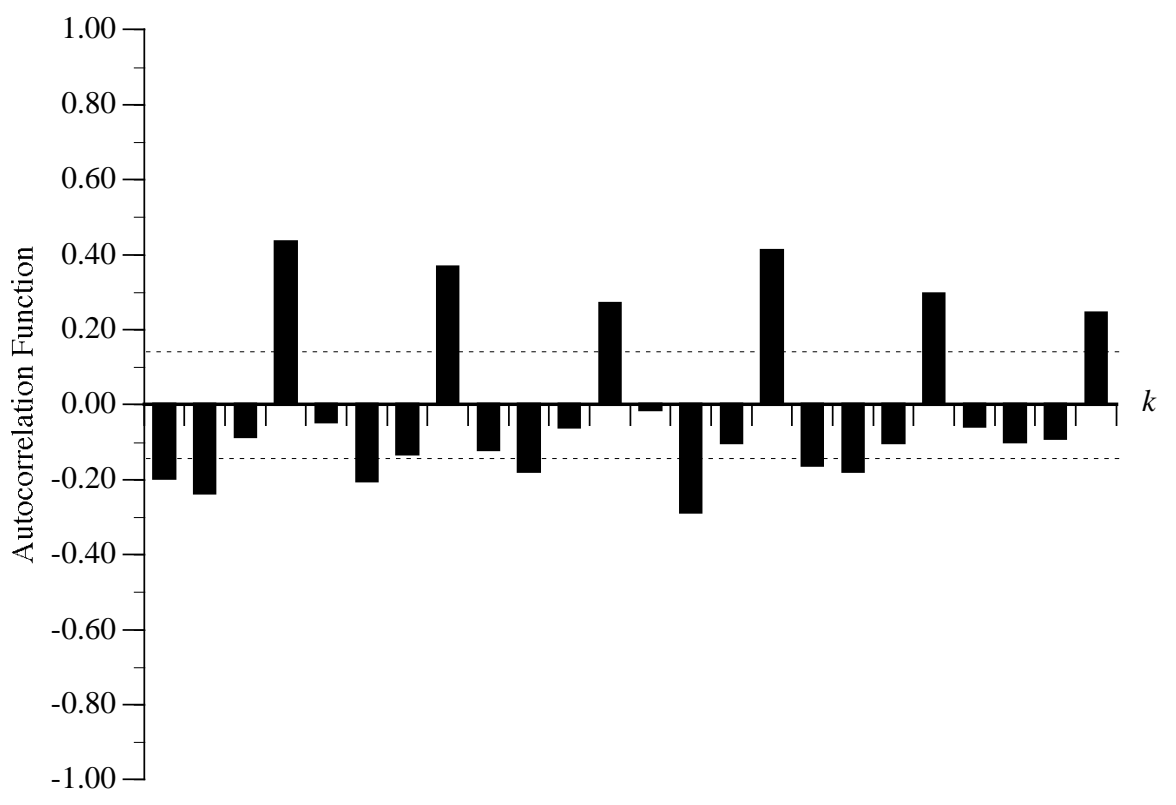

Figure 6. Autocorrelation Function ( \pm 2 S.E.) of Quarterly Consumer Durable Good (CDG) Series Constructed by Linear Interpolation of the Annual Depreciation Data (Method 3), U.S., 1948:1-1991:4. $k=$ number of lags. 


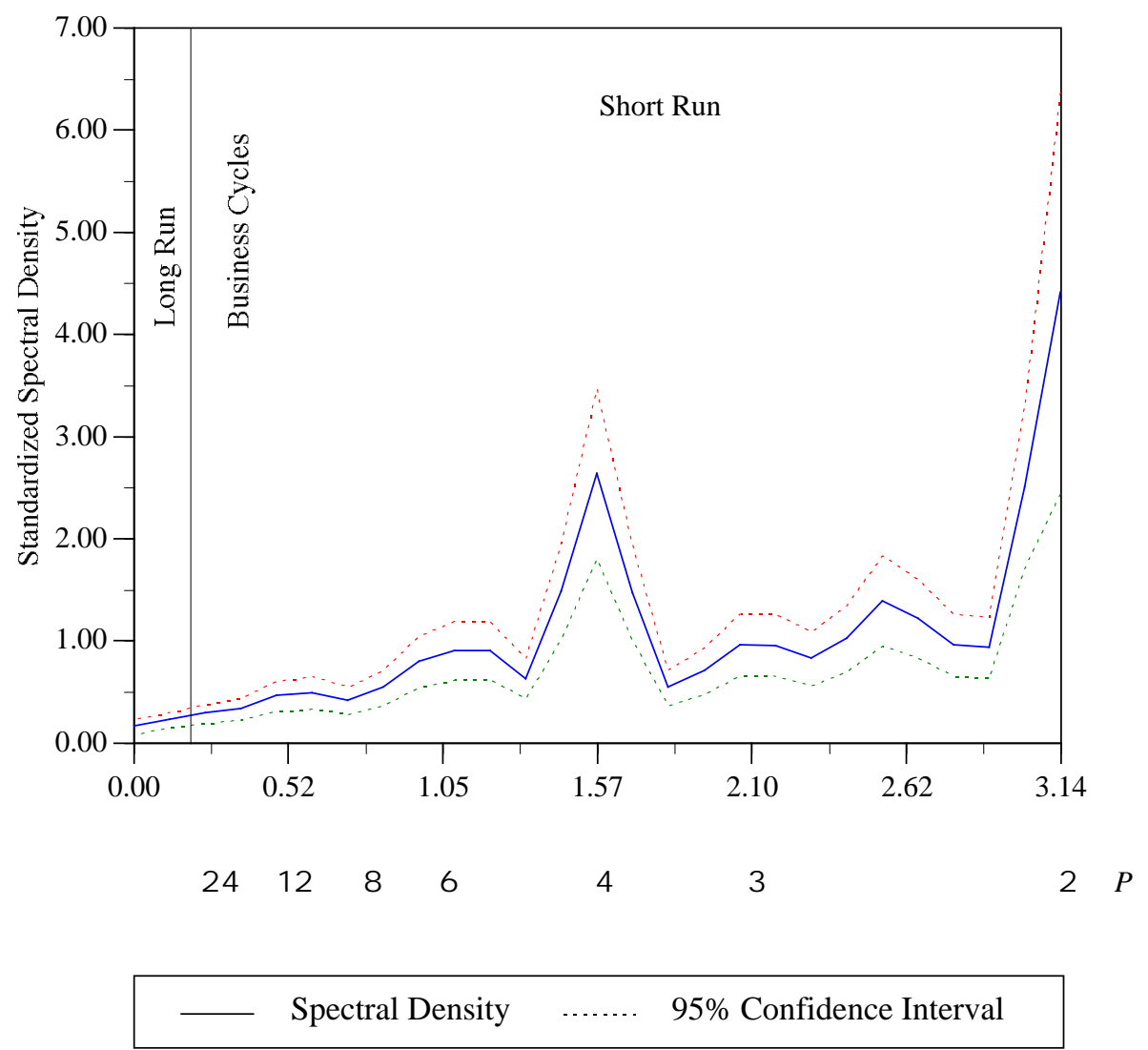

Figure 7. Estimate of Spectral Density Function ( \pm 2 S.E.) of Consumer Durable Good (CDG) Series Constructed by Linear Interpolation of the Annual Depreciation Data (Method 3), U.S., 1948:1-1991:4. 


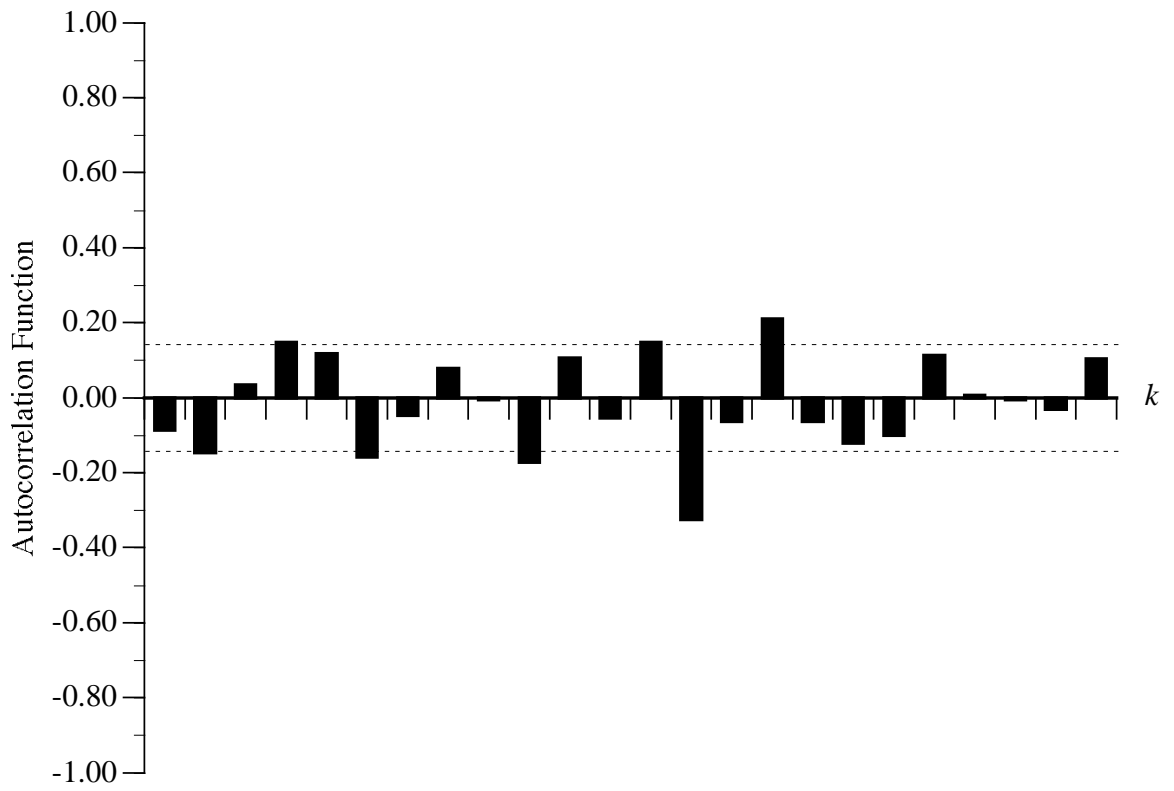

Figure 8. Autocorrelation Function ( \pm 2 S.E.) of Quarterly Consumer Durable Good (CDG) Series Constructed by Assuming Equal Annual Depreciation (Method 4), U.S., 1948:1-1991:4. $k=$ number of lags. 


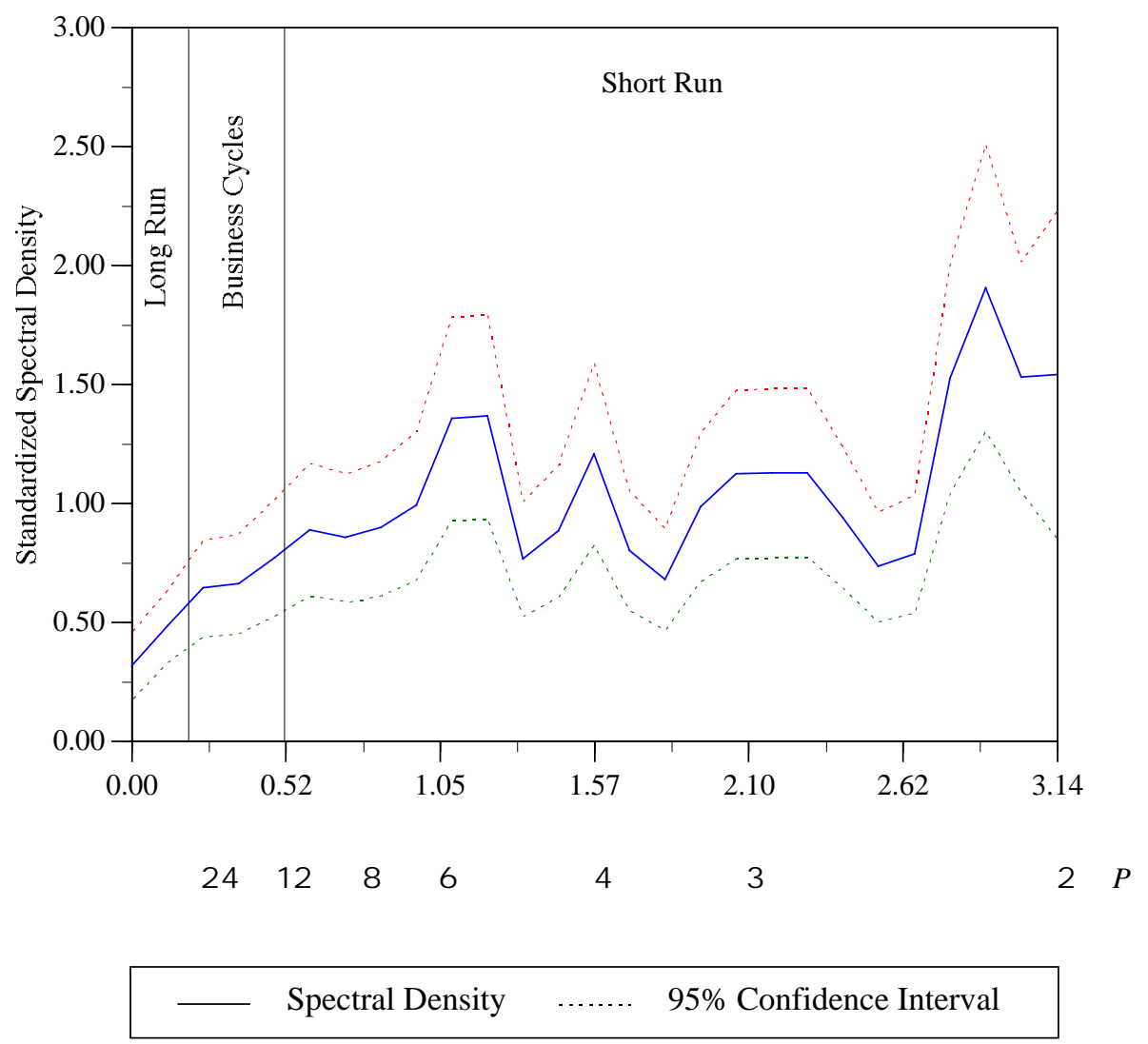

Figure 9. Estimate of Spectral Density Function ( \pm 2 S.E.) of Consumer Durable Good (CDG) Series Constructed by Assuming Equal Annual Depreciation (Method 4), U.S., 1948:1-1991:4. 


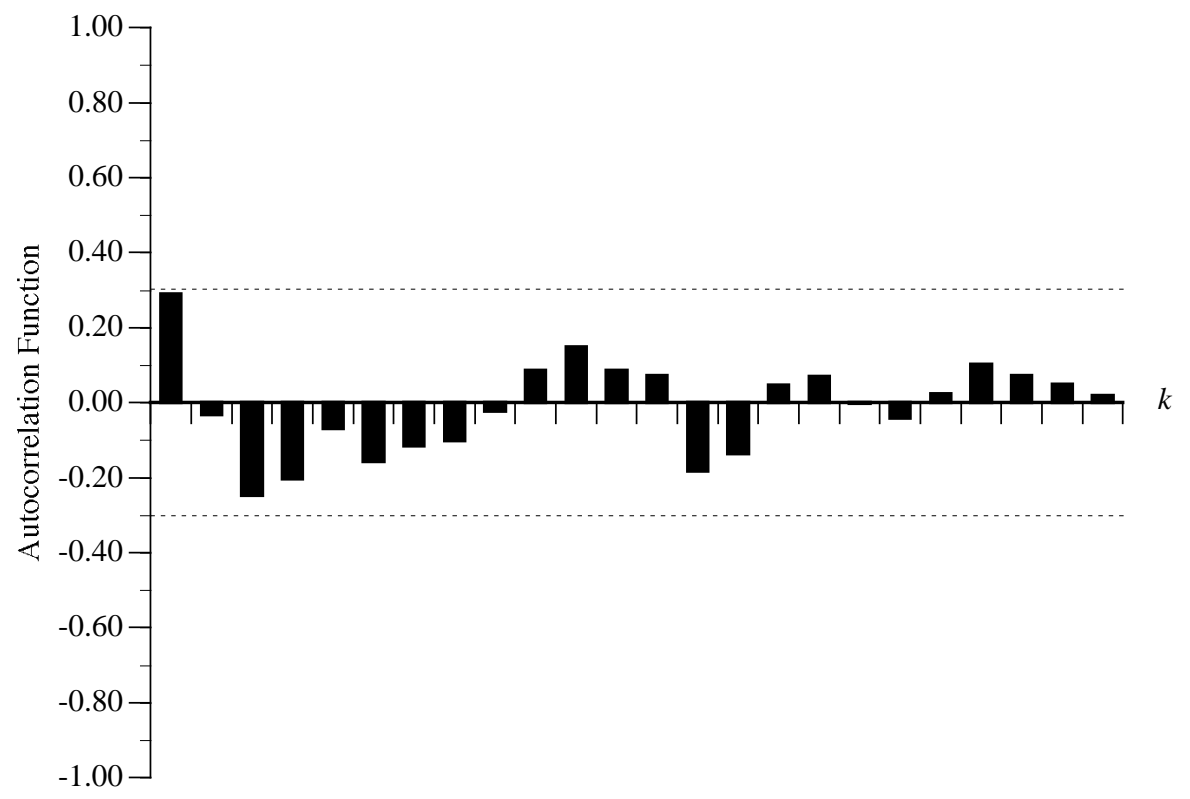

Figure 10. Autocorrelation Function ( \pm 2 S.E.) of the Original Annual Consumer Durable Good (CDG) Series, U.S., 1948-91. $k=$ number of lags. 


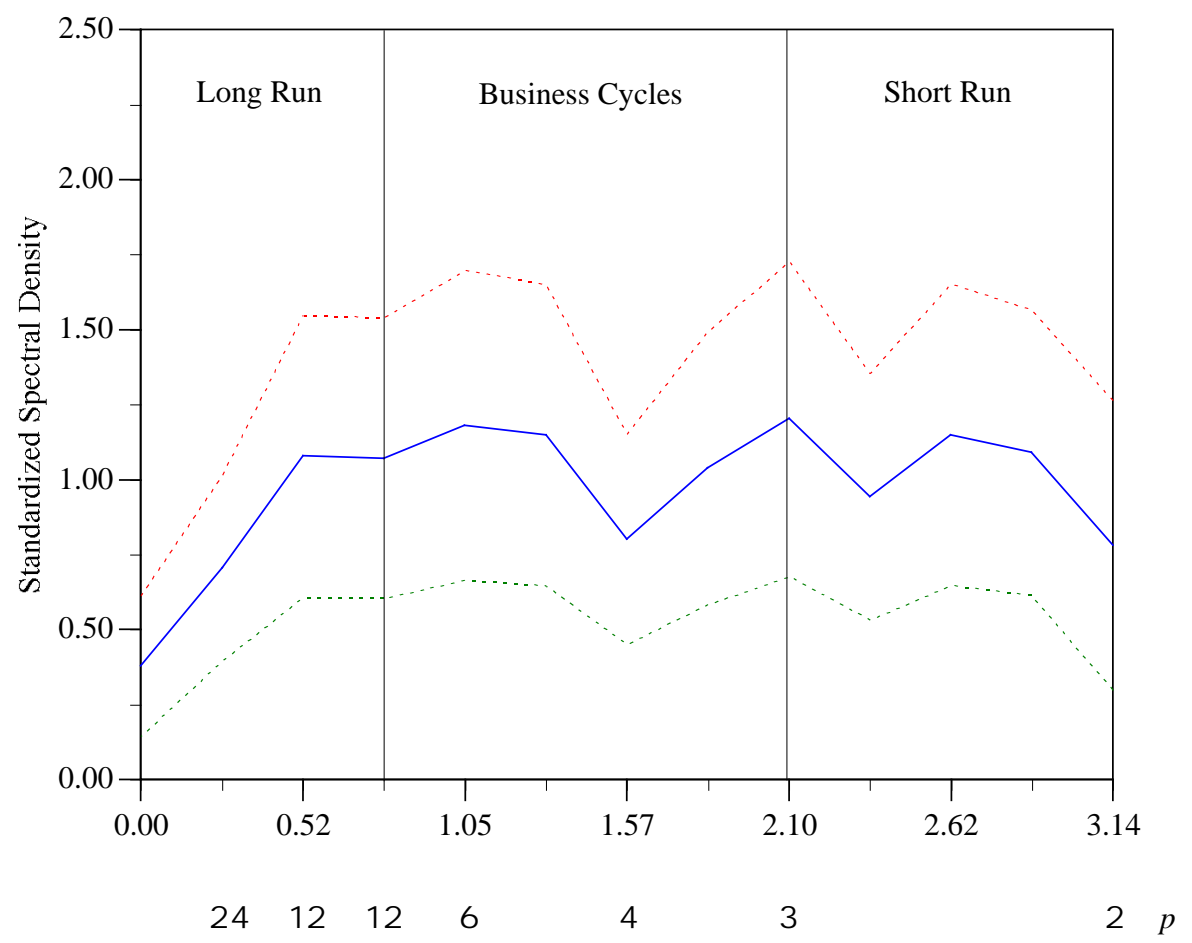

Spectral Density

95\% Confidence Interval

Figure 11. Estimate of Spectral Density Function ( \pm 2 S.E.) of the Original Annual Consumer Durable Good (CDG) Series, U.S., 1948-1991. 


\title{
Estimates of the Aggregate Quarterly Capital Stock for the Post-War U.S. Economy
}

\author{
Daniel Levy and Haiwei Chen
}

\author{
Review of Income and Wealth
}

Volume 40, No. 3, September 1994, pp. 317-349

\section{Unpublished Supplementary Appendix}


The published version of the paper does not contain all the series we have actually constructed for the project. This unpublished supplementary appendix contains all 36 series (nominal and real, gross and net, CDG, PDG, and BS) we have constructed.

The notation used is as follows:

$\mathrm{CDG}=$ Consumer Durable Goods

PDG $=$ Producer Durable Goods and Equipment

$\mathrm{BS}=\quad$ Business Structures (Nonresidential)

If the series’ name ends with 87, then it is in real terms, measured in 1987 dollars. Otherwise it is in nominal terms.

To save space, the series in this appendix are presented in a format different from the published version. For example the series in the published version in column 1 of Table 1 is now displayed in column 2 of Table 3 of this appendix. 
Table 1. Quarterly Gross Capital Stock, U.S., 1948-91, Linear Interpolation Technique (Method 1)

\begin{tabular}{|c|c|c|c|c|c|c|}
\hline Time & $\mathrm{CDG}$ & CDG87 & PDG & PDG87 & BS & BS87 \\
\hline 1948.1 & 76.57 & 241.18 & 65.88 & 395.73 & 108.52 & 710.56 \\
\hline 1948.2 & 82.07 & 248.15 & 69.32 & 407.41 & 113.53 & 713.22 \\
\hline 1948.3 & 87.19 & 255.13 & 74.84 & 419.10 & 118.48 & 715.89 \\
\hline 1948.4 & 87.95 & 262.10 & 77.88 & 430.78 & 121.43 & 718.55 \\
\hline 1949.1 & 89.86 & 269.80 & 80.33 & 438.41 & 122.60 & 721.57 \\
\hline 1949.2 & 91.09 & 277.49 & 85.44 & 446.04 & 123.04 & 724.59 \\
\hline 1949.3 & 95.56 & 285.19 & 87.52 & 453.67 & 125.48 & 727.61 \\
\hline 1949.4 & 101.35 & 292.88 & 89.15 & 461.30 & 129.38 & 730.63 \\
\hline 1950.1 & 106.24 & 302.91 & 90.76 & 469.78 & 128.18 & 734.54 \\
\hline 1950.2 & 110.87 & 312.94 & 92.74 & 478.26 & 126.26 & 738.45 \\
\hline 1950.3 & 115.90 & 322.97 & 96.78 & 486.74 & 128.57 & 742.36 \\
\hline 1950.4 & 117.32 & 333.00 & 100.00 & 495.22 & 132.88 & 746.27 \\
\hline 1951.1 & 129.35 & 339.78 & 107.60 & 503.87 & 138.83 & 751.31 \\
\hline 1951.2 & 130.08 & 346.57 & 109.52 & 512.53 & 141.94 & 756.34 \\
\hline 1951.3 & 134.11 & 353.35 & 110.86 & 521.18 & 144.99 & 761.38 \\
\hline 1951.4 & 138.05 & 360.13 & 114.47 & 529.83 & 145.88 & 766.42 \\
\hline 1952.1 & 140.21 & 365.80 & 117.01 & 537.06 & 150.39 & 770.46 \\
\hline 1952.2 & 139.32 & 371.48 & 120.51 & 544.29 & 152.76 & 774.50 \\
\hline 1952.3 & 143.43 & 377.15 & 122.00 & 551.52 & 155.86 & 778.54 \\
\hline 1952.4 & 153.63 & 382.83 & 126.50 & 558.75 & 158.93 & 782.58 \\
\hline 1953.1 & 157.99 & 389.28 & 128.11 & 566.49 & 160.62 & 789.25 \\
\hline 1953.2 & 166.63 & 395.74 & 132.31 & 574.23 & 163.80 & 795.91 \\
\hline 1953.3 & 171.72 & 402.20 & 135.51 & 581.98 & 167.00 & 802.58 \\
\hline 1953.4 & 166.68 & 408.65 & 136.02 & 589.72 & 167.88 & 809.25 \\
\hline 1954.1 & 172.80 & 414.51 & 138.23 & 595.16 & 167.97 & 815.59 \\
\hline 1954.2 & 179.03 & 420.38 & 140.43 & 600.59 & 168.00 & 821.94 \\
\hline 1954.3 & 174.73 & 426.24 & 141.53 & 606.03 & 171.23 & 828.28 \\
\hline 1954.4 & 175.10 & 432.10 & 143.70 & 611.47 & 173.68 & 834.63 \\
\hline 1955.1 & 183.96 & 440.62 & 145.35 & 618.39 & 174.11 & 841.92 \\
\hline 1955.2 & 184.68 & 449.15 & 146.42 & 625.31 & 175.34 & 849.20 \\
\hline 1955.3 & 190.31 & 457.67 & 150.88 & 632.23 & 177.34 & 856.49 \\
\hline 1955.4 & 185.98 & 466.20 & 153.07 & 639.15 & 180.95 & 863.78 \\
\hline 1956.1 & 187.92 & 471.49 & 155.69 & 646.08 & 190.00 & 872.47 \\
\hline 1956.2 & 190.35 & 476.78 & 159.97 & 653.00 & 190.01 & 881.17 \\
\hline 1956.3 & 188.35 & 482.06 & 162.44 & 659.92 & 196.48 & 889.86 \\
\hline 1956.4 & 195.50 & 487.35 & 167.72 & 666.85 & 198.78 & 898.55 \\
\hline 1957.1 & 198.27 & 491.59 & 174.43 & 673.40 & 204.23 & 907.41 \\
\hline 1957.2 & 203.80 & 495.82 & 178.19 & 679.94 & 210.55 & 916.26 \\
\hline 1957.3 & 210.54 & 500.06 & 181.88 & 686.49 & 215.15 & 925.12 \\
\hline 1957.4 & 211.55 & 504.30 & 186.75 & 693.03 & 218.85 & 933.98 \\
\hline 1958.1 & 211.86 & 506.07 & 186.91 & 695.40 & 216.63 & 941.28 \\
\hline
\end{tabular}




\begin{tabular}{|c|c|c|c|c|c|c|}
\hline 1958.2 & 209.26 & 507.85 & 188.90 & 697.77 & 220.66 & 948.57 \\
\hline 1958.3 & 212.48 & 509.62 & 193.41 & 700.13 & 224.73 & 955.87 \\
\hline 1958.4 & 213.38 & 511.40 & 196.68 & 702.50 & 228.85 & 963.17 \\
\hline 1959.1 & 218.90 & 515.46 & 200.31 & 706.28 & 229.58 & 970.43 \\
\hline 1959.2 & 220.89 & 519.52 & 202.66 & 710.06 & 232.18 & 977.70 \\
\hline 1959.3 & 224.04 & 523.57 & 205.68 & 713.85 & 233.85 & 984.96 \\
\hline 1959.4 & 224.80 & 527.63 & 206.05 & 717.63 & 235.52 & 992.22 \\
\hline 1960.1 & 228.52 & 530.67 & 210.52 & 721.60 & 240.12 & 1001.14 \\
\hline 1960.2 & 229.23 & 533.70 & 212.33 & 725.57 & 241.80 & 1010.06 \\
\hline 1960.3 & 231.13 & 536.74 & 214.78 & 729.53 & 244.46 & 1018.98 \\
\hline 1960.4 & 232.43 & 539.78 & 215.88 & 733.50 & 245.07 & 1027.90 \\
\hline 1961.1 & 231.24 & 541.01 & 215.73 & 736.46 & 245.99 & 1036.90 \\
\hline 1961.2 & 234.97 & 542.24 & 218.26 & 739.43 & 246.90 & 1045.90 \\
\hline 1961.3 & 236.21 & 543.47 & 220.13 & 742.39 & 248.85 & 1054.90 \\
\hline 1961.4 & 235.60 & 544.70 & 221.32 & 745.35 & 250.80 & 1063.90 \\
\hline 1962.1 & 236.90 & 548.71 & 224.04 & 750.25 & 252.96 & 1073.55 \\
\hline 1962.2 & 240.02 & 552.71 & 223.30 & 755.15 & 255.11 & 1083.20 \\
\hline 1962.3 & 241.93 & 556.72 & 225.33 & 760.05 & 257.26 & 1092.85 \\
\hline 1962.4 & 243.83 & 560.72 & 228.05 & 764.95 & 260.48 & 1102.50 \\
\hline 1963.1 & 245.79 & 566.57 & 230.69 & 771.16 & 263.40 & 1112.03 \\
\hline 1963.2 & 248.98 & 572.43 & 232.61 & 777.37 & 266.32 & 1121.55 \\
\hline 1963.3 & 250.91 & 578.28 & 234.52 & 783.57 & 268.15 & 1131.08 \\
\hline 1963.4 & 254.10 & 584.13 & 237.88 & 789.78 & 271.07 & 1140.60 \\
\hline 1964.1 & 257.83 & 591.64 & 242.69 & 798.63 & 271.57 & 1151.95 \\
\hline 1964.2 & 262.21 & 599.14 & 246.79 & 807.47 & 276.50 & 1163.30 \\
\hline 1964.3 & 265.93 & 606.65 & 249.39 & 816.32 & 278.07 & 1174.65 \\
\hline 1964.4 & 269.65 & 614.15 & 251.20 & 825.17 & 284.13 & 1186.00 \\
\hline 1965.1 & 275.38 & 624.46 & 257.74 & 838.68 & 286.97 & 1200.97 \\
\hline 1965.2 & 278.41 & 634.77 & 261.94 & 852.18 & 292.07 & 1215.95 \\
\hline 1965.3 & 282.09 & 645.07 & 266.11 & 865.69 & 294.81 & 1230.92 \\
\hline 1965.4 & 287.17 & 655.38 & 271.08 & 879.20 & 303.40 & 1245.90 \\
\hline 1966.1 & 290.14 & 667.02 & 275.72 & 896.30 & 307.29 & 1262.05 \\
\hline 1966.2 & 295.21 & 678.67 & 281.98 & 913.40 & 318.34 & 1278.20 \\
\hline 1966.3 & 300.28 & 690.31 & 288.21 & 930.50 & 322.13 & 1294.35 \\
\hline 1966.4 & 304.63 & 701.95 & 297.00 & 947.60 & 329.55 & 1310.50 \\
\hline 1967.1 & 307.65 & 712.63 & 303.38 & 962.20 & 336.36 & 1324.70 \\
\hline 1967.2 & 312.81 & 723.31 & 309.72 & 976.80 & 341.88 & 1338.90 \\
\hline 1967.3 & 320.21 & 733.99 & 316.94 & 991.40 & 348.62 & 1353.10 \\
\hline 1967.4 & 329.13 & 744.67 & 326.00 & 1006.00 & 357.92 & 1367.30 \\
\hline 1968.1 & 337.54 & 758.18 & 333.72 & 1021.20 & 363.67 & 1381.30 \\
\hline 1968.2 & 345.13 & 771.70 & 342.35 & 1036.40 & 368.03 & 1395.30 \\
\hline 1968.3 & 355.06 & 785.21 & 350.94 & 1051.60 & 372.30 & 1409.30 \\
\hline 1968.4 & 364.20 & 798.72 & 358.55 & 1066.80 & 382.98 & 1423.30 \\
\hline 1969.1 & 372.66 & 811.91 & 365.99 & 1083.33 & 392.97 & 1438.43 \\
\hline 1969.2 & 383.62 & 825.11 & 376.35 & 1099.85 & 404.17 & 1453.55 \\
\hline 1969.3 & 391.18 & 838.30 & 386.65 & 1116.38 & 413.94 & 1468.68 \\
\hline
\end{tabular}




\begin{tabular}{|c|c|c|c|c|c|c|}
\hline 1969.4 & 400.43 & 851.50 & 395.88 & 1132.90 & 426.30 & 1483.80 \\
\hline 1970.1 & 407.41 & 860.51 & 405.73 & 1147.10 & 437.00 & 1498.25 \\
\hline 1970.2 & 411.68 & 869.52 & 414.54 & 1161.30 & 455.92 & 1512.70 \\
\hline 1970.3 & 417.67 & 878.52 & 418.02 & 1175.50 & 463.58 & 1527.15 \\
\hline 1970.4 & 429.05 & 887.53 & 427.83 & 1189.70 & 475.30 & 1541.60 \\
\hline 1971.1 & 445.45 & 899.20 & 441.66 & 1201.30 & 488.09 & 1554.78 \\
\hline 1971.2 & 456.43 & 910.86 & 454.37 & 1212.90 & 502.13 & 1567.95 \\
\hline 1971.3 & 462.63 & 922.53 & 461.55 & 1224.50 & 514.53 & 1581.13 \\
\hline 1971.4 & 469.65 & 934.20 & 465.28 & 1236.10 & 525.28 & 1594.30 \\
\hline 1972.1 & 481.58 & 949.72 & 479.31 & 1251.78 & 544.08 & 1607.80 \\
\hline 1972.2 & 490.58 & 965.25 & 487.77 & 1267.45 & 556.85 & 1621.30 \\
\hline 1972.3 & 500.58 & 980.78 & 498.51 & 1283.13 & 572.38 & 1634.80 \\
\hline 1972.4 & 504.45 & 996.30 & 504.48 & 1298.80 & 589.27 & 1648.30 \\
\hline 1973.1 & 514.54 & 1014.27 & 514.92 & 1321.05 & 606.05 & 1662.55 \\
\hline 1973.2 & 527.74 & 1032.25 & 528.98 & 1343.30 & 625.55 & 1676.80 \\
\hline 1973.3 & 538.82 & 1050.22 & 541.81 & 1365.55 & 651.02 & 1691.05 \\
\hline 1973.4 & 548.78 & 1068.20 & 553.35 & 1387.80 & 673.07 & 1705.30 \\
\hline 1974.1 & 553.71 & 1078.92 & 556.76 & 1408.85 & 688.62 & 1718.58 \\
\hline 1974.2 & 561.47 & 1089.65 & 564.68 & 1429.90 & 715.83 & 1731.85 \\
\hline 1974.3 & 577.24 & 1100.37 & 591.95 & 1450.95 & 745.10 & 1745.13 \\
\hline 1974.4 & 593.47 & 1111.10 & 617.00 & 1472.00 & 771.63 & 1758.40 \\
\hline 1975.1 & 613.60 & 1120.18 & 662.18 & 1485.03 & 809.96 & 1767.15 \\
\hline 1975.2 & 640.05 & 1129.25 & 695.87 & 1498.05 & 838.67 & 1775.90 \\
\hline 1975.3 & 657.75 & 1138.32 & 719.93 & 1511.08 & 860.53 & 1784.65 \\
\hline 1975.4 & 678.55 & 1147.40 & 743.20 & 1524.10 & 885.25 & 1793.40 \\
\hline 1976.1 & 696.33 & 1162.47 & 770.94 & 1536.78 & 898.12 & 1802.97 \\
\hline 1976.2 & 715.09 & 1177.55 & 798.41 & 1549.45 & 925.98 & 1812.55 \\
\hline 1976.3 & 734.88 & 1192.62 & 822.78 & 1562.13 & 950.35 & 1822.12 \\
\hline 1976.4 & 755.72 & 1207.70 & 852.45 & 1574.80 & 972.83 & 1831.70 \\
\hline 1977.1 & 774.25 & 1225.75 & 873.26 & 1592.75 & 990.63 & 1841.25 \\
\hline 1977.2 & 792.67 & 1243.80 & 901.00 & 1610.70 & 1013.17 & 1850.80 \\
\hline 1977.3 & 812.22 & 1261.85 & 927.06 & 1628.65 & 1035.20 & 1860.35 \\
\hline 1977.4 & 835.45 & 1279.90 & 954.35 & 1646.60 & 1053.30 & 1869.90 \\
\hline 1978.1 & 856.99 & 1298.40 & 984.76 & 1670.38 & 1072.25 & 1883.20 \\
\hline 1978.2 & 879.54 & 1316.90 & 1019.38 & 1694.15 & 1107.67 & 1896.50 \\
\hline 1978.3 & 903.13 & 1335.40 & 1050.63 & 1717.93 & 1138.86 & 1909.80 \\
\hline 1978.4 & 927.78 & 1353.90 & 1081.50 & 1741.70 & 1174.40 & 1923.10 \\
\hline 1979.1 & 952.32 & 1369.53 & 1118.63 & 1766.82 & 1215.91 & 1940.85 \\
\hline 1979.2 & 981.87 & 1385.15 & 1156.78 & 1791.95 & 1249.55 & 1958.60 \\
\hline 1979.3 & 1003.12 & 1400.78 & 1192.75 & 1817.07 & 1307.06 & 1976.35 \\
\hline 1979.4 & 1029.40 & 1416.40 & 1233.00 & 1842.20 & 1344.30 & 1994.10 \\
\hline 1980.1 & 1061.49 & 1423.47 & 1271.14 & 1860.10 & 1386.09 & 2012.35 \\
\hline 1980.2 & 1095.80 & 1430.55 & 1321.56 & 1878.00 & 1421.06 & 2030.60 \\
\hline 1980.3 & 1115.96 & 1437.62 & 1367.80 & 1895.90 & 1481.69 & 2048.85 \\
\hline 1980.4 & 1136.90 & 1444.70 & 1394.80 & 1913.80 & 1544.60 & 2067.10 \\
\hline 1981.1 & 1157.62 & 1450.42 & 1450.16 & 1930.65 & 1571.70 & 2088.12 \\
\hline
\end{tabular}




\begin{tabular}{|c|c|c|c|c|c|c|}
\hline 1981.2 & 1190.44 & 1456.15 & 1503.29 & 1947.50 & 1636.38 & 2109.15 \\
\hline 1981.3 & 1214.68 & 1461.87 & 1547.11 & 1964.35 & 1675.23 & 2130.17 \\
\hline 1981.4 & 1242.80 & 1467.60 & 1600.60 & 1981.20 & 1783.70 & 2151.20 \\
\hline 1982.1 & 1262.84 & 1472.03 & 1652.25 & 1989.82 & 1853.83 & 2170.62 \\
\hline 1982.2 & 1289.99 & 1476.45 & 1687.72 & 1998.45 & 1907.66 & 2190.05 \\
\hline 1982.3 & 1307.12 & 1480.88 & 1733.94 & 2007.07 & 1953.39 & 2209.48 \\
\hline 1982.4 & 1322.70 & 1485.30 & 1774.50 & 2015.70 & 2002.60 & 2228.90 \\
\hline 1983.1 & 1347.62 & 1497.45 & 1813.92 & 2022.42 & 2028.32 & 2241.38 \\
\hline 1983.2 & 1365.11 & 1509.60 & 1840.04 & 2029.15 & 2030.50 & 2253.85 \\
\hline 1983.3 & 1386.94 & 1521.75 & 1862.20 & 2035.87 & 2059.97 & 2266.33 \\
\hline 1983.4 & 1408.70 & 1533.90 & 1884.20 & 2042.60 & 2105.00 & 2278.80 \\
\hline 1984.1 & 1430.25 & 1554.53 & 1906.87 & 2059.90 & 2118.16 & 2296.25 \\
\hline 1984.2 & 1459.45 & 1575.15 & 1923.42 & 2077.20 & 2135.65 & 2313.70 \\
\hline 1984.3 & 1487.15 & 1595.78 & 1950.03 & 2094.50 & 2166.49 & 2331.15 \\
\hline 1984.4 & 1511.70 & 1616.40 & 1980.80 & 2111.80 & 2195.10 & 2348.60 \\
\hline 1985.1 & 1546.08 & 1642.80 & 1983.28 & 2130.50 & 2236.73 & 2369.48 \\
\hline 1985.2 & 1573.93 & 1669.20 & 2012.70 & 2149.20 & 2255.42 & 2390.35 \\
\hline 1985.3 & 1599.99 & 1695.60 & 2040.11 & 2167.90 & 2290.12 & 2411.23 \\
\hline 1985.4 & 1634.40 & 1722.00 & 2076.20 & 2186.60 & 2327.20 & 2432.10 \\
\hline 1986.1 & 1664.53 & 1752.57 & 2096.65 & 2203.12 & 2357.06 & 2447.95 \\
\hline 1986.2 & 1699.70 & 1783.15 & 2121.28 & 2219.65 & 2367.68 & 2463.80 \\
\hline 1986.3 & 1743.73 & 1813.72 & 2150.15 & 2236.17 & 2397.45 & 2479.65 \\
\hline 1986.4 & 1780.70 & 1844.30 & 2170.20 & 2252.70 & 2434.70 & 2495.50 \\
\hline 1987.1 & 1822.19 & 1871.00 & 2202.53 & 2267.70 & 2452.44 & 2508.25 \\
\hline 1987.2 & 1859.93 & 1897.70 & 2230.40 & 2282.70 & 2467.58 & 2521.00 \\
\hline 1987.3 & 1899.43 & 1924.40 & 2251.40 & 2297.70 & 2487.56 & 2533.75 \\
\hline 1987.4 & 1931.20 & 1951.10 & 2295.00 & 2312.70 & 2524.90 & 2546.50 \\
\hline 1988.1 & 1960.49 & 1980.28 & 2328.37 & 2332.25 & 2566.06 & 2559.10 \\
\hline 1988.2 & 2003.15 & 2009.45 & 2354.74 & 2351.80 & 2591.87 & 2571.70 \\
\hline 1988.3 & 2049.82 & 2038.63 & 2373.98 & 2371.35 & 2617.29 & 2584.30 \\
\hline 1988.4 & 2096.60 & 2067.80 & 2416.50 & 2390.90 & 2644.81 & 2596.90 \\
\hline 1989.1 & 2140.49 & 2095.62 & 2447.76 & 2406.77 & 2695.10 & 2609.52 \\
\hline 1989.2 & 2182.28 & 2123.45 & 2476.58 & 2422.65 & 2747.79 & 2622.15 \\
\hline 1989.3 & 2226.13 & 2151.27 & 2514.99 & 2438.52 & 2787.62 & 2634.77 \\
\hline 1989.4 & 2267.81 & 2179.10 & 2548.61 & 2454.40 & 2829.69 & 2647.40 \\
\hline 1990.1 & 2306.89 & 2202.80 & 2578.13 & 2471.27 & 2879.64 & 2659.95 \\
\hline 1990.2 & 2332.84 & 2226.50 & 2605.03 & 2488.15 & 2913.96 & 2672.50 \\
\hline 1990.3 & 2360.86 & 2250.20 & 2651.89 & 2505.02 & 2953.29 & 2685.05 \\
\hline 1990.4 & 2397.80 & 2273.90 & 2683.70 & 2521.90 & 2987.20 & 2697.60 \\
\hline 1991.1 & 2426.79 & 2287.85 & 2736.68 & 2531.10 & 3019.58 & 2705.33 \\
\hline 1991.2 & 2446.65 & 2301.80 & 2761.51 & 2540.30 & 3044.08 & 2713.05 \\
\hline 1991.3 & 2468.76 & 2315.75 & 2780.78 & 2549.50 & 3073.97 & 2720.78 \\
\hline 1991.4 & 2488.50 & 2329.70 & 2813.10 & 2558.70 & 3076.91 & 2728.50 \\
\hline
\end{tabular}


Table 2. Quarterly Gross Capital Stock, U.S., 1948-91, Capital Accumulation Technique (Method 2)

\begin{tabular}{|c|c|c|c|c|c|c|}
\hline Time & $\mathrm{CDG}$ & CDG87 & PDG & PDG87 & BS & BS87 \\
\hline 1948.1 & 76.35 & 242.47 & 65.89 & 396.71 & 108.34 & 710.03 \\
\hline 1948.2 & 81.74 & 250.65 & 69.19 & 408.14 & 113.27 & 712.50 \\
\hline 1948.3 & 87.07 & 259.48 & 74.68 & 419.11 & 118.32 & 715.40 \\
\hline 1948.4 & 87.95 & 268.60 & 77.90 & 430.82 & 121.43 & 718.55 \\
\hline 1949.1 & 89.31 & 268.08 & 80.60 & 440.16 & 122.73 & 722.14 \\
\hline 1949.2 & 90.48 & 276.03 & 85.80 & 448.02 & 123.22 & 725.45 \\
\hline 1949.3 & 95.13 & 284.38 & 87.73 & 454.80 & 125.60 & 728.21 \\
\hline 1949.4 & 101.35 & 292.88 & 89.15 & 461.31 & 129.38 & 730.62 \\
\hline 1950.1 & 105.49 & 300.54 & 90.09 & 467.20 & 127.96 & 733.62 \\
\hline 1950.2 & 109.45 & 308.47 & 91.89 & 475.25 & 125.93 & 737.24 \\
\hline 1950.3 & 115.71 & 321.97 & 96.34 & 485.30 & 128.31 & 741.59 \\
\hline 1950.4 & 117.33 & 333.01 & 100.00 & 495.22 & 132.88 & 746.28 \\
\hline 1951.1 & 130.40 & 342.42 & 107.48 & 503.16 & 138.70 & 751.13 \\
\hline 1951.2 & 130.83 & 348.72 & 109.34 & 511.56 & 141.88 & 756.46 \\
\hline 1951.3 & 134.47 & 354.45 & 110.78 & 520.73 & 145.01 & 761.71 \\
\hline 1951.4 & 138.04 & 360.12 & 114.47 & 529.82 & 145.88 & 766.42 \\
\hline 1952.1 & 140.12 & 365.62 & 117.18 & 538.07 & 150.34 & 770.16 \\
\hline 1952.2 & 139.22 & 371.72 & 120.95 & 546.47 & 152.68 & 774.03 \\
\hline 1952.3 & 142.87 & 376.34 & 121.95 & 551.71 & 155.76 & 778.03 \\
\hline 1952.4 & 153.62 & 382.83 & 126.50 & 558.76 & 158.93 & 782.57 \\
\hline 1953.1 & 158.07 & 389.27 & 128.05 & 566.46 & 160.50 & 788.94 \\
\hline 1953.2 & 166.78 & 395.32 & 132.20 & 573.95 & 163.67 & 795.57 \\
\hline 1953.3 & 171.87 & 401.41 & 135.54 & 582.06 & 166.90 & 802.27 \\
\hline 1953.4 & 166.68 & 408.65 & 136.02 & 589.72 & 167.88 & 809.26 \\
\hline 1954.1 & 172.62 & 413.86 & 138.18 & 595.21 & 167.97 & 815.56 \\
\hline 1954.2 & 178.85 & 419.02 & 140.28 & 600.33 & 168.01 & 821.97 \\
\hline 1954.3 & 174.43 & 424.76 & 141.45 & 606.08 & 171.25 & 828.34 \\
\hline 1954.4 & 175.10 & 432.10 & 143.69 & 611.47 & 173.68 & 834.62 \\
\hline 1955.1 & 183.35 & 438.98 & 144.66 & 615.98 & 173.90 & 841.25 \\
\hline 1955.2 & 184.05 & 447.60 & 145.55 & 622.41 & 175.01 & 848.27 \\
\hline 1955.3 & 190.11 & 456.83 & 150.27 & 630.21 & 177.08 & 855.81 \\
\hline 1955.4 & 185.97 & 466.20 & 153.07 & 639.15 & 180.96 & 863.78 \\
\hline 1956.1 & 187.85 & 471.98 & 155.46 & 646.06 & 189.80 & 871.91 \\
\hline 1956.2 & 190.23 & 477.25 & 159.63 & 652.80 & 189.76 & 880.72 \\
\hline 1956.3 & 188.09 & 482.35 & 162.22 & 660.04 & 196.35 & 889.65 \\
\hline 1956.4 & 195.50 & 487.35 & 167.72 & 666.85 & 198.78 & 898.56 \\
\hline 1957.1 & 198.44 & 492.29 & 174.34 & 673.39 & 204.19 & 907.44 \\
\hline 1957.2 & 204.01 & 496.65 & 177.98 & 679.67 & 210.52 & 916.33 \\
\hline 1957.3 & 210.68 & 500.39 & 181.87 & 686.79 & 215.17 & 925.21 \\
\hline 1957.4 & 211.55 & 504.30 & 186.75 & 693.02 & 218.85 & 933.98 \\
\hline 1958.1 & 211.84 & 505.95 & 187.07 & 696.10 & 216.74 & 941.86 \\
\hline
\end{tabular}




\begin{tabular}{|c|c|c|c|c|c|c|}
\hline 1958.2 & 209.03 & 507.40 & 188.94 & 698.19 & 220.76 & 949.14 \\
\hline 1958.3 & 212.20 & 508.98 & 193.25 & 699.89 & 224.74 & 956.02 \\
\hline 1958.4 & 213.38 & 511.40 & 196.68 & 702.51 & 228.85 & 963.18 \\
\hline 1959.1 & 218.60 & 514.83 & 200.00 & 705.38 & 229.40 & 969.75 \\
\hline 1959.2 & 220.74 & 519.33 & 202.29 & 708.92 & 231.98 & 976.88 \\
\hline 1959.3 & 224.25 & 524.17 & 205.49 & 713.22 & 233.76 & 984.61 \\
\hline 1959.4 & 224.81 & 527.62 & 206.05 & 717.62 & 235.53 & 992.22 \\
\hline 1960.1 & 228.49 & 530.45 & 210.63 & 722.15 & 240.07 & 1000.74 \\
\hline 1960.2 & 229.39 & 534.04 & 212.69 & 727.02 & 241.74 & 1009.48 \\
\hline 1960.3 & 231.37 & 537.29 & 215.10 & 730.71 & 244.36 & 1018.30 \\
\hline 1960.4 & 232.43 & 539.78 & 215.88 & 733.51 & 245.07 & 1027.94 \\
\hline 1961.1 & 230.78 & 540.34 & 215.38 & 735.38 & 246.04 & 1037.19 \\
\hline 1961.2 & 234.27 & 541.02 & 217.85 & 738.10 & 246.93 & 1046.12 \\
\hline 1961.3 & 235.61 & 542.22 & 219.72 & 741.05 & 248.87 & 1055.04 \\
\hline 1961.4 & 235.61 & 544.70 & 221.33 & 745.35 & 250.79 & 1063.85 \\
\hline 1962.1 & 236.47 & 547.83 & 223.88 & 749.79 & 252.77 & 1072.80 \\
\hline 1962.2 & 239.49 & 551.55 & 223.18 & 754.95 & 254.92 & 1082.50 \\
\hline 1962.3 & 241.41 & 555.52 & 225.26 & 760.04 & 257.23 & 1092.80 \\
\hline 1962.4 & 243.82 & 560.72 & 228.04 & 764.95 & 260.48 & 1102.53 \\
\hline 1963.1 & 245.39 & 565.81 & 230.32 & 769.91 & 263.16 & 1111.12 \\
\hline 1963.2 & 248.50 & 571.51 & 232.02 & 775.40 & 266.09 & 1120.69 \\
\hline 1963.3 & 250.54 & 577.60 & 234.06 & 782.09 & 267.98 & 1130.43 \\
\hline 1963.4 & 254.10 & 584.12 & 237.88 & 789.78 & 271.08 & 1140.58 \\
\hline 1964.1 & 257.46 & 590.92 & 242.32 & 797.46 & 271.24 & 1150.92 \\
\hline 1964.2 & 261.83 & 598.42 & 246.24 & 805.67 & 276.08 & 1162.02 \\
\hline 1964.3 & 266.00 & 606.96 & 248.99 & 814.90 & 277.79 & 1173.95 \\
\hline 1964.4 & 269.65 & 614.16 & 251.21 & 825.18 & 284.12 & 1186.05 \\
\hline 1965.1 & 275.04 & 623.46 & 257.17 & 836.98 & 286.42 & 1199.11 \\
\hline 1965.2 & 277.67 & 632.83 & 261.00 & 849.33 & 291.49 & 1214.05 \\
\hline 1965.3 & 281.45 & 643.41 & 265.42 & 863.66 & 294.30 & 1229.29 \\
\hline 1965.4 & 287.17 & 655.38 & 271.07 & 879.20 & 303.40 & 1245.85 \\
\hline 1966.1 & 290.30 & 667.99 & 275.26 & 895.50 & 307.23 & 1262.45 \\
\hline 1966.2 & 294.87 & 678.62 & 281.52 & 912.85 & 318.23 & 1278.38 \\
\hline 1966.3 & 300.08 & 690.33 & 287.84 & 930.15 & 322.17 & 1294.95 \\
\hline 1966.4 & 304.62 & 701.96 & 297.01 & 947.60 & 329.55 & 1310.50 \\
\hline 1967.1 & 306.95 & 711.54 & 303.13 & 961.77 & 336.41 & 1325.20 \\
\hline 1967.2 & 312.26 & 722.93 & 309.46 & 976.50 & 341.77 & 1339.02 \\
\hline 1967.3 & 319.81 & 733.84 & 316.54 & 990.70 & 348.50 & 1353.17 \\
\hline 1967.4 & 329.13 & 744.68 & 326.00 & 1006.00 & 357.92 & 1367.35 \\
\hline 1968.1 & 336.61 & 756.60 & 333.48 & 1021.25 & 363.55 & 1381.44 \\
\hline 1968.2 & 343.79 & 769.48 & 341.64 & 1035.35 & 367.82 & 1395.35 \\
\hline 1968.3 & 354.37 & 784.21 & 350.25 & 1050.30 & 371.99 & 1408.99 \\
\hline 1968.4 & 364.21 & 798.71 & 358.55 & 1066.82 & 382.97 & 1423.22 \\
\hline 1969.1 & 372.55 & 812.21 & 365.62 & 1083.35 & 392.50 & 1437.58 \\
\hline 1969.2 & 383.50 & 825.43 & 375.85 & 1099.82 & 403.45 & 1452.11 \\
\hline 1969.3 & 391.11 & 838.58 & 386.39 & 1116.61 & 413.52 & 1468.07 \\
\hline
\end{tabular}




\begin{tabular}{|c|c|c|c|c|c|c|}
\hline 1969.4 & 400.43 & 851.50 & 395.87 & 1132.88 & 426.31 & 1483.78 \\
\hline 1970.1 & 407.38 & 860.88 & 405.72 & 1147.47 & 436.80 & 1498.64 \\
\hline 1970.2 & 411.91 & 870.78 & 414.63 & 1161.85 & 455.72 & 1513.05 \\
\hline 1970.3 & 418.38 & 880.90 & 418.40 & 1176.92 & 463.45 & 1527.54 \\
\hline 1970.4 & 429.05 & 887.53 & 427.83 & 1189.70 & 475.30 & 1541.65 \\
\hline 1971.1 & 444.40 & 897.10 & 441.07 & 1200.72 & 487.80 & 1554.88 \\
\hline 1971.2 & 455.03 & 907.87 & 453.70 & 1212.17 & 501.74 & 1568.05 \\
\hline 1971.3 & 461.46 & 920.01 & 460.93 & 1223.55 & 514.25 & 1581.20 \\
\hline 1971.4 & 469.65 & 934.20 & 465.28 & 1236.12 & 525.28 & 1594.28 \\
\hline 1972.1 & 480.21 & 947.40 & 478.28 & 1249.07 & 543.74 & 1607.53 \\
\hline 1972.2 & 488.63 & 961.85 & 486.25 & 1263.44 & 556.36 & 1620.96 \\
\hline 1972.3 & 498.90 & 977.50 & 496.99 & 1279.10 & 571.93 & 1634.42 \\
\hline 1972.4 & 504.45 & 996.30 & 504.48 & 1298.72 & 589.28 & 1648.35 \\
\hline 1973.1 & 514.95 & 1015.97 & 513.63 & 1318.84 & 605.14 & 1661.49 \\
\hline 1973.2 & 528.27 & 1034.35 & 527.66 & 1341.22 & 624.42 & 1675.69 \\
\hline 1973.3 & 539.41 & 1052.15 & 540.93 & 1364.21 & 650.34 & 1690.63 \\
\hline 1973.4 & 548.78 & 1068.22 & 553.36 & 1387.80 & 673.07 & 1705.30 \\
\hline 1974.1 & 552.86 & 1079.84 & 555.71 & 1409.81 & 688.06 & 1719.47 \\
\hline 1974.2 & 560.78 & 1092.14 & 563.16 & 1431.78 & 715.30 & 1733.54 \\
\hline 1974.3 & 578.15 & 1104.89 & 591.08 & 1453.11 & 744.60 & 1746.13 \\
\hline 1974.4 & 593.48 & 1111.08 & 617.00 & 1472.05 & 771.62 & 1758.35 \\
\hline 1975.1 & 611.01 & 1117.12 & 661.41 & 1485.20 & 810.04 & 1767.96 \\
\hline 1975.2 & 636.13 & 1124.12 & 694.59 & 1497.50 & 838.51 & 1776.34 \\
\hline 1975.3 & 654.98 & 1134.82 & 718.87 & 1510.43 & 860.37 & 1784.89 \\
\hline 1975.4 & 678.54 & 1147.38 & 743.20 & 1524.10 & 885.26 & 1793.43 \\
\hline 1976.1 & 695.13 & 1161.88 & 769.38 & 1535.50 & 897.67 & 1802.97 \\
\hline 1976.2 & 713.26 & 1176.46 & 796.11 & 1547.40 & 925.32 & 1812.38 \\
\hline 1976.3 & 733.24 & 1191.49 & 820.94 & 1560.53 & 949.87 & 1822.03 \\
\hline 1976.4 & 755.72 & 1207.72 & 852.45 & 1574.80 & 972.83 & 1831.72 \\
\hline 1977.1 & 772.40 & 1223.85 & 870.89 & 1590.55 & 989.43 & 1840.24 \\
\hline 1977.2 & 790.23 & 1241.45 & 897.66 & 1607.58 & 1011.74 & 1849.74 \\
\hline 1977.3 & 810.26 & 1260.05 & 924.15 & 1625.70 & 1034.26 & 1859.68 \\
\hline 1977.4 & 835.44 & 1279.95 & 954.35 & 1646.55 & 1053.36 & 1869.85 \\
\hline 1978.1 & 853.40 & 1294.91 & 980.74 & 1666.31 & 1069.09 & 1879.83 \\
\hline 1978.2 & 876.71 & 1315.28 & 1015.10 & 1690.38 & 1103.64 & 1892.41 \\
\hline 1978.3 & 901.09 & 1334.34 & 1047.60 & 1715.34 & 1135.95 & 1907.07 \\
\hline 1978.4 & 927.78 & 1353.85 & 1081.53 & 1741.75 & 1174.35 & 1923.10 \\
\hline 1979.1 & 951.72 & 1370.72 & 1117.44 & 1767.55 & 1213.43 & 1938.96 \\
\hline 1979.2 & 980.36 & 1385.57 & 1154.65 & 1792.12 & 1245.85 & 1955.79 \\
\hline 1979.3 & 1002.64 & 1402.05 & 1191.64 & 1818.00 & 1304.35 & 1974.29 \\
\hline 1979.4 & 1029.38 & 1416.37 & 1232.92 & 1842.17 & 1344.30 & 1994.15 \\
\hline 1980.1 & 1063.05 & 1427.71 & 1271.98 & 1864.28 & 1385.22 & 2013.17 \\
\hline 1980.2 & 1093.77 & 1430.67 & 1320.57 & 1880.64 & 1419.24 & 2031.19 \\
\hline 1980.3 & 1113.64 & 1436.65 & 1366.49 & 1896.85 & 1479.76 & 2048.73 \\
\hline 1980.4 & 1136.93 & 1444.68 & 1394.82 & 1913.88 & 1544.65 & 2067.10 \\
\hline 1981.1 & 1158.19 & 1452.89 & 1447.99 & 1930.19 & 1567.37 & 2086.09 \\
\hline
\end{tabular}




\begin{tabular}{|c|c|c|c|c|c|c|}
\hline 1981.2 & 1190.27 & 1458.12 & 1500.43 & 1946.80 & 1630.42 & 2106.34 \\
\hline 1981.3 & 1216.45 & 1465.54 & 1545.74 & 1964.76 & 1669.94 & 2127.88 \\
\hline 1981.4 & 1242.80 & 1467.62 & 1600.65 & 1981.18 & 1783.60 & 2151.20 \\
\hline 1982.1 & 1261.44 & 1471.21 & 1654.28 & 1992.44 & 1856.57 & 2172.89 \\
\hline 1982.2 & 1287.68 & 1474.64 & 1689.88 & 2001.51 & 1911.71 & 2193.38 \\
\hline 1982.3 & 1304.49 & 1478.42 & 1735.43 & 2009.18 & 1955.94 & 2211.45 \\
\hline 1982.4 & 1322.67 & 1485.28 & 1774.45 & 2015.63 & 2002.67 & 2228.84 \\
\hline 1983.1 & 1341.67 & 1491.61 & 1808.94 & 2017.34 & 2029.54 & 2242.06 \\
\hline 1983.2 & 1357.95 & 1502.85 & 1832.96 & 2021.82 & 2030.56 & 2253.49 \\
\hline 1983.3 & 1381.29 & 1516.41 & 1855.89 & 2029.31 & 2059.55 & 2265.77 \\
\hline 1983.4 & 1408.73 & 1533.93 & 1884.22 & 2042.68 & 2104.95 & 2278.83 \\
\hline 1984.1 & 1427.69 & 1552.31 & 1902.84 & 2055.94 & 2115.23 & 2293.57 \\
\hline 1984.2 & 1456.87 & 1573.06 & 1918.65 & 2072.68 & 2132.28 & 2310.82 \\
\hline 1984.3 & 1484.60 & 1593.47 & 1946.56 & 2091.33 & 2164.42 & 2329.47 \\
\hline 1984.4 & 1511.72 & 1616.40 & 1980.85 & 2111.79 & 2195.15 & 2348.60 \\
\hline 1985.1 & 1543.38 & 1640.31 & 1981.90 & 2129.57 & 2236.85 & 2369.65 \\
\hline 1985.2 & 1569.76 & 1665.29 & 2011.61 & 2148.81 & 2255.76 & 2390.95 \\
\hline 1985.3 & 1599.64 & 1695.77 & 2038.76 & 2167.23 & 2289.61 & 2410.95 \\
\hline 1985.4 & 1634.42 & 1722.06 & 2076.15 & 2186.62 & 2327.18 & 2432.05 \\
\hline 1986.1 & 1658.09 & 1746.79 & 2095.10 & 2202.54 & 2360.94 & 2451.79 \\
\hline 1986.2 & 1689.89 & 1774.41 & 2119.68 & 2219.38 & 2371.01 & 2467.28 \\
\hline 1986.3 & 1739.37 & 1810.25 & 2148.92 & 2235.81 & 2398.86 & 2481.24 \\
\hline 1986.4 & 1780.63 & 1844.25 & 2170.20 & 2252.65 & 2434.73 & 2495.55 \\
\hline 1987.1 & 1817.49 & 1867.43 & 2199.72 & 2265.02 & 2450.63 & 2506.77 \\
\hline 1987.2 & 1854.66 & 1893.99 & 2226.80 & 2279.27 & 2464.55 & 2518.52 \\
\hline 1987.3 & 1898.17 & 1924.19 & 2249.46 & 2296.15 & 2485.40 & 2532.12 \\
\hline 1987.4 & 1931.22 & 1951.15 & 2295.02 & 2312.72 & 2524.90 & 2546.52 \\
\hline 1988.1 & 1958.42 & 1979.34 & 2325.05 & 2329.57 & 2564.70 & 2558.52 \\
\hline 1988.2 & 2000.09 & 2008.04 & 2351.23 & 2349.13 & 2590.35 & 2571.24 \\
\hline 1988.3 & 2045.85 & 2035.95 & 2371.45 & 2369.73 & 2616.04 & 2583.89 \\
\hline 1988.4 & 2096.57 & 2067.72 & 2416.46 & 2390.84 & 2644.76 & 2596.93 \\
\hline 1989.1 & 2138.35 & 2094.26 & 2447.42 & 2406.78 & 2694.34 & 2609.36 \\
\hline 1989.2 & 2179.69 & 2121.97 & 2477.26 & 2423.93 & 2746.10 & 2621.25 \\
\hline 1989.3 & 2226.40 & 2152.29 & 2516.03 & 2439.96 & 2786.48 & 2634.16 \\
\hline 1989.4 & 2267.81 & 2179.15 & 2548.68 & 2454.47 & 2829.74 & 2647.32 \\
\hline 1990.1 & 2309.81 & 2205.73 & 2577.46 & 2471.34 & 2880.15 & 2660.78 \\
\hline 1990.2 & 2335.21 & 2229.10 & 2602.82 & 2487.20 & 2914.85 & 2673.84 \\
\hline 1990.3 & 2363.00 & 2252.62 & 2650.96 & 2504.89 & 2954.73 & 2686.72 \\
\hline 1990.4 & 2397.78 & 2273.85 & 2683.65 & 2521.85 & 2987.15 & 2697.58 \\
\hline 1991.1 & 2424.56 & 2286.29 & 2737.01 & 2530.62 & 3021.99 & 2707.54 \\
\hline 1991.2 & 2443.00 & 2299.10 & 2761.66 & 2539.38 & 3047.95 & 2716.53 \\
\hline 1991.3 & 2466.94 & 2314.56 & 2781.26 & 2549.27 & 3076.70 & 2723.11 \\
\hline 1991.4 & 2488.55 & 2329.75 & 2813.12 & 2558.67 & 3076.91 & 2728.55 \\
\hline
\end{tabular}


Table 3. Quarterly Net Capital Stock, U.S., 1948-91, Linear Interpolation Technique (Method 1)

\begin{tabular}{|c|c|c|c|c|c|c|}
\hline Time & $\mathrm{CDG}$ & CDG87 & PDG & PDG87 & BS & BS87 \\
\hline 1948.1 & 67.36 & 195.62 & 62.97 & 357.53 & 115.51 & 669.90 \\
\hline 1948.2 & 71.83 & 201.35 & 65.92 & 368.35 & 117.77 & 673.20 \\
\hline 1948.3 & 75.96 & 207.08 & 70.84 & 379.18 & 119.97 & 676.50 \\
\hline 1948.4 & 76.30 & 212.80 & 73.40 & 390.00 & 120.20 & 679.80 \\
\hline 1949.1 & 77.64 & 219.10 & 75.26 & 396.73 & 120.08 & 682.88 \\
\hline 1949.2 & 78.38 & 225.40 & 79.60 & 403.45 & 119.25 & 685.95 \\
\hline 1949.3 & 81.92 & 231.70 & 81.10 & 410.18 & 120.40 & 689.03 \\
\hline 1949.4 & 86.60 & 238.00 & 82.20 & 416.90 & 122.90 & 692.10 \\
\hline 1950.1 & 92.79 & 246.48 & 84.27 & 424.52 & 123.64 & 696.12 \\
\hline 1950.2 & 98.77 & 254.95 & 86.68 & 432.15 & 123.63 & 700.15 \\
\hline 1950.3 & 105.13 & 263.43 & 91.02 & 439.77 & 127.73 & 704.18 \\
\hline 1950.4 & 108.20 & 271.90 & 94.60 & 447.40 & 133.90 & 708.20 \\
\hline 1951.1 & 118.53 & 278.02 & 101.40 & 455.12 & 139.82 & 712.25 \\
\hline 1951.2 & 118.48 & 284.15 & 102.84 & 462.85 & 142.88 & 716.30 \\
\hline 1951.3 & 121.47 & 290.27 & 103.76 & 470.58 & 145.87 & 720.35 \\
\hline 1951.4 & 124.40 & 296.40 & 106.80 & 478.30 & 146.70 & 724.40 \\
\hline 1952.1 & 125.24 & 300.73 & 108.29 & 484.72 & 149.84 & 729.83 \\
\hline 1952.2 & 123.43 & 305.05 & 110.66 & 491.15 & 150.86 & 735.25 \\
\hline 1952.3 & 126.05 & 309.38 & 111.22 & 497.57 & 152.58 & 740.67 \\
\hline 1952.4 & 134.00 & 313.70 & 114.50 & 504.00 & 154.30 & 746.10 \\
\hline 1953.1 & 137.21 & 319.10 & 115.90 & 510.65 & 155.14 & 751.90 \\
\hline 1953.2 & 144.11 & 324.50 & 119.65 & 517.30 & 157.44 & 757.70 \\
\hline 1953.3 & 147.90 & 329.90 & 122.49 & 523.95 & 159.73 & 763.50 \\
\hline 1953.4 & 143.00 & 335.30 & 122.90 & 530.60 & 159.80 & 769.30 \\
\hline 1954.1 & 147.44 & 339.32 & 124.73 & 535.05 & 160.00 & 775.47 \\
\hline 1954.2 & 151.96 & 343.35 & 126.57 & 539.50 & 160.15 & 781.65 \\
\hline 1954.3 & 147.53 & 347.37 & 127.39 & 543.95 & 163.35 & 787.82 \\
\hline 1954.4 & 147.10 & 351.40 & 129.20 & 548.40 & 165.80 & 794.00 \\
\hline 1955.1 & 154.82 & 358.08 & 131.62 & 554.45 & 168.16 & 800.90 \\
\hline 1955.2 & 155.69 & 364.75 & 133.51 & 560.50 & 171.26 & 807.80 \\
\hline 1955.3 & 160.71 & 371.42 & 138.49 & 566.55 & 175.13 & 814.70 \\
\hline 1955.4 & 157.30 & 378.10 & 141.40 & 572.60 & 180.60 & 821.60 \\
\hline 1956.1 & 160.58 & 382.45 & 144.63 & 578.95 & 190.02 & 830.42 \\
\hline 1956.2 & 164.26 & 386.80 & 149.40 & 585.30 & 190.39 & 839.25 \\
\hline 1956.3 & 164.09 & 391.15 & 152.48 & 591.65 & 197.24 & 848.08 \\
\hline 1956.4 & 171.90 & 395.50 & 158.20 & 598.00 & 199.90 & 856.90 \\
\hline 1957.1 & 171.90 & 398.85 & 163.43 & 603.70 & 203.15 & 865.30 \\
\hline 1957.2 & 174.29 & 402.20 & 165.88 & 609.40 & 207.25 & 873.70 \\
\hline 1957.3 & 177.65 & 405.55 & 168.30 & 615.10 & 209.65 & 882.10 \\
\hline 1957.4 & 176.20 & 408.90 & 171.80 & 620.80 & 211.20 & 890.50 \\
\hline 1958.1 & 177.53 & 409.98 & 171.15 & 622.33 & 208.22 & 897.33 \\
\hline
\end{tabular}




\begin{tabular}{|c|c|c|c|c|c|c|}
\hline 1958.2 & 176.40 & 411.05 & 172.19 & 623.85 & 211.25 & 904.15 \\
\hline 1958.3 & 180.18 & 412.13 & 175.51 & 625.38 & 214.31 & 910.98 \\
\hline 1958.4 & 182.00 & 413.20 & 177.70 & 626.90 & 217.40 & 917.80 \\
\hline 1959.1 & 186.01 & 416.00 & 180.99 & 630.43 & 218.52 & 925.15 \\
\hline 1959.2 & 187.02 & 418.80 & 183.13 & 633.95 & 221.45 & 932.50 \\
\hline 1959.3 & 189.02 & 421.60 & 185.85 & 637.48 & 223.47 & 939.85 \\
\hline 1959.4 & 189.00 & 424.40 & 186.20 & 641.00 & 225.50 & 947.20 \\
\hline 1960.1 & 191.70 & 427.12 & 189.56 & 644.62 & 229.01 & 955.80 \\
\hline 1960.2 & 191.86 & 429.85 & 190.52 & 648.25 & 229.73 & 964.40 \\
\hline 1960.3 & 193.04 & 432.58 & 192.06 & 651.88 & 231.38 & 973.00 \\
\hline 1960.4 & 193.70 & 435.30 & 192.40 & 655.50 & 231.10 & 981.60 \\
\hline 1961.1 & 192.83 & 436.60 & 191.96 & 658.15 & 232.76 & 990.30 \\
\hline 1961.2 & 196.05 & 437.90 & 193.90 & 660.80 & 234.42 & 999.00 \\
\hline 1961.3 & 197.19 & 439.20 & 195.25 & 663.45 & 237.06 & 1007.70 \\
\hline 1961.4 & 196.80 & 440.50 & 196.00 & 666.10 & 239.70 & 1016.40 \\
\hline 1962.1 & 197.55 & 443.83 & 198.81 & 670.67 & 242.00 & 1025.72 \\
\hline 1962.2 & 199.81 & 447.15 & 198.53 & 675.25 & 244.29 & 1035.05 \\
\hline 1962.3 & 201.06 & 450.48 & 200.70 & 679.83 & 246.58 & 1044.37 \\
\hline 1962.4 & 202.30 & 453.80 & 203.50 & 684.40 & 249.90 & 1053.70 \\
\hline 1963.1 & 204.42 & 458.72 & 205.91 & 690.08 & 252.78 & 1062.80 \\
\hline 1963.2 & 207.56 & 463.65 & 207.68 & 695.75 & 255.68 & 1071.90 \\
\hline 1963.3 & 209.66 & 468.57 & 209.44 & 701.42 & 257.51 & 1081.00 \\
\hline 1963.4 & 212.80 & 473.50 & 212.50 & 707.10 & 260.40 & 1090.10 \\
\hline 1964.1 & 215.39 & 479.92 & 217.02 & 715.35 & 261.42 & 1101.18 \\
\hline 1964.2 & 218.52 & 486.35 & 220.91 & 723.60 & 266.69 & 1112.25 \\
\hline 1964.3 & 221.12 & 492.77 & 223.46 & 731.85 & 268.72 & 1123.32 \\
\hline 1964.4 & 223.70 & 499.20 & 225.30 & 740.10 & 275.10 & 1134.40 \\
\hline 1965.1 & 227.92 & 508.38 & 231.39 & 752.57 & 278.96 & 1148.65 \\
\hline 1965.2 & 229.90 & 517.55 & 235.37 & 765.05 & 284.99 & 1162.90 \\
\hline 1965.3 & 232.43 & 526.72 & 239.33 & 777.52 & 288.73 & 1177.15 \\
\hline 1965.4 & 236.10 & 535.90 & 244.00 & 790.00 & 298.20 & 1191.40 \\
\hline 1966.1 & 240.54 & 546.30 & 249.41 & 805.30 & 302.64 & 1206.40 \\
\hline 1966.2 & 246.73 & 556.70 & 256.28 & 820.60 & 314.13 & 1221.40 \\
\hline 1966.3 & 252.92 & 567.10 & 263.11 & 835.90 & 318.48 & 1236.40 \\
\hline 1966.4 & 258.50 & 577.50 & 272.30 & 851.20 & 326.40 & 1251.40 \\
\hline 1967.1 & 262.02 & 586.67 & 278.42 & 864.42 & 331.88 & 1265.03 \\
\hline 1967.2 & 267.37 & 595.85 & 284.52 & 877.65 & 336.08 & 1278.65 \\
\hline 1967.3 & 274.62 & 605.02 & 291.40 & 890.87 & 341.49 & 1292.28 \\
\hline 1967.4 & 283.20 & 614.20 & 300.00 & 904.10 & 349.40 & 1305.90 \\
\hline 1968.1 & 290.64 & 625.83 & 307.28 & 918.07 & 358.70 & 1319.50 \\
\hline 1968.2 & 297.37 & 637.45 & 315.41 & 932.05 & 366.59 & 1333.10 \\
\hline 1968.3 & 306.13 & 649.08 & 323.51 & 946.02 & 374.36 & 1346.70 \\
\hline 1968.4 & 314.20 & 660.70 & 330.70 & 960.00 & 388.60 & 1360.30 \\
\hline 1969.1 & 321.06 & 671.47 & 336.64 & 975.25 & 399.34 & 1374.80 \\
\hline 1969.2 & 330.07 & 682.25 & 345.25 & 990.50 & 411.32 & 1389.30 \\
\hline 1969.3 & 336.16 & 693.03 & 353.81 & 1005.75 & 421.84 & 1403.80 \\
\hline
\end{tabular}




\begin{tabular}{|c|c|c|c|c|c|c|}
\hline 1969.4 & 343.70 & 703.80 & 361.40 & 1021.00 & 435.00 & 1418.30 \\
\hline 1970.1 & 350.73 & 711.05 & 371.81 & 1033.38 & 445.32 & 1432.00 \\
\hline 1970.2 & 355.41 & 718.30 & 381.27 & 1045.75 & 464.01 & 1445.70 \\
\hline 1970.3 & 361.56 & 725.55 & 385.82 & 1058.12 & 471.24 & 1459.40 \\
\hline 1970.4 & 372.40 & 732.80 & 396.20 & 1070.50 & 482.60 & 1473.10 \\
\hline 1971.1 & 383.11 & 742.38 & 407.68 & 1080.88 & 497.79 & 1485.70 \\
\hline 1971.2 & 389.08 & 751.95 & 418.09 & 1091.25 & 514.24 & 1498.30 \\
\hline 1971.3 & 391.02 & 761.53 & 423.41 & 1101.62 & 529.02 & 1510.90 \\
\hline 1971.4 & 393.70 & 771.10 & 425.60 & 1112.00 & 542.10 & 1523.50 \\
\hline 1972.1 & 404.16 & 783.72 & 437.63 & 1125.32 & 564.00 & 1535.22 \\
\hline 1972.2 & 412.16 & 796.35 & 444.58 & 1138.65 & 579.65 & 1546.95 \\
\hline 1972.3 & 421.01 & 808.97 & 453.61 & 1151.97 & 598.17 & 1558.67 \\
\hline 1972.4 & 424.70 & 821.60 & 458.30 & 1165.30 & 618.10 & 1570.40 \\
\hline 1973.1 & 435.31 & 837.17 & 470.27 & 1185.93 & 636.79 & 1584.32 \\
\hline 1973.2 & 448.55 & 852.75 & 485.57 & 1206.55 & 658.34 & 1598.25 \\
\hline 1973.3 & 460.00 & 868.33 & 499.73 & 1227.18 & 686.17 & 1612.18 \\
\hline 1973.4 & 470.50 & 883.90 & 512.70 & 1247.80 & 710.40 & 1626.10 \\
\hline 1974.1 & 483.47 & 893.08 & 531.49 & 1267.18 & 729.15 & 1638.43 \\
\hline 1974.2 & 498.78 & 902.25 & 554.04 & 1286.55 & 760.23 & 1650.75 \\
\hline 1974.3 & 521.20 & 911.42 & 595.67 & 1305.93 & 793.51 & 1663.07 \\
\hline 1974.4 & 544.20 & 920.60 & 635.60 & 1325.30 & 823.90 & 1675.40 \\
\hline 1975.1 & 556.04 & 928.27 & 673.36 & 1335.62 & 855.13 & 1684.35 \\
\hline 1975.2 & 573.57 & 935.95 & 699.25 & 1345.95 & 876.08 & 1693.30 \\
\hline 1975.3 & 583.25 & 943.62 & 715.53 & 1356.27 & 889.96 & 1702.25 \\
\hline 1975.4 & 595.70 & 951.30 & 731.20 & 1366.60 & 906.90 & 1711.20 \\
\hline 1976.1 & 608.65 & 963.47 & 750.24 & 1377.03 & 915.68 & 1719.35 \\
\hline 1976.2 & 622.47 & 975.65 & 769.01 & 1387.45 & 939.75 & 1727.50 \\
\hline 1976.3 & 637.19 & 987.82 & 784.83 & 1397.88 & 960.22 & 1735.65 \\
\hline 1976.4 & 652.80 & 1000.00 & 805.70 & 1408.30 & 978.80 & 1743.80 \\
\hline 1977.1 & 669.76 & 1015.25 & 825.10 & 1424.45 & 1001.88 & 1752.60 \\
\hline 1977.2 & 686.63 & 1030.50 & 851.04 & 1440.60 & 1029.75 & 1761.40 \\
\hline 1977.3 & 704.46 & 1045.75 & 875.39 & 1456.75 & 1057.15 & 1770.20 \\
\hline 1977.4 & 725.50 & 1061.00 & 900.90 & 1472.90 & 1080.50 & 1779.00 \\
\hline 1978.1 & 746.57 & 1077.60 & 930.60 & 1493.85 & 1105.17 & 1791.95 \\
\hline 1978.2 & 768.54 & 1094.20 & 964.28 & 1514.80 & 1146.80 & 1804.90 \\
\hline 1978.3 & 791.39 & 1110.80 & 994.77 & 1535.75 & 1184.07 & 1817.85 \\
\hline 1978.4 & 815.20 & 1127.40 & 1024.90 & 1556.70 & 1225.90 & 1830.80 \\
\hline 1979.1 & 841.73 & 1141.03 & 1062.57 & 1579.07 & 1270.20 & 1847.33 \\
\hline 1979.2 & 872.71 & 1154.65 & 1101.21 & 1601.45 & 1306.30 & 1863.85 \\
\hline 1979.3 & 896.32 & 1168.28 & 1137.77 & 1623.82 & 1367.35 & 1880.38 \\
\hline 1979.4 & 924.40 & 1181.90 & 1178.40 & 1646.20 & 1407.20 & 1896.90 \\
\hline 1980.1 & 951.55 & 1187.18 & 1221.53 & 1661.95 & 1450.35 & 1914.75 \\
\hline 1980.2 & 980.67 & 1192.45 & 1276.50 & 1677.70 & 1486.38 & 1932.60 \\
\hline 1980.3 & 997.12 & 1197.73 & 1327.50 & 1693.45 & 1549.26 & 1950.45 \\
\hline 1980.4 & 1014.30 & 1203.00 & 1359.80 & 1709.20 & 1614.50 & 1968.30 \\
\hline 1981.1 & 1027.17 & 1207.93 & 1408.55 & 1722.65 & 1632.86 & 1988.12 \\
\hline
\end{tabular}




\begin{tabular}{|c|c|c|c|c|c|c|}
\hline 1981.2 & 1050.77 & 1212.85 & 1455.11 & 1736.10 & 1690.47 & 2007.95 \\
\hline 1981.3 & 1066.78 & 1217.78 & 1492.69 & 1749.55 & 1721.42 & 2027.77 \\
\hline 1981.4 & 1086.20 & 1222.70 & 1539.60 & 1763.00 & 1823.80 & 2047.60 \\
\hline 1982.1 & 1098.12 & 1226.07 & 1571.75 & 1767.78 & 1871.38 & 2065.32 \\
\hline 1982.2 & 1116.21 & 1229.45 & 1588.51 & 1772.55 & 1902.32 & 2083.05 \\
\hline 1982.3 & 1125.61 & 1232.82 & 1615.44 & 1777.33 & 1925.33 & 2100.78 \\
\hline 1982.4 & 1133.70 & 1236.20 & 1637.10 & 1782.10 & 1951.90 & 2118.50 \\
\hline 1983.1 & 1151.65 & 1246.62 & 1660.70 & 1787.68 & 1968.91 & 2130.32 \\
\hline 1983.2 & 1163.24 & 1257.05 & 1672.07 & 1793.25 & 1963.17 & 2142.15 \\
\hline 1983.3 & 1178.56 & 1267.48 & 1679.86 & 1798.82 & 1983.88 & 2153.97 \\
\hline 1983.4 & 1193.80 & 1277.90 & 1687.60 & 1804.40 & 2019.50 & 2165.80 \\
\hline 1984.1 & 1212.17 & 1296.40 & 1705.78 & 1818.85 & 2039.06 & 2183.02 \\
\hline 1984.2 & 1237.01 & 1314.90 & 1718.49 & 1833.30 & 2062.74 & 2200.25 \\
\hline 1984.3 & 1260.60 & 1333.40 & 1740.20 & 1847.75 & 2099.33 & 2217.48 \\
\hline 1984.4 & 1281.50 & 1351.90 & 1765.60 & 1862.20 & 2133.80 & 2234.70 \\
\hline 1985.1 & 1312.04 & 1374.50 & 1768.10 & 1878.90 & 2173.91 & 2255.75 \\
\hline 1985.2 & 1337.04 & 1397.10 & 1794.61 & 1895.60 & 2191.73 & 2276.80 \\
\hline 1985.3 & 1360.52 & 1419.70 & 1819.33 & 1912.30 & 2225.11 & 2297.85 \\
\hline 1985.4 & 1391.10 & 1442.30 & 1851.80 & 1929.00 & 2260.80 & 2318.90 \\
\hline 1986.1 & 1419.71 & 1468.58 & 1878.27 & 1943.32 & 2286.90 & 2332.97 \\
\hline 1986.2 & 1452.59 & 1494.85 & 1908.48 & 1957.65 & 2294.34 & 2347.05 \\
\hline 1986.3 & 1493.07 & 1521.13 & 1942.52 & 1971.97 & 2320.37 & 2361.12 \\
\hline 1986.4 & 1527.50 & 1547.40 & 1968.60 & 1986.30 & 2353.60 & 2375.20 \\
\hline 1987.1 & 1563.82 & 1570.30 & 1990.74 & 1998.25 & 2376.24 & 2387.15 \\
\hline 1987.2 & 1596.92 & 1593.20 & 2008.87 & 2010.20 & 2396.33 & 2399.10 \\
\hline 1987.3 & 1631.53 & 1616.10 & 2020.84 & 2022.15 & 2421.11 & 2411.05 \\
\hline 1987.4 & 1659.50 & 1639.00 & 2053.10 & 2034.10 & 2462.80 & 2423.00 \\
\hline 1988.1 & 1686.34 & 1663.85 & 2085.98 & 2048.57 & 2517.17 & 2434.70 \\
\hline 1988.2 & 1724.70 & 1688.70 & 2112.60 & 2063.05 & 2556.52 & 2446.40 \\
\hline 1988.3 & 1766.49 & 1713.55 & 2132.79 & 2077.53 & 2595.44 & 2458.10 \\
\hline 1988.4 & 1808.40 & 1738.40 & 2173.90 & 2092.00 & 2636.41 & 2469.80 \\
\hline 1989.1 & 1839.64 & 1761.50 & 2203.49 & 2107.73 & 2677.75 & 2481.85 \\
\hline 1989.2 & 1869.07 & 1784.60 & 2230.87 & 2123.45 & 2721.44 & 2493.90 \\
\hline 1989.3 & 1900.27 & 1807.70 & 2266.91 & 2139.18 & 2752.39 & 2505.95 \\
\hline 1989.4 & 1929.60 & 1830.80 & 2298.61 & 2154.90 & 2785.59 & 2518.00 \\
\hline 1990.1 & 1960.48 & 1848.88 & 2330.06 & 2167.25 & 2823.15 & 2530.57 \\
\hline 1990.2 & 1980.18 & 1866.95 & 2359.13 & 2179.60 & 2845.33 & 2543.15 \\
\hline 1990.3 & 2001.66 & 1885.02 & 2406.28 & 2191.95 & 2872.45 & 2555.72 \\
\hline 1990.4 & 2030.70 & 1903.10 & 2439.80 & 2204.30 & 2894.30 & 2568.30 \\
\hline 1991.1 & 2059.05 & 1912.32 & 2469.41 & 2210.73 & 2918.92 & 2574.98 \\
\hline 1991.2 & 2079.68 & 1921.55 & 2473.54 & 2217.15 & 2935.90 & 2581.65 \\
\hline 1991.3 & 2102.19 & 1930.77 & 2472.83 & 2223.58 & 2958.06 & 2588.33 \\
\hline 1991.4 & 2122.70 & 1940.00 & 2483.80 & 2230.00 & 2954.31 & 2595.00 \\
\hline
\end{tabular}


Table 4. Quarterly Net Capital Stock, U.S., 1948-91, Numerical Iteration Technique (Method 2)

\begin{tabular}{|c|c|c|c|c|c|c|}
\hline Time & CDG & CDG87 & PDG & PDG87 & BS & BS87 \\
\hline 1948.1 & 67.32 & 195.84 & 63.06 & 358.98 & 115.33 & 669.43 \\
\hline 1948.2 & 71.74 & 201.30 & 65.90 & 369.67 & 117.54 & 672.57 \\
\hline 1948.3 & 76.03 & 207.08 & 70.74 & 379.61 & 119.84 & 676.08 \\
\hline 1948.4 & 76.30 & 212.80 & 73.40 & 390.00 & 120.20 & 679.80 \\
\hline 1949.1 & 77.24 & 217.93 & 75.60 & 398.79 & 120.22 & 683.52 \\
\hline 1949.2 & 78.01 & 224.73 & 80.06 & 405.82 & 119.46 & 686.91 \\
\hline 1949.3 & 81.68 & 231.50 & 81.39 & 411.58 & 120.53 & 689.70 \\
\hline 1949.4 & 86.60 & 238.00 & 82.20 & 416.90 & 122.90 & 692.10 \\
\hline 1950.1 & 92.21 & 244.80 & 83.67 & 422.22 & 123.41 & 695.28 \\
\hline 1950.2 & 97.59 & 251.45 & 85.93 & 429.54 & 123.30 & 699.04 \\
\hline 1950.3 & 105.14 & 263.28 & 90.64 & 438.66 & 127.48 & 703.48 \\
\hline 1950.4 & 108.20 & 271.90 & 94.60 & 447.40 & 133.90 & 708.20 \\
\hline 1951.1 & 119.78 & 281.30 & 101.37 & 454.74 & 139.68 & 712.16 \\
\hline 1951.2 & 119.49 & 287.04 & 102.80 & 462.32 & 142.81 & 716.54 \\
\hline 1951.3 & 122.02 & 291.88 & 103.77 & 470.46 & 145.89 & 720.77 \\
\hline 1951.4 & 124.40 & 296.40 & 106.80 & 478.30 & 146.70 & 724.40 \\
\hline 1952.1 & 125.29 & 300.92 & 108.54 & 486.04 & 149.81 & 729.63 \\
\hline 1952.2 & 123.48 & 305.78 & 111.22 & 493.71 & 150.80 & 734.92 \\
\hline 1952.3 & 125.63 & 308.89 & 111.24 & 498.01 & 152.51 & 740.27 \\
\hline 1952.4 & 134.00 & 313.70 & 114.50 & 504.00 & 154.30 & 746.10 \\
\hline 1953.1 & 137.45 & 319.55 & 115.93 & 510.91 & 155.04 & 751.70 \\
\hline 1953.2 & 144.46 & 324.67 & 119.66 & 517.40 & 157.34 & 757.50 \\
\hline 1953.3 & 148.21 & 329.55 & 122.61 & 524.32 & 159.65 & 763.30 \\
\hline 1953.4 & 143.00 & 335.30 & 122.90 & 530.60 & 159.80 & 769.30 \\
\hline 1954.1 & 147.34 & 339.00 & 124.75 & 535.31 & 160.03 & 775.57 \\
\hline 1954.2 & 151.87 & 342.42 & 126.51 & 539.50 & 160.20 & 781.85 \\
\hline 1954.3 & 147.30 & 346.22 & 127.39 & 544.19 & 163.40 & 788.00 \\
\hline 1954.4 & 147.10 & 351.40 & 129.20 & 548.40 & 165.80 & 794.00 \\
\hline 1955.1 & 154.38 & 357.01 & 131.03 & 552.26 & 167.95 & 800.36 \\
\hline 1955.2 & 155.31 & 364.02 & 132.76 & 557.93 & 170.95 & 807.04 \\
\hline 1955.3 & 160.72 & 371.20 & 137.97 & 564.81 & 174.88 & 814.15 \\
\hline 1955.4 & 157.30 & 378.10 & 141.40 & 572.60 & 180.60 & 821.60 \\
\hline 1956.1 & 160.71 & 383.37 & 144.50 & 579.23 & 189.81 & 830.03 \\
\hline 1956.2 & 164.40 & 387.82 & 149.20 & 585.48 & 190.14 & 839.02 \\
\hline 1956.3 & 164.02 & 391.83 & 152.36 & 592.05 & 197.10 & 848.03 \\
\hline 1956.4 & 171.90 & 395.50 & 158.20 & 598.00 & 199.90 & 856.90 \\
\hline 1957.1 & 172.16 & 399.89 & 163.46 & 603.95 & 203.16 & 865.49 \\
\hline 1957.2 & 174.61 & 403.45 & 165.84 & 609.48 & 207.28 & 873.97 \\
\hline 1957.3 & 177.88 & 406.17 & 168.41 & 615.67 & 209.72 & 882.35 \\
\hline 1957.4 & 176.20 & 408.90 & 171.80 & 620.80 & 211.20 & 890.50 \\
\hline 1958.1 & 177.60 & 409.93 & 171.36 & 623.10 & 208.35 & 898.04 \\
\hline
\end{tabular}




\begin{tabular}{|c|c|c|c|c|c|c|}
\hline 1958.2 & 176.28 & 410.70 & 172.30 & 624.36 & 211.39 & 904.89 \\
\hline 1958.3 & 179.99 & 411.55 & 175.41 & 625.18 & 214.35 & 911.25 \\
\hline 1958.4 & 182.00 & 413.20 & 177.70 & 626.90 & 217.40 & 917.80 \\
\hline 1959.1 & 185.84 & 415.64 & 180.77 & 629.66 & 218.38 & 924.60 \\
\hline 1959.2 & 187.05 & 419.00 & 182.87 & 633.02 & 221.28 & 931.86 \\
\hline 1959.3 & 189.37 & 422.51 & 185.76 & 637.02 & 223.42 & 939.64 \\
\hline 1959.4 & 189.00 & 424.40 & 186.20 & 641.00 & 225.50 & 947.20 \\
\hline 1960.1 & 191.76 & 427.18 & 189.76 & 645.37 & 229.00 & 955.54 \\
\hline 1960.2 & 192.16 & 430.56 & 191.00 & 649.95 & 229.71 & 964.00 \\
\hline 1960.3 & 193.36 & 433.39 & 192.47 & 653.23 & 231.31 & 972.44 \\
\hline 1960.4 & 193.70 & 435.30 & 192.40 & 655.50 & 231.10 & 981.60 \\
\hline 1961.1 & 192.39 & 436.00 & 191.64 & 657.16 & 232.85 & 990.76 \\
\hline 1961.2 & 195.40 & 436.78 & 193.54 & 659.61 & 234.50 & 999.46 \\
\hline 1961.3 & 196.64 & 438.04 & 194.87 & 662.22 & 237.12 & 1008.03 \\
\hline 1961.4 & 196.80 & 440.50 & 196.00 & 666.10 & 239.70 & 1016.40 \\
\hline 1962.1 & 197.21 & 443.21 & 198.73 & 670.42 & 241.85 & 1025.13 \\
\hline 1962.2 & 199.40 & 446.35 & 198.52 & 675.33 & 244.16 & 1034.56 \\
\hline 1962.3 & 200.64 & 449.56 & 200.73 & 680.02 & 246.59 & 1044.48 \\
\hline 1962.4 & 202.30 & 453.80 & 203.50 & 684.40 & 249.90 & 1053.70 \\
\hline 1963.1 & 204.20 & 458.40 & 205.64 & 689.06 & 252.58 & 1062.06 \\
\hline 1963.2 & 207.34 & 463.32 & 207.22 & 694.10 & 255.50 & 1071.26 \\
\hline 1963.3 & 209.48 & 468.35 & 209.09 & 700.19 & 257.38 & 1080.54 \\
\hline 1963.4 & 212.80 & 473.50 & 212.50 & 707.10 & 260.40 & 1090.10 \\
\hline 1964.1 & 215.25 & 479.80 & 216.78 & 714.52 & 261.13 & 1100.32 \\
\hline 1964.2 & 218.44 & 486.42 & 220.55 & 722.25 & 266.34 & 1111.20 \\
\hline 1964.3 & 221.41 & 493.70 & 223.20 & 730.78 & 268.50 & 1122.78 \\
\hline 1964.4 & 223.70 & 499.20 & 225.30 & 740.10 & 275.10 & 1134.40 \\
\hline 1965.1 & 227.82 & 508.15 & 231.01 & 751.39 & 278.44 & 1147.04 \\
\hline 1965.2 & 229.49 & 516.64 & 234.69 & 762.90 & 284.47 & 1161.35 \\
\hline 1965.3 & 232.02 & 525.85 & 238.85 & 776.04 & 288.26 & 1175.80 \\
\hline 1965.4 & 236.10 & 535.90 & 244.00 & 790.00 & 298.20 & 1191.40 \\
\hline 1966.1 & 241.11 & 548.20 & 249.19 & 805.18 & 302.60 & 1207.08 \\
\hline 1966.2 & 246.92 & 557.82 & 256.15 & 820.97 & 314.07 & 1221.94 \\
\hline 1966.3 & 253.12 & 567.99 & 263.00 & 836.24 & 318.54 & 1237.28 \\
\hline 1966.4 & 258.50 & 577.50 & 272.30 & 851.20 & 326.40 & 1251.40 \\
\hline 1967.1 & 261.72 & 586.35 & 278.41 & 864.58 & 331.98 & 1265.76 \\
\hline 1967.2 & 267.34 & 596.52 & 284.56 & 878.13 & 336.04 & 1279.08 \\
\hline 1967.3 & 274.63 & 605.65 & 291.25 & 890.75 & 341.43 & 1292.56 \\
\hline 1967.4 & 283.20 & 614.20 & 300.00 & 904.10 & 349.40 & 1305.90 \\
\hline 1968.1 & 290.19 & 625.17 & 307.30 & 918.72 & 358.53 & 1319.90 \\
\hline 1968.2 & 296.68 & 636.50 & 315.04 & 931.77 & 366.31 & 1333.51 \\
\hline 1968.3 & 305.93 & 649.06 & 323.08 & 945.29 & 374.00 & 1346.68 \\
\hline 1968.4 & 314.20 & 660.70 & 330.70 & 960.00 & 388.60 & 1360.30 \\
\hline 1969.1 & 321.45 & 672.71 & 336.56 & 975.94 & 398.77 & 1374.21 \\
\hline 1969.2 & 330.61 & 683.79 & 345.15 & 991.36 & 410.47 & 1388.21 \\
\hline 1969.3 & 336.57 & 694.19 & 353.85 & 1006.66 & 421.32 & 1403.47 \\
\hline
\end{tabular}




\begin{tabular}{|c|c|c|c|c|c|c|}
\hline 1969.4 & 343.70 & 703.80 & 361.40 & 1021.00 & 435.00 & 1418.30 \\
\hline 1970.1 & 351.14 & 712.09 & 372.09 & 1034.31 & 445.05 & 1432.63 \\
\hline 1970.2 & 356.24 & 720.46 & 381.73 & 1047.04 & 463.70 & 1446.35 \\
\hline 1970.3 & 362.72 & 728.60 & 386.48 & 1060.11 & 471.04 & 1460.00 \\
\hline 1970.4 & 372.40 & 732.80 & 396.20 & 1070.50 & 482.60 & 1473.10 \\
\hline 1971.1 & 382.43 & 740.99 & 407.34 & 1080.73 & 497.31 & 1486.03 \\
\hline 1971.2 & 388.20 & 749.93 & 417.78 & 1091.10 & 513.61 & 1498.71 \\
\hline 1971.3 & 390.24 & 759.76 & 423.07 & 1101.09 & 528.56 & 1511.22 \\
\hline 1971.4 & 393.70 & 771.10 & 425.60 & 1112.00 & 542.10 & 1523.50 \\
\hline 1972.1 & 403.33 & 782.37 & 436.92 & 1123.16 & 563.30 & 1535.17 \\
\hline 1972.2 & 410.96 & 794.27 & 443.47 & 1135.40 & 578.69 & 1546.88 \\
\hline 1972.3 & 419.89 & 806.70 & 452.41 & 1148.57 & 597.36 & 1558.48 \\
\hline 1972.4 & 424.70 & 821.60 & 458.30 & 1165.30 & 618.10 & 1570.40 \\
\hline 1973.1 & 436.52 & 840.28 & 469.42 & 1184.60 & 635.41 & 1583.52 \\
\hline 1973.2 & 450.14 & 856.64 & 484.81 & 1205.68 & 656.57 & 1597.48 \\
\hline 1973.3 & 461.38 & 871.54 & 499.28 & 1226.75 & 684.99 & 1612.02 \\
\hline 1973.4 & 470.50 & 883.90 & 512.70 & 1247.80 & 710.40 & 1626.10 \\
\hline 1974.1 & 483.30 & 894.87 & 530.08 & 1269.01 & 727.89 & 1639.58 \\
\hline 1974.2 & 498.99 & 905.91 & 552.04 & 1289.57 & 758.73 & 1652.79 \\
\hline 1974.3 & 522.82 & 916.82 & 594.44 & 1308.91 & 792.29 & 1664.35 \\
\hline 1974.4 & 544.20 & 920.60 & 635.60 & 1325.30 & 823.90 & 1675.40 \\
\hline 1975.1 & 554.10 & 925.71 & 672.75 & 1336.26 & 855.01 & 1685.32 \\
\hline 1975.2 & 570.54 & 931.52 & 698.19 & 1345.99 & 875.67 & 1693.94 \\
\hline 1975.3 & 581.17 & 940.73 & 714.63 & 1356.07 & 889.60 & 1702.64 \\
\hline 1975.4 & 595.70 & 951.30 & 731.20 & 1366.60 & 906.90 & 1711.20 \\
\hline 1976.1 & 608.32 & 963.86 & 749.09 & 1376.20 & 915.18 & 1719.50 \\
\hline 1976.2 & 621.80 & 975.84 & 767.27 & 1386.00 & 939.03 & 1727.52 \\
\hline 1976.3 & 636.42 & 987.64 & 783.41 & 1396.74 & 959.71 & 1735.69 \\
\hline 1976.4 & 652.80 & 1000.00 & 805.70 & 1408.30 & 978.80 & 1743.80 \\
\hline 1977.1 & 668.98 & 1014.53 & 823.26 & 1422.95 & 1000.43 & 1751.77 \\
\hline 1977.2 & 685.63 & 1029.74 & 848.42 & 1438.44 & 1027.97 & 1760.59 \\
\hline 1977.3 & 703.60 & 1045.13 & 873.04 & 1454.55 & 1055.89 & 1769.74 \\
\hline 1977.4 & 725.50 & 1061.00 & 900.90 & 1472.90 & 1080.50 & 1779.00 \\
\hline 1978.1 & 744.20 & 1075.40 & 927.23 & 1490.69 & 1101.45 & 1788.80 \\
\hline 1978.2 & 767.38 & 1094.40 & 960.89 & 1512.27 & 1142.00 & 1801.13 \\
\hline 1978.3 & 790.63 & 1111.11 & 992.41 & 1534.10 & 1180.59 & 1815.37 \\
\hline 1978.4 & 815.20 & 1127.40 & 1024.90 & 1556.70 & 1225.90 & 1830.80 \\
\hline 1979.1 & 842.40 & 1143.36 & 1062.12 & 1580.88 & 1266.95 & 1845.72 \\
\hline 1979.2 & 872.90 & 1156.53 & 1100.07 & 1603.04 & 1301.54 & 1861.43 \\
\hline 1979.3 & 897.13 & 1170.65 & 1137.43 & 1625.82 & 1363.82 & 1878.60 \\
\hline 1979.4 & 924.40 & 1181.90 & 1178.40 & 1646.20 & 1407.20 & 1896.90 \\
\hline 1980.1 & 954.19 & 1191.87 & 1222.84 & 1666.91 & 1448.58 & 1915.92 \\
\hline 1980.2 & 980.00 & 1192.99 & 1276.13 & 1681.27 & 1483.36 & 1933.65 \\
\hline 1980.3 & 995.82 & 1197.07 & 1326.65 & 1695.03 & 1546.39 & 1950.67 \\
\hline 1980.4 & 1014.30 & 1203.00 & 1359.80 & 1709.20 & 1614.50 & 1968.30 \\
\hline 1981.1 & 1028.80 & 1210.88 & 1407.08 & 1722.84 & 1628.14 & 1986.46 \\
\hline
\end{tabular}




\begin{tabular}{|c|c|c|c|c|c|c|}
\hline 1981.2 & 1051.99 & 1215.40 & 1453.19 & 1736.28 & 1683.96 & 2005.64 \\
\hline 1981.3 & 1069.62 & 1221.88 & 1492.00 & 1750.64 & 1715.77 & 2025.86 \\
\hline 1981.4 & 1086.20 & 1222.70 & 1539.60 & 1763.00 & 1823.80 & 2047.60 \\
\hline 1982.1 & 1097.45 & 1225.46 & 1574.64 & 1770.72 & 1874.44 & 2067.99 \\
\hline 1982.2 & 1114.89 & 1227.91 & 1591.79 & 1776.01 & 1906.79 & 2086.91 \\
\hline 1982.3 & 1123.72 & 1230.59 & 1617.76 & 1779.73 & 1928.13 & 2103.15 \\
\hline 1982.4 & 1133.70 & 1236.20 & 1637.10 & 1782.10 & 1951.90 & 2118.50 \\
\hline 1983.1 & 1146.55 & 1241.38 & 1656.16 & 1782.69 & 1970.42 & 2131.24 \\
\hline 1983.2 & 1157.35 & 1251.22 & 1665.62 & 1786.12 & 1963.62 & 2142.08 \\
\hline 1983.3 & 1173.90 & 1262.89 & 1674.06 & 1792.43 & 1983.78 & 2153.63 \\
\hline 1983.4 & 1193.80 & 1277.90 & 1687.60 & 1804.40 & 2019.50 & 2165.80 \\
\hline 1984.1 & 1211.11 & 1295.56 & 1702.59 & 1815.56 & 2036.42 & 2180.67 \\
\hline 1984.2 & 1236.47 & 1314.68 & 1714.86 & 1829.73 & 2059.76 & 2197.81 \\
\hline 1984.3 & 1259.55 & 1332.48 & 1737.60 & 1845.32 & 2097.54 & 2216.14 \\
\hline 1984.4 & 1281.50 & 1351.90 & 1765.60 & 1862.20 & 2133.80 & 2234.70 \\
\hline 1985.1 & 1311.23 & 1373.70 & 1767.73 & 1878.82 & 2174.41 & 2256.34 \\
\hline 1985.2 & 1335.40 & 1395.47 & 1794.88 & 1896.36 & 2192.56 & 2277.95 \\
\hline 1985.3 & 1362.13 & 1421.65 & 1819.02 & 1912.47 & 2224.97 & 2298.00 \\
\hline 1985.4 & 1391.10 & 1442.30 & 1851.80 & 1929.00 & 2260.80 & 2318.90 \\
\hline 1986.1 & 1415.38 & 1464.64 & 1877.88 & 1943.49 & 2291.10 & 2337.10 \\
\hline 1986.2 & 1445.71 & 1488.68 & 1908.44 & 1958.39 & 2298.07 & 2350.87 \\
\hline 1986.3 & 1491.07 & 1519.75 & 1942.46 & 1972.39 & 2322.04 & 2362.94 \\
\hline 1986.4 & 1527.50 & 1547.40 & 1968.60 & 1986.30 & 2353.60 & 2375.20 \\
\hline 1987.1 & 1561.20 & 1568.39 & 1988.86 & 1996.14 & 2374.69 & 2385.88 \\
\hline 1987.2 & 1594.50 & 1591.77 & 2006.51 & 2007.57 & 2393.66 & 2396.91 \\
\hline 1987.3 & 1632.47 & 1617.65 & 2019.85 & 2021.22 & 2419.21 & 2409.64 \\
\hline 1987.4 & 1659.50 & 1639.00 & 2053.10 & 2034.10 & 2462.80 & 2423.00 \\
\hline 1988.1 & 1686.61 & 1664.78 & 2083.95 & 2046.66 & 2515.87 & 2434.34 \\
\hline 1988.2 & 1724.73 & 1689.75 & 2110.85 & 2061.46 & 2555.10 & 2446.23 \\
\hline 1988.3 & 1764.84 & 1712.71 & 2131.60 & 2076.74 & 2594.29 & 2457.89 \\
\hline 1988.4 & 1808.40 & 1738.40 & 2173.90 & 2092.00 & 2636.41 & 2469.80 \\
\hline 1989.1 & 1839.60 & 1761.87 & 2204.49 & 2108.60 & 2677.20 & 2481.94 \\
\hline 1989.2 & 1869.31 & 1785.45 & 2233.33 & 2125.88 & 2720.03 & 2493.34 \\
\hline 1989.3 & 1902.69 & 1810.46 & 2269.23 & 2141.43 & 2751.45 & 2505.63 \\
\hline 1989.4 & 1929.60 & 1830.80 & 2298.61 & 2154.90 & 2785.59 & 2518.00 \\
\hline 1990.1 & 1965.32 & 1853.32 & 2330.79 & 2168.01 & 2823.99 & 2531.67 \\
\hline 1990.2 & 1985.00 & 1871.47 & 2358.75 & 2179.57 & 2846.70 & 2544.84 \\
\hline 1990.3 & 2005.60 & 1888.87 & 2406.76 & 2192.54 & 2874.26 & 2557.66 \\
\hline 1990.4 & 2030.70 & 1903.10 & 2439.80 & 2204.30 & 2894.30 & 2568.30 \\
\hline 1991.1 & 2058.32 & 1911.41 & 2470.32 & 2210.61 & 2921.60 & 2577.33 \\
\hline 1991.2 & 2078.02 & 1919.73 & 2474.43 & 2216.71 & 2940.11 & 2585.30 \\
\hline 1991.3 & 2101.88 & 1930.27 & 2473.85 & 2223.74 & 2961.04 & 2590.76 \\
\hline 1991.4 & 2122.70 & 1940.00 & 2483.80 & 2230.00 & 2954.31 & 2595.00 \\
\hline
\end{tabular}


Table 5. Quarterly Net Capital Stock, U.S., 1948-91, Interpolated Depreciation Technique (Method 3)

\begin{tabular}{|c|c|c|c|c|c|c|}
\hline Time & CDG & CDG87 & PDG & PDG87 & BS & BS87 \\
\hline 1948.1 & 67.73 & 196.24 & 63.36 & 359.16 & 117.38 & 668.88 \\
\hline 1948.2 & 72.51 & 202.17 & 66.43 & 370.15 & 120.96 & 671.68 \\
\hline 1948.3 & 77.08 & 208.43 & 71.45 & 380.47 & 123.95 & 675.06 \\
\hline 1948.4 & 77.49 & 214.68 & 74.18 & 391.30 & 124.26 & 678.84 \\
\hline 1949.1 & 77.66 & 218.43 & 75.99 & 399.15 & 121.18 & 683.40 \\
\hline 1949.2 & 78.72 & 225.68 & 80.75 & 406.56 & 121.05 & 686.74 \\
\hline 1949.3 & 82.64 & 232.99 & 82.26 & 412.66 & 122.45 & 689.55 \\
\hline 1949.4 & 87.76 & 240.09 & 83.13 & 418.26 & 124.87 & 692.02 \\
\hline 1950.1 & 90.96 & 245.27 & 83.32 & 422.58 & 122.04 & 695.12 \\
\hline 1950.2 & 95.55 & 252.42 & 85.37 & 430.21 & 121.05 & 698.80 \\
\hline 1950.3 & 102.78 & 264.76 & 90.00 & 439.61 & 124.74 & 703.22 \\
\hline 1950.4 & 106.09 & 274.24 & 94.02 & 448.68 & 131.09 & 708.03 \\
\hline 1951.1 & 120.46 & 281.16 & 101.72 & 455.11 & 139.73 & 712.81 \\
\hline 1951.2 & 120.68 & 287.13 & 103.40 & 463.04 & 142.88 & 717.65 \\
\hline 1951.3 & 123.55 & 292.37 & 104.53 & 471.52 & 145.97 & 722.16 \\
\hline 1951.4 & 126.10 & 297.38 & 107.65 & 479.68 & 146.77 & 725.88 \\
\hline 1952.1 & 126.27 & 301.55 & 109.27 & 486.34 & 150.82 & 728.49 \\
\hline 1952.2 & 125.11 & 306.98 & 112.47 & 494.33 & 152.48 & 733.05 \\
\hline 1952.3 & 127.65 & 310.58 & 112.78 & 498.97 & 154.53 & 738.09 \\
\hline 1952.4 & 136.24 & 315.73 & 116.12 & 505.21 & 156.35 & 744.02 \\
\hline 1953.1 & 138.05 & 319.88 & 116.05 & 511.44 & 155.66 & 752.24 \\
\hline 1953.2 & 145.56 & 325.40 & 119.89 & 518.38 & 158.38 & 758.44 \\
\hline 1953.3 & 149.65 & 330.70 & 122.94 & 525.67 & 160.92 & 764.49 \\
\hline 1953.4 & 144.52 & 336.89 & 123.32 & 532.24 & 161.10 & 770.60 \\
\hline 1954.1 & 148.10 & 340.05 & 124.94 & 535.85 & 159.97 & 775.57 \\
\hline 1954.2 & 153.19 & 344.29 & 126.85 & 540.47 & 160.11 & 781.90 \\
\hline 1954.3 & 148.88 & 348.65 & 127.84 & 545.47 & 163.30 & 788.13 \\
\hline 1954.4 & 148.72 & 354.15 & 129.71 & 549.88 & 165.73 & 794.25 \\
\hline 1955.1 & 154.33 & 357.81 & 130.41 & 552.69 & 166.55 & 800.52 \\
\hline 1955.2 & 155.28 & 365.51 & 131.76 & 558.69 & 168.62 & 807.35 \\
\hline 1955.3 & 160.78 & 373.35 & 136.81 & 565.84 & 172.09 & 814.60 \\
\hline 1955.4 & 157.55 & 380.88 & 140.34 & 573.91 & 177.78 & 822.18 \\
\hline 1956.1 & 159.55 & 383.64 & 144.00 & 579.37 & 189.54 & 829.76 \\
\hline 1956.2 & 162.55 & 388.45 & 148.39 & 585.82 & 189.69 & 838.64 \\
\hline 1956.3 & 161.97 & 392.85 & 151.46 & 592.62 & 196.55 & 847.67 \\
\hline 1956.4 & 169.99 & 396.91 & 157.39 & 598.86 & 199.35 & 856.70 \\
\hline 1957.1 & 174.25 & 400.21 & 164.37 & 604.33 & 204.76 & 865.67 \\
\hline 1957.2 & 178.17 & 404.13 & 167.38 & 610.19 & 209.99 & 874.33 \\
\hline 1957.3 & 182.26 & 407.21 & 170.32 & 616.67 & 212.99 & 882.88 \\
\hline 1957.4 & 180.60 & 410.23 & 173.84 & 622.07 & 214.49 & 891.18 \\
\hline 1958.1 & 176.76 & 410.38 & 172.05 & 623.66 & 209.02 & 898.26 \\
\hline
\end{tabular}




\begin{tabular}{|c|c|c|c|c|c|c|}
\hline 1958.2 & 174.94 & 411.48 & 173.46 & 625.33 & 212.52 & 905.30 \\
\hline 1958.3 & 178.41 & 412.52 & 176.86 & 626.39 & 215.74 & 911.83 \\
\hline 1958.4 & 180.51 & 414.25 & 179.21 & 628.16 & 218.82 & 918.51 \\
\hline 1959.1 & 186.55 & 416.31 & 180.85 & 629.71 & 218.08 & 924.40 \\
\hline 1959.2 & 188.26 & 420.18 & 183.03 & 633.13 & 220.79 & 931.58 \\
\hline 1959.3 & 190.90 & 424.09 & 186.00 & 637.24 & 222.85 & 939.37 \\
\hline 1959.4 & 190.66 & 426.28 & 186.53 & 641.38 & 224.97 & 947.07 \\
\hline 1960.1 & 192.22 & 427.14 & 190.36 & 645.43 & 229.72 & 955.64 \\
\hline 1960.2 & 192.94 & 430.58 & 192.02 & 650.13 & 230.91 & 964.21 \\
\hline 1960.3 & 194.38 & 433.59 & 193.76 & 653.57 & 232.76 & 972.78 \\
\hline 1960.4 & 194.80 & 435.77 & 193.76 & 656.02 & 232.58 & 982.10 \\
\hline 1961.1 & 192.36 & 435.87 & 191.95 & 657.30 & 232.28 & 990.82 \\
\hline 1961.2 & 195.36 & 436.59 & 194.06 & 659.86 & 233.55 & 999.61 \\
\hline 1961.3 & 196.62 & 437.85 & 195.52 & 662.58 & 236.01 & 1008.31 \\
\hline 1961.4 & 196.83 & 440.39 & 196.69 & 666.57 & 238.62 & 1016.83 \\
\hline 1962.1 & 197.63 & 443.45 & 198.50 & 670.45 & 241.71 & 1025.22 \\
\hline 1962.2 & 200.13 & 446.84 & 198.16 & 675.45 & 243.94 & 1034.75 \\
\hline 1962.3 & 201.56 & 450.30 & 200.35 & 680.30 & 246.35 & 1044.81 \\
\hline 1962.4 & 203.32 & 454.82 & 203.21 & 684.89 & 249.70 & 1054.20 \\
\hline 1963.1 & 203.97 & 458.66 & 205.70 & 689.23 & 252.56 & 1062.21 \\
\hline 1963.2 & 207.02 & 463.89 & 207.35 & 694.45 & 255.47 & 1071.57 \\
\hline 1963.3 & 209.20 & 469.29 & 209.30 & 700.74 & 257.37 & 1081.01 \\
\hline 1963.4 & 212.72 & 474.89 & 212.81 & 707.90 & 260.44 & 1090.73 \\
\hline 1964.1 & 215.91 & 480.02 & 216.74 & 714.63 & 260.77 & 1100.35 \\
\hline 1964.2 & 219.61 & 486.98 & 220.52 & 722.54 & 265.76 & 1111.31 \\
\hline 1964.3 & 222.92 & 494.71 & 223.25 & 731.32 & 267.84 & 1123.02 \\
\hline 1964.4 & 225.44 & 500.82 & 225.49 & 741.00 & 274.48 & 1134.83 \\
\hline 1965.1 & 228.54 & 508.23 & 231.04 & 751.65 & 277.69 & 1147.34 \\
\hline 1965.2 & 230.76 & 517.03 & 234.80 & 763.49 & 283.23 & 1161.92 \\
\hline 1965.3 & 233.69 & 526.77 & 239.09 & 777.04 & 286.80 & 1176.62 \\
\hline 1965.4 & 238.02 & 537.60 & 244.44 & 791.54 & 296.76 & 1192.47 \\
\hline 1966.1 & 239.78 & 548.20 & 248.50 & 805.85 & 302.20 & 1207.66 \\
\hline 1966.2 & 244.85 & 558.21 & 255.07 & 822.30 & 313.39 & 1223.01 \\
\hline 1966.3 & 250.87 & 568.98 & 261.86 & 838.25 & 317.75 & 1238.72 \\
\hline 1966.4 & 256.64 & 579.37 & 271.41 & 853.90 & 325.63 & 1253.12 \\
\hline 1967.1 & 261.29 & 586.71 & 278.42 & 865.03 & 332.93 & 1265.95 \\
\hline 1967.2 & 266.76 & 597.35 & 284.65 & 879.07 & 337.64 & 1279.48 \\
\hline 1967.3 & 274.16 & 607.13 & 291.49 & 892.23 & 343.38 & 1293.19 \\
\hline 1967.4 & 283.13 & 616.46 & 300.49 & 906.16 & 351.42 & 1306.78 \\
\hline 1968.1 & 290.48 & 625.66 & 307.40 & 919.04 & 355.93 & 1319.94 \\
\hline 1968.2 & 297.29 & 637.60 & 315.29 & 932.53 & 361.98 & 1333.67 \\
\hline 1968.3 & 306.96 & 650.91 & 323.52 & 946.55 & 368.81 & 1347.02 \\
\hline 1968.4 & 315.73 & 663.53 & 331.39 & 961.85 & 383.30 & 1360.88 \\
\hline 1969.1 & 322.21 & 673.59 & 337.51 & 976.23 & 398.30 & 1374.43 \\
\hline 1969.2 & 332.07 & 685.60 & 346.83 & 992.06 & 409.64 & 1388.65 \\
\hline 1969.3 & 338.61 & 696.93 & 356.04 & 1007.91 & 420.26 & 1404.14 \\
\hline
\end{tabular}




\begin{tabular}{|c|c|c|c|c|c|c|}
\hline 1969.4 & 346.23 & 707.43 & 363.88 & 1022.91 & 433.84 & 1419.23 \\
\hline 1970.1 & 350.67 & 712.73 & 371.26 & 1035.12 & 445.38 & 1432.95 \\
\hline 1970.2 & 355.61 & 721.76 & 380.47 & 1048.58 & 464.25 & 1446.98 \\
\hline 1970.3 & 362.25 & 730.57 & 385.13 & 1062.29 & 471.64 & 1460.89 \\
\hline 1970.4 & 372.37 & 735.43 & 395.13 & 1073.24 & 483.12 & 1474.24 \\
\hline 1971.1 & 385.71 & 741.84 & 408.61 & 1081.22 & 495.71 & 1486.23 \\
\hline 1971.2 & 393.81 & 751.57 & 419.98 & 1092.05 & 510.87 & 1499.12 \\
\hline 1971.3 & 397.14 & 762.14 & 425.85 & 1102.51 & 525.16 & 1511.84 \\
\hline 1971.4 & 400.94 & 774.24 & 428.62 & 1113.85 & 538.53 & 1524.35 \\
\hline 1972.1 & 403.51 & 783.57 & 437.85 & 1124.39 & 561.40 & 1536.29 \\
\hline 1972.2 & 411.42 & 796.57 & 445.10 & 1137.59 & 575.41 & 1548.82 \\
\hline 1972.3 & 420.77 & 810.05 & 454.54 & 1151.51 & 593.22 & 1560.94 \\
\hline 1972.4 & 426.13 & 825.95 & 460.73 & 1168.80 & 613.60 & 1573.08 \\
\hline 1973.1 & 435.44 & 840.67 & 467.96 & 1184.93 & 634.30 & 1583.51 \\
\hline 1973.2 & 448.63 & 857.84 & 482.51 & 1206.51 & 654.58 & 1597.54 \\
\hline 1973.3 & 460.04 & 873.84 & 496.77 & 1228.28 & 682.31 & 1612.24 \\
\hline 1973.4 & 469.95 & 887.51 & 510.63 & 1250.24 & 707.21 & 1626.59 \\
\hline 1974.1 & 477.24 & 895.16 & 519.57 & 1269.39 & 725.84 & 1640.03 \\
\hline 1974.2 & 489.16 & 906.68 & 534.66 & 1290.51 & 755.07 & 1653.63 \\
\hline 1974.3 & 511.33 & 918.27 & 572.93 & 1310.58 & 787.43 & 1665.52 \\
\hline 1974.4 & 533.33 & 922.92 & 613.38 & 1327.83 & 818.30 & 1676.81 \\
\hline 1975.1 & 559.74 & 926.28 & 678.45 & 1337.83 & 861.03 & 1685.01 \\
\hline 1975.2 & 580.20 & 932.58 & 707.75 & 1348.78 & 885.62 & 1693.48 \\
\hline 1975.3 & 593.07 & 942.23 & 726.07 & 1359.68 & 901.33 & 1702.19 \\
\hline 1975.4 & 608.29 & 953.39 & 742.67 & 1370.65 & 918.39 & 1710.91 \\
\hline 1976.1 & 611.20 & 965.05 & 755.20 & 1377.44 & 918.13 & 1720.42 \\
\hline 1976.2 & 626.90 & 978.18 & 777.58 & 1388.21 & 943.97 & 1729.10 \\
\hline 1976.3 & 643.05 & 991.03 & 795.98 & 1399.65 & 965.63 & 1737.68 \\
\hline 1976.4 & 660.33 & 1004.36 & 818.73 & 1411.68 & 984.68 & 1745.95 \\
\hline 1977.1 & 669.22 & 1015.45 & 823.97 & 1423.60 & 996.71 & 1752.16 \\
\hline 1977.2 & 686.38 & 1031.64 & 849.78 & 1439.73 & 1021.68 & 1761.29 \\
\hline 1977.3 & 705.13 & 1048.13 & 874.99 & 1456.52 & 1048.20 & 1770.68 \\
\hline 1977.4 & 728.14 & 1065.22 & 903.41 & 1475.58 & 1072.56 & 1780.11 \\
\hline 1978.1 & 743.48 & 1075.54 & 927.17 & 1491.90 & 1097.51 & 1788.84 \\
\hline 1978.2 & 766.52 & 1094.96 & 960.98 & 1514.54 & 1135.23 & 1801.25 \\
\hline 1978.3 & 790.36 & 1112.61 & 992.92 & 1537.38 & 1172.12 & 1815.65 \\
\hline 1978.4 & 816.19 & 1130.23 & 1026.09 & 1560.95 & 1216.77 & 1831.33 \\
\hline 1979.1 & 839.72 & 1143.73 & 1061.01 & 1581.86 & 1265.60 & 1846.35 \\
\hline 1979.2 & 868.84 & 1157.58 & 1098.46 & 1605.07 & 1299.07 & 1862.56 \\
\hline 1979.3 & 893.02 & 1172.56 & 1135.92 & 1628.89 & 1360.35 & 1880.14 \\
\hline 1979.4 & 921.56 & 1184.89 & 1177.62 & 1650.32 & 1402.93 & 1898.76 \\
\hline 1980.1 & 956.43 & 1192.76 & 1218.69 & 1667.74 & 1448.17 & 1915.87 \\
\hline 1980.2 & 984.19 & 1194.82 & 1269.35 & 1683.01 & 1482.40 & 1933.69 \\
\hline 1980.3 & 1001.43 & 1199.45 & 1318.76 & 1697.59 & 1544.70 & 1950.93 \\
\hline 1980.4 & 1020.91 & 1205.69 & 1352.46 & 1712.45 & 1611.89 & 1968.90 \\
\hline 1981.1 & 1034.08 & 1210.98 & 1411.26 & 1724.74 & 1634.03 & 1986.99 \\
\hline
\end{tabular}




\begin{tabular}{|c|c|c|c|c|c|c|}
\hline 1981.2 & 1061.23 & 1215.82 & 1460.41 & 1739.66 & 1693.67 & 2006.64 \\
\hline 1981.3 & 1081.29 & 1222.63 & 1501.02 & 1755.07 & 1727.04 & 2027.28 \\
\hline 1981.4 & 1098.95 & 1223.91 & 1549.37 & 1768.09 & 1834.94 & 2049.40 \\
\hline 1982.1 & 1102.80 & 1226.04 & 1588.18 & 1773.29 & 1891.28 & 2068.87 \\
\hline 1982.2 & 1124.09 & 1228.95 & 1614.56 & 1780.44 & 1934.95 & 2088.52 \\
\hline 1982.3 & 1135.18 & 1231.95 & 1645.65 & 1785.23 & 1961.98 & 2105.32 \\
\hline 1982.4 & 1145.84 & 1237.77 & 1665.73 & 1787.85 & 1985.97 & 2121.03 \\
\hline 1983.1 & 1150.56 & 1242.08 & 1666.90 & 1783.44 & 1976.67 & 2131.49 \\
\hline 1983.2 & 1164.17 & 1252.45 & 1683.60 & 1787.35 & 1974.00 & 2142.59 \\
\hline 1983.3 & 1182.60 & 1264.72 & 1695.83 & 1793.96 & 1996.42 & 2154.39 \\
\hline 1983.4 & 1203.52 & 1280.50 & 1709.81 & 1806.15 & 2032.53 & 2166.78 \\
\hline 1984.1 & 1212.46 & 1295.78 & 1705.24 & 1817.03 & 2031.61 & 2180.52 \\
\hline 1984.2 & 1239.21 & 1315.47 & 1719.49 & 1832.35 & 2051.85 & 2197.66 \\
\hline 1984.3 & 1263.78 & 1334.28 & 1743.66 & 1848.85 & 2088.19 & 2216.14 \\
\hline 1984.4 & 1287.25 & 1355.09 & 1772.59 & 1866.47 & 2124.75 & 2235.04 \\
\hline 1985.1 & 1311.81 & 1374.85 & 1768.43 & 1879.47 & 2175.00 & 2255.80 \\
\hline 1985.2 & 1336.96 & 1397.93 & 1796.38 & 1897.71 & 2193.67 & 2277.19 \\
\hline 1985.3 & 1365.07 & 1425.55 & 1821.43 & 1914.62 & 2226.52 & 2297.33 \\
\hline 1985.4 & 1396.02 & 1448.02 & 1855.23 & 1932.01 & 2262.71 & 2318.62 \\
\hline 1986.1 & 1415.12 & 1466.02 & 1872.45 & 1944.39 & 2293.53 & 2338.14 \\
\hline 1986.2 & 1445.88 & 1491.50 & 1899.76 & 1960.14 & 2302.23 & 2352.73 \\
\hline 1986.3 & 1492.45 & 1524.12 & 1932.73 & 1974.93 & 2327.25 & 2365.35 \\
\hline 1986.4 & 1531.18 & 1553.83 & 1960.05 & 1989.58 & 2359.13 & 2377.88 \\
\hline 1987.1 & 1562.59 & 1569.58 & 1995.50 & 1997.86 & 2370.88 & 2386.27 \\
\hline 1987.2 & 1597.43 & 1594.23 & 2017.85 & 2010.58 & 2387.41 & 2397.62 \\
\hline 1987.3 & 1637.22 & 1621.58 & 2033.93 & 2025.17 & 2411.87 & 2410.61 \\
\hline 1987.4 & 1666.44 & 1644.72 & 2068.23 & 2038.68 & 2455.67 & 2424.21 \\
\hline 1988.1 & 1687.36 & 1666.17 & 2082.80 & 2049.70 & 2505.70 & 2434.79 \\
\hline 1988.2 & 1726.78 & 1692.71 & 2109.32 & 2066.74 & 2538.19 & 2447.06 \\
\hline 1988.3 & 1768.72 & 1717.40 & 2130.54 & 2083.54 & 2574.06 & 2459.02 \\
\hline 1988.4 & 1814.58 & 1744.86 & 2174.14 & 2099.60 & 2616.25 & 2471.16 \\
\hline 1989.1 & 1846.87 & 1763.68 & 2204.53 & 2107.84 & 2683.68 & 2482.12 \\
\hline 1989.2 & 1882.11 & 1789.02 & 2233.86 & 2124.91 & 2730.94 & 2493.73 \\
\hline 1989.3 & 1919.29 & 1815.78 & 2270.70 & 2140.82 & 2764.65 & 2506.23 \\
\hline 1989.4 & 1948.35 & 1837.91 & 2301.42 & 2155.16 & 2799.00 & 2518.83 \\
\hline 1990.1 & 1968.82 & 1856.02 & 2328.26 & 2170.71 & 2832.82 & 2531.39 \\
\hline 1990.2 & 1991.58 & 1876.59 & 2355.02 & 2184.32 & 2861.51 & 2544.46 \\
\hline 1990.3 & 2014.63 & 1895.91 & 2403.08 & 2198.62 & 2892.24 & 2557.37 \\
\hline 1990.4 & 2041.53 & 1911.52 & 2437.50 & 2211.07 & 2912.58 & 2568.25 \\
\hline 1991.1 & 2056.58 & 1914.30 & 2485.88 & 2212.33 & 2926.93 & 2577.97 \\
\hline 1991.2 & 2075.60 & 1924.74 & 2500.50 & 2219.70 & 2949.09 & 2586.43 \\
\hline 1991.3 & 2099.87 & 1936.66 & 2505.32 & 2227.52 & 2972.00 & 2592.22 \\
\hline 1991.4 & 2122.23 & 1947.10 & 2515.83 & 2234.15 & 2965.45 & 2596.59 \\
\hline
\end{tabular}


Table 6. Quarterly Net Capital Stock, U.S., 1948-91, Equal Depreciation Technique (Method 4)

\begin{tabular}{|c|c|c|c|c|c|c|}
\hline Time & CDG & CDG87 & PDG & PDG87 & BS & BS87 \\
\hline 1948.1 & 67.15 & 195.30 & 62.98 & 358.51 & 115.32 & 669.36 \\
\hline 1948.2 & 71.50 & 200.60 & 65.79 & 369.06 & 117.53 & 672.47 \\
\hline 1948.3 & 75.85 & 206.55 & 70.66 & 379.17 & 119.83 & 676.01 \\
\hline 1948.4 & 76.30 & 212.80 & 73.40 & 390.00 & 120.20 & 679.80 \\
\hline 1949.1 & 77.08 & 217.38 & 75.52 & 398.48 & 120.21 & 683.44 \\
\hline 1949.2 & 77.78 & 223.94 & 79.96 & 405.43 & 119.44 & 686.81 \\
\hline 1949.3 & 81.50 & 230.89 & 81.31 & 411.30 & 120.51 & 689.63 \\
\hline 1949.4 & 86.60 & 238.00 & 82.20 & 416.90 & 122.90 & 692.10 \\
\hline 1950.1 & 92.02 & 244.10 & 83.60 & 421.94 & 123.42 & 695.21 \\
\hline 1950.2 & 97.34 & 250.48 & 85.84 & 429.14 & 123.30 & 698.94 \\
\hline 1950.3 & 104.94 & 262.43 & 90.58 & 438.33 & 127.48 & 703.39 \\
\hline 1950.4 & 108.20 & 271.90 & 94.60 & 447.40 & 133.90 & 708.20 \\
\hline 1951.1 & 119.57 & 280.67 & 101.28 & 454.42 & 139.69 & 712.07 \\
\hline 1951.2 & 119.24 & 286.31 & 102.68 & 461.89 & 142.82 & 716.41 \\
\hline 1951.3 & 121.84 & 291.38 & 103.68 & 470.13 & 145.90 & 720.68 \\
\hline 1951.4 & 124.40 & 296.40 & 106.80 & 478.30 & 146.70 & 724.40 \\
\hline 1952.1 & 125.16 & 300.54 & 108.46 & 485.74 & 149.78 & 729.53 \\
\hline 1952.2 & 123.32 & 305.29 & 111.11 & 493.32 & 150.77 & 734.79 \\
\hline 1952.3 & 125.50 & 308.56 & 111.17 & 497.76 & 152.49 & 740.17 \\
\hline 1952.4 & 134.00 & 313.70 & 114.50 & 504.00 & 154.30 & 746.10 \\
\hline 1953.1 & 137.29 & 319.09 & 115.84 & 510.62 & 155.02 & 751.59 \\
\hline 1953.2 & 144.25 & 324.08 & 119.54 & 517.01 & 157.30 & 757.35 \\
\hline 1953.3 & 148.05 & 329.11 & 122.52 & 524.03 & 159.62 & 763.19 \\
\hline 1953.4 & 143.00 & 335.30 & 122.90 & 530.60 & 159.80 & 769.30 \\
\hline 1954.1 & 147.27 & 338.67 & 124.69 & 535.11 & 160.01 & 775.44 \\
\hline 1954.2 & 151.78 & 342.00 & 126.42 & 539.24 & 160.16 & 781.69 \\
\hline 1954.3 & 147.23 & 345.90 & 127.32 & 543.99 & 163.37 & 787.88 \\
\hline 1954.4 & 147.10 & 351.40 & 129.20 & 548.40 & 165.80 & 794.00 \\
\hline 1955.1 & 154.21 & 356.42 & 130.94 & 552.04 & 167.95 & 800.23 \\
\hline 1955.2 & 155.06 & 363.20 & 132.63 & 557.60 & 170.95 & 806.86 \\
\hline 1955.3 & 160.52 & 370.57 & 137.87 & 564.54 & 174.88 & 814.02 \\
\hline 1955.4 & 157.30 & 378.10 & 141.40 & 572.60 & 180.60 & 821.60 \\
\hline 1956.1 & 160.51 & 382.94 & 144.40 & 578.94 & 189.82 & 829.86 \\
\hline 1956.2 & 164.14 & 387.27 & 149.06 & 585.10 & 190.15 & 838.80 \\
\hline 1956.3 & 163.83 & 391.44 & 152.26 & 591.76 & 197.11 & 847.86 \\
\hline 1956.4 & 171.90 & 395.50 & 158.20 & 598.00 & 199.90 & 856.90 \\
\hline 1957.1 & 172.07 & 399.55 & 163.34 & 603.69 & 203.12 & 865.33 \\
\hline 1957.2 & 174.49 & 403.02 & 165.68 & 609.14 & 207.22 & 873.76 \\
\hline 1957.3 & 177.79 & 405.88 & 168.29 & 615.41 & 209.67 & 882.19 \\
\hline 1957.4 & 176.20 & 408.90 & 171.80 & 620.80 & 211.20 & 890.50 \\
\hline 1958.1 & 177.51 & 409.85 & 171.30 & 623.02 & 208.32 & 897.91 \\
\hline
\end{tabular}




\begin{tabular}{|c|c|c|c|c|c|c|}
\hline 1958.2 & 176.16 & 410.60 & 172.23 & 624.27 & 211.35 & 904.71 \\
\hline 1958.3 & 179.90 & 411.48 & 175.36 & 625.12 & 214.32 & 911.12 \\
\hline 1958.4 & 182.00 & 413.20 & 177.70 & 626.90 & 217.40 & 917.80 \\
\hline 1959.1 & 185.71 & 415.37 & 180.67 & 629.52 & 218.34 & 924.47 \\
\hline 1959.2 & 186.87 & 418.61 & 182.75 & 632.81 & 221.24 & 931.69 \\
\hline 1959.3 & 189.22 & 422.20 & 185.67 & 636.86 & 223.38 & 939.51 \\
\hline 1959.4 & 189.00 & 424.40 & 186.20 & 641.00 & 225.50 & 947.20 \\
\hline 1960.1 & 191.66 & 426.90 & 189.67 & 645.17 & 228.97 & 955.39 \\
\hline 1960.2 & 192.02 & 430.18 & 190.89 & 649.70 & 229.67 & 963.80 \\
\hline 1960.3 & 193.27 & 433.11 & 192.39 & 653.05 & 231.27 & 972.29 \\
\hline 1960.4 & 193.70 & 435.29 & 192.40 & 655.50 & 231.10 & 981.60 \\
\hline 1961.1 & 192.35 & 435.92 & 191.60 & 657.06 & 232.81 & 990.60 \\
\hline 1961.2 & 195.34 & 436.67 & 193.49 & 659.47 & 234.45 & 999.25 \\
\hline 1961.3 & 196.59 & 437.95 & 194.83 & 662.11 & 237.08 & 1007.88 \\
\hline 1961.4 & 196.80 & 440.50 & 196.00 & 666.10 & 239.70 & 1016.40 \\
\hline 1962.1 & 197.11 & 442.94 & 198.64 & 670.21 & 241.81 & 1024.97 \\
\hline 1962.2 & 199.27 & 445.99 & 198.40 & 675.05 & 244.10 & 1034.34 \\
\hline 1962.3 & 200.54 & 449.28 & 200.64 & 679.81 & 246.55 & 1044.31 \\
\hline 1962.4 & 202.30 & 453.80 & 203.50 & 684.40 & 249.90 & 1053.70 \\
\hline 1963.1 & 204.02 & 457.97 & 205.54 & 688.83 & 252.54 & 1061.90 \\
\hline 1963.2 & 207.09 & 462.74 & 207.09 & 693.79 & 255.44 & 1071.05 \\
\hline 1963.3 & 209.28 & 467.91 & 208.99 & 699.94 & 257.33 & 1080.37 \\
\hline 1963.4 & 212.80 & 473.51 & 212.50 & 707.10 & 260.40 & 1090.10 \\
\hline 1964.1 & 215.03 & 479.21 & 216.64 & 714.18 & 261.08 & 1100.14 \\
\hline 1964.2 & 218.15 & 485.62 & 220.36 & 721.79 & 266.28 & 1110.95 \\
\hline 1964.3 & 221.18 & 493.09 & 223.06 & 730.42 & 268.46 & 1122.59 \\
\hline 1964.4 & 223.70 & 499.20 & 225.30 & 740.10 & 275.10 & 1134.40 \\
\hline 1965.1 & 227.58 & 507.38 & 230.82 & 750.88 & 278.41 & 1146.80 \\
\hline 1965.2 & 229.16 & 515.61 & 234.43 & 762.20 & 284.42 & 1161.03 \\
\hline 1965.3 & 231.77 & 525.07 & 238.64 & 775.50 & 288.22 & 1175.55 \\
\hline 1965.4 & 236.10 & 535.91 & 244.00 & 790.00 & 298.20 & 1191.40 \\
\hline 1966.1 & 240.71 & 547.26 & 248.94 & 804.50 & 302.58 & 1206.80 \\
\hline 1966.2 & 246.39 & 556.65 & 255.81 & 820.05 & 314.03 & 1221.58 \\
\hline 1966.3 & 252.73 & 567.11 & 262.74 & 835.55 & 318.52 & 1237.00 \\
\hline 1966.4 & 258.50 & 577.50 & 272.30 & 851.20 & 326.40 & 1251.40 \\
\hline 1967.1 & 261.33 & 585.58 & 278.18 & 864.00 & 331.92 & 1265.51 \\
\hline 1967.2 & 266.82 & 595.47 & 284.24 & 877.35 & 335.97 & 1278.75 \\
\hline 1967.3 & 274.23 & 604.87 & 291.01 & 890.17 & 341.37 & 1292.31 \\
\hline 1967.4 & 283.20 & 614.21 & 300.00 & 904.10 & 349.40 & 1305.90 \\
\hline 1968.1 & 289.72 & 624.24 & 307.05 & 918.12 & 358.58 & 1319.66 \\
\hline 1968.2 & 296.03 & 635.24 & 314.71 & 930.99 & 366.38 & 1333.19 \\
\hline 1968.3 & 305.43 & 648.08 & 322.83 & 944.71 & 374.05 & 1346.44 \\
\hline 1968.4 & 314.20 & 660.70 & 330.70 & 960.00 & 388.60 & 1360.30 \\
\hline 1969.1 & 320.95 & 671.78 & 336.27 & 975.28 & 398.87 & 1373.96 \\
\hline 1969.2 & 329.96 & 682.58 & 344.76 & 990.48 & 410.60 & 1387.88 \\
\hline 1969.3 & 336.09 & 693.30 & 353.56 & 1006.00 & 421.42 & 1403.21 \\
\hline
\end{tabular}




\begin{tabular}{|c|c|c|c|c|c|c|}
\hline 1969.4 & 343.70 & 703.80 & 361.40 & 1021.00 & 435.00 & 1418.30 \\
\hline 1970.1 & 350.69 & 711.42 & 371.80 & 1033.75 & 445.12 & 1432.38 \\
\hline 1970.2 & 355.64 & 719.56 & 381.36 & 1046.30 & 463.81 & 1446.03 \\
\hline 1970.3 & 362.28 & 727.93 & 386.20 & 1059.55 & 471.12 & 1459.75 \\
\hline 1970.4 & 372.40 & 732.79 & 396.20 & 1070.50 & 482.60 & 1473.10 \\
\hline 1971.1 & 382.05 & 740.27 & 407.08 & 1080.29 & 497.49 & 1485.81 \\
\hline 1971.2 & 387.68 & 748.95 & 417.42 & 1090.51 & 513.85 & 1498.41 \\
\hline 1971.3 & 389.85 & 759.00 & 422.79 & 1100.65 & 528.74 & 1510.99 \\
\hline 1971.4 & 393.70 & 771.10 & 425.60 & 1111.99 & 542.10 & 1523.50 \\
\hline 1972.1 & 402.79 & 781.40 & 436.61 & 1122.64 & 563.66 & 1534.94 \\
\hline 1972.2 & 410.23 & 792.95 & 443.06 & 1134.67 & 579.16 & 1546.59 \\
\hline 1972.3 & 419.33 & 805.70 & 452.10 & 1148.01 & 597.71 & 1558.26 \\
\hline 1972.4 & 424.70 & 821.60 & 458.30 & 1165.30 & 618.10 & 1570.40 \\
\hline 1973.1 & 435.72 & 838.87 & 468.99 & 1183.71 & 635.89 & 1583.27 \\
\hline 1973.2 & 449.09 & 854.84 & 484.23 & 1204.47 & 657.21 & 1597.14 \\
\hline 1973.3 & 460.59 & 870.23 & 498.84 & 1225.84 & 685.48 & 1611.76 \\
\hline 1973.4 & 470.50 & 883.90 & 512.70 & 1247.80 & 710.40 & 1626.10 \\
\hline 1974.1 & 482.62 & 894.00 & 530.44 & 1268.12 & 728.60 & 1639.33 \\
\hline 1974.2 & 498.08 & 904.75 & 552.53 & 1288.40 & 759.69 & 1652.46 \\
\hline 1974.3 & 522.11 & 915.95 & 594.81 & 1308.05 & 793.02 & 1664.12 \\
\hline 1974.4 & 544.20 & 920.60 & 635.60 & 1325.30 & 823.90 & 1675.40 \\
\hline 1975.1 & 553.46 & 925.23 & 672.59 & 1335.80 & 855.22 & 1685.15 \\
\hline 1975.2 & 569.65 & 930.84 & 697.97 & 1345.40 & 875.93 & 1693.72 \\
\hline 1975.3 & 580.47 & 940.15 & 714.47 & 1355.62 & 889.80 & 1702.47 \\
\hline 1975.4 & 595.70 & 951.30 & 731.20 & 1366.60 & 906.90 & 1711.20 \\
\hline 1976.1 & 607.45 & 962.88 & 748.67 & 1375.75 & 915.22 & 1719.34 \\
\hline 1976.2 & 620.64 & 974.55 & 766.71 & 1385.40 & 939.09 & 1727.31 \\
\hline 1976.3 & 635.54 & 986.67 & 782.99 & 1396.28 & 959.76 & 1735.53 \\
\hline 1976.4 & 652.80 & 1000.00 & 805.70 & 1408.30 & 978.80 & 1743.80 \\
\hline 1977.1 & 667.90 & 1013.34 & 822.72 & 1422.26 & 1000.67 & 1751.61 \\
\hline 1977.2 & 684.19 & 1028.12 & 847.70 & 1437.50 & 1028.30 & 1760.36 \\
\hline 1977.3 & 702.50 & 1043.91 & 872.48 & 1453.84 & 1056.15 & 1769.57 \\
\hline 1977.4 & 725.50 & 1061.00 & 900.90 & 1472.90 & 1080.50 & 1779.00 \\
\hline 1978.1 & 742.99 & 1074.12 & 926.57 & 1489.78 & 1102.03 & 1788.58 \\
\hline 1978.2 & 765.71 & 1092.60 & 959.98 & 1511.00 & 1142.80 & 1800.81 \\
\hline 1978.3 & 789.38 & 1109.78 & 991.72 & 1533.12 & 1181.21 & 1815.12 \\
\hline 1978.4 & 815.21 & 1127.40 & 1024.90 & 1556.70 & 1225.90 & 1830.80 \\
\hline 1979.1 & 841.14 & 1142.23 & 1061.40 & 1579.80 & 1267.74 & 1845.42 \\
\hline 1979.2 & 871.23 & 1155.08 & 1099.11 & 1601.63 & 1302.60 & 1861.01 \\
\hline 1979.3 & 895.87 & 1169.56 & 1136.70 & 1624.76 & 1364.64 & 1878.28 \\
\hline 1979.4 & 924.41 & 1181.89 & 1178.40 & 1646.19 & 1407.20 & 1896.90 \\
\hline 1980.1 & 953.11 & 1191.41 & 1222.36 & 1666.11 & 1449.47 & 1915.57 \\
\hline 1980.2 & 978.63 & 1192.57 & 1275.50 & 1680.30 & 1484.53 & 1933.19 \\
\hline 1980.3 & 994.79 & 1196.76 & 1326.18 & 1694.34 & 1547.29 & 1950.33 \\
\hline 1980.4 & 1014.30 & 1203.00 & 1359.80 & 1709.20 & 1614.50 & 1968.30 \\
\hline 1981.1 & 1027.74 & 1210.38 & 1406.36 & 1722.19 & 1628.57 & 1986.09 \\
\hline
\end{tabular}




\begin{tabular}{|c|c|c|c|c|c|c|}
\hline 1981.2 & 1050.59 & 1214.81 & 1452.24 & 1735.41 & 1684.54 & 2005.14 \\
\hline 1981.3 & 1068.55 & 1221.42 & 1491.27 & 1749.98 & 1716.22 & 2025.48 \\
\hline 1981.4 & 1086.20 & 1222.70 & 1539.60 & 1763.00 & 1823.80 & 2047.60 \\
\hline 1982.1 & 1096.73 & 1225.26 & 1573.80 & 1770.41 & 1874.10 & 2067.61 \\
\hline 1982.2 & 1113.91 & 1227.65 & 1590.70 & 1775.65 & 1906.34 & 2086.42 \\
\hline 1982.3 & 1122.99 & 1230.39 & 1616.96 & 1779.49 & 1927.81 & 2102.80 \\
\hline 1982.4 & 1133.69 & 1236.20 & 1637.09 & 1782.10 & 1951.90 & 2118.51 \\
\hline 1983.1 & 1145.68 & 1240.78 & 1655.73 & 1782.57 & 1970.14 & 2131.00 \\
\hline 1983.2 & 1156.07 & 1250.29 & 1664.98 & 1785.89 & 1963.26 & 2141.77 \\
\hline 1983.3 & 1172.88 & 1262.12 & 1673.55 & 1792.21 & 1983.51 & 2153.40 \\
\hline 1983.4 & 1193.80 & 1277.90 & 1687.60 & 1804.40 & 2019.50 & 2165.80 \\
\hline 1984.1 & 1209.59 & 1294.18 & 1701.74 & 1814.89 & 2036.12 & 2180.35 \\
\hline 1984.2 & 1234.42 & 1312.81 & 1713.69 & 1828.79 & 2059.35 & 2197.38 \\
\hline 1984.3 & 1258.02 & 1331.09 & 1736.70 & 1844.58 & 2097.22 & 2215.80 \\
\hline 1984.4 & 1281.50 & 1351.90 & 1765.60 & 1862.20 & 2133.80 & 2234.70 \\
\hline 1985.1 & 1309.34 & 1371.99 & 1766.74 & 1877.96 & 2174.04 & 2255.94 \\
\hline 1985.2 & 1332.86 & 1393.17 & 1793.54 & 1895.20 & 2192.08 & 2277.43 \\
\hline 1985.3 & 1360.16 & 1419.84 & 1818.02 & 1911.61 & 2224.61 & 2297.61 \\
\hline 1985.4 & 1391.10 & 1442.31 & 1851.80 & 1929.00 & 2260.80 & 2318.90 \\
\hline 1986.1 & 1413.29 & 1462.81 & 1876.72 & 1942.75 & 2290.77 & 2336.80 \\
\hline 1986.2 & 1442.82 & 1486.14 & 1906.88 & 1957.40 & 2297.66 & 2350.50 \\
\hline 1986.3 & 1488.77 & 1517.69 & 1941.30 & 1971.65 & 2321.74 & 2362.67 \\
\hline 1986.4 & 1527.51 & 1547.40 & 1968.60 & 1986.30 & 2353.60 & 2375.20 \\
\hline 1987.1 & 1559.11 & 1566.72 & 1987.94 & 1995.57 & 2374.43 & 2385.67 \\
\hline 1987.2 & 1591.63 & 1589.46 & 2005.26 & 2006.76 & 2393.31 & 2396.61 \\
\hline 1987.3 & 1630.26 & 1615.85 & 2018.89 & 2020.58 & 2418.95 & 2409.41 \\
\hline 1987.4 & 1659.50 & 1638.99 & 2053.10 & 2034.09 & 2462.80 & 2423.00 \\
\hline 1988.1 & 1684.30 & 1662.94 & 2082.68 & 2045.91 & 2515.82 & 2434.11 \\
\hline 1988.2 & 1721.65 & 1687.32 & 2109.11 & 2060.42 & 2555.03 & 2445.93 \\
\hline 1988.3 & 1762.55 & 1710.94 & 2130.29 & 2075.95 & 2594.23 & 2457.66 \\
\hline 1988.4 & 1808.41 & 1738.40 & 2173.90 & 2092.01 & 2636.41 & 2469.80 \\
\hline 1989.1 & 1837.50 & 1760.12 & 2203.13 & 2107.71 & 2676.97 & 2481.71 \\
\hline 1989.2 & 1866.48 & 1783.10 & 2231.52 & 2124.70 & 2719.72 & 2493.04 \\
\hline 1989.3 & 1900.54 & 1808.67 & 2267.89 & 2140.56 & 2751.22 & 2505.39 \\
\hline 1989.4 & 1929.60 & 1830.80 & 2298.61 & 2154.90 & 2785.59 & 2518.00 \\
\hline 1990.1 & 1963.40 & 1851.81 & 2329.41 & 2167.32 & 2823.65 & 2531.41 \\
\hline 1990.2 & 1982.56 & 1869.57 & 2356.94 & 2178.68 & 2846.24 & 2544.50 \\
\hline 1990.3 & 2003.82 & 1887.49 & 2405.38 & 2191.85 & 2873.91 & 2557.41 \\
\hline 1990.4 & 2030.70 & 1903.10 & 2439.80 & 2204.30 & 2894.30 & 2568.30 \\
\hline 1991.1 & 2056.81 & 1910.75 & 2469.74 & 2210.26 & 2921.34 & 2577.18 \\
\hline 1991.2 & 2075.99 & 1918.82 & 2473.68 & 2216.24 & 2939.78 & 2585.10 \\
\hline 1991.3 & 2100.34 & 1929.55 & 2473.28 & 2223.37 & 2960.79 & 2590.62 \\
\hline 1991.4 & 2122.70 & 1940.00 & 2483.79 & 2230.00 & 2954.31 & 2595.00 \\
\hline
\end{tabular}

